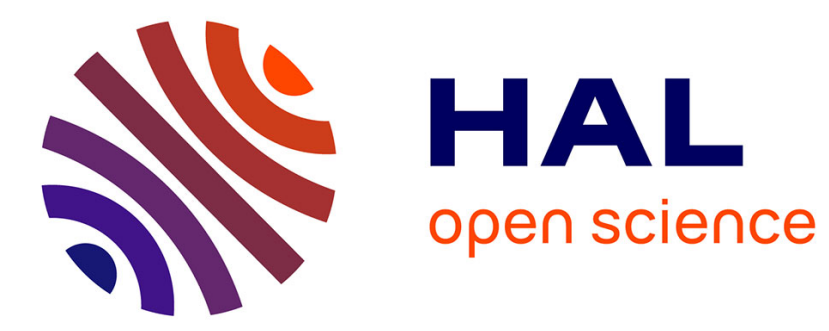

\title{
Technological Change and Domestic Outsourcing
}

Antonin Bergeaud, Clément Malgouyres, Clément Mazet-Sonilhac, Sara

Signorelli

\section{To cite this version:}

Antonin Bergeaud, Clément Malgouyres, Clément Mazet-Sonilhac, Sara Signorelli. Technological Change and Domestic Outsourcing. 2021. halshs-03265792

\section{HAL Id: halshs-03265792 \\ https://shs.hal.science/halshs-03265792}

Preprint submitted on 21 Jun 2021

HAL is a multi-disciplinary open access archive for the deposit and dissemination of scientific research documents, whether they are published or not. The documents may come from teaching and research institutions in France or abroad, or from public or private research centers.
L'archive ouverte pluridisciplinaire HAL, est destinée au dépôt et à la diffusion de documents scientifiques de niveau recherche, publiés ou non, émanant des établissements d'enseignement et de recherche français ou étrangers, des laboratoires publics ou privés. 


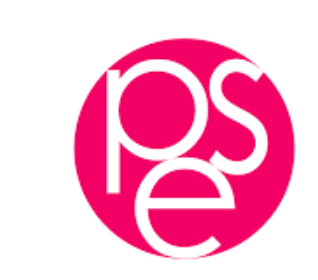

PARISSCHOOL OFECONOMICS
ECOLED'ECONOMIEDE PARIS

WORKING PAPER Nº 2021 - 45

Technological Change and Domestic Outsourcing

\author{
Antonin Bergeaud \\ Clément Malgouyres \\ Clément Mazet-Sonilhac \\ Sara Signorelli
}

JEL Codes: G14, G21, 033.

Keywords: Broadband, Firm organization, Labor market, Outsourcing.

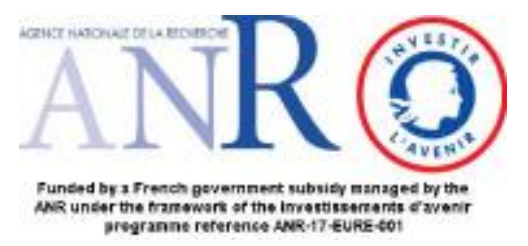




\title{
Technological Change and Domestic Outsourcing*
}

\author{
Antonin Bergeaud \\ Clément Mazet-Sonilhac \\ Clément Malgouyres \\ Sara Signorelli
}

June 2021

\begin{abstract}
Domestic outsourcing has grown substantially in developed countries over the past two decades. This paper addresses the question of the technological drivers of this phenomenon by studying the impact of the staggered diffusion of broadband internet in France during the 2000s. Our results confirm that broadband technology increases firm productivity and the relative demand for high-skill workers. Further, we show that broadband internet led firms to outsource some non-core occupations to service contractors, both in the low and high-skill segments. In both cases, we find that employment related to these occupations became increasingly concentrated in firms specializing in these activities, and was less likely to be performed in-house within firms specialized in other activities. As a result, after the arrival of broadband internet, establishments become increasingly homogeneous in their occupational composition. Finally, we provide suggestive evidence that high-skill workers experience salary gains from being outsourced, while low-skill workers lose out.
\end{abstract}

JEL classification: G14, G21, O33

Keywords: Broadband, Firm organization, Labor market, Outsourcing.

*Addresses: Bergeaud: Banque de France and CEP; Malgouyres: Institut des Politiques Publiques and PSE; Mazet-Sonilhac: Banque de France and Sciences Po; Signorelli: University of Amsterdam. We would like to thank without implicating Philippe Aghion, Adrien Bilal, Johannes Boehm, Mathilde Le Moigne and seminar participants at College de France, Sciences Po, X-CREST, LAGV, JMA, AFSE and RCEA for helpful comments. Corresponding author: Antonin Bergeaud: antonin.bergeaud@banquefrance.fr 


\section{Introduction}

The implications of international outsourcing (or offshoring), i.e. the process of using a third-party firm based abroad to perform services that would otherwise be performed in-house by local employees, have been at the century of recurrent public debates and the focus of a large body of economic research and policy analysis. ${ }^{1}$ More recently, empirical work has highlighted the pervasiveness of domestic outsourcing among developed economies (Dube and Kaplan, 2010; Goldschmidt and Schmieder, 2017; Bernhardt et al., 2016; Dorn et al., 2018) and has started to document its implications for the distribution of earnings. However, this nascent literature is silent on the factors underlying these trends and in particular, on whether the rising prevalence of domestic outsourcing is primarily driven by changes in (labor market) institutions or whether the adoption of new technologies played a role in this development.

In this paper, we look at the role played by innovation in Information and Communication Technology (ICT) in fostering the rise of domestic outsourcing. To do so, we estimate the impact associated with the diffusion of a new General-Purpose Technology (GPT), namely broadband internet (BI hereafter)- on employment outsourcing by French firms.

As explained in Abramovsky and Griffith (2006), GPTs such as ICT improve the adaptability of firms which results in important organizational changes. In particular, to the extent that BI has reduced communication and transaction costs, its diffusion is likely to have modified the optimal boundaries of firms and affected the terms of the make-or-buy decisions that they face (see e.g. Lewis and Sappington, 1991; Garicano and Rossi-Hansberg, 2006; Bloom et al., 2014; Aghion et al., 2019b). It is therefore natural to assess the impact it has had on the allocation of workers to firms, in particular through the rise of domestic outsourcing. BI is also likely to directly improve the productivity of the impacted firms through various channels, in a way that is biased towards workers with a more formal education (Akerman et al., 2015) and those employed in more complementary occupations (Aghion et al., 2019a).

To better understand the global impact of BI on the propensity to outsource labor, we build a partial-equilibrium model in which firms are defined as a collection of different tasks that can either be performed in-house or by outsourced workers. In this model, BI represents a positive shock on a representative firm's revenue produc-

\footnotetext{
${ }^{1}$ See Hummels et al. (2018) for a review of recent empirical works and Biscourp and Kramarz (2007) for a seminal work on French administrative data.
} 
tivity and/or a reduction in the cost of outsourcing. ${ }^{2}$ We show that, in the presence of imperfections on the labor market and under a broad set of conditions, BI expansion leads firms to outsource a greater share of their labor force-so that the ratio of outsourcing expenditure over sales or in-house labor cost goes up-and become more specialized regarding the composition of their in-house employment-in particular they spend a relatively larger share of their (in-house) labor cost on a small set of core occupations.

We then take the main predictions of the model to the data. We use individual- and firm-level administrative data on the universe of French workers from 1994 to 2010. This time interval covers the full roll-out of broadband connection across the French territory, which essentially took place between 2000 and 2007. We first confirm the skill-biased nature of BI. As cities become progressively connected, the average productivity of local firms increases and so does the share of high-skill workers. This increasing demand for high skill workers is confirmed by a wage regression on individual panel data which shows a positive average effect on wage dynamics that is more pronounced for high-skill workers, even after controlling for a rich set of observed and unobserved heterogeneity. These results are in line with Akerman et al. (2015), who study the effect of broadband expansion in Norway. We go one step further and show evidence that this skill-biased technological change is accompanied by important changes in the composition of workforce as BI led firms to outsource some non-core occupations to service contractors. We start by documenting how BI increases both the expenditure in outsourcing services and the occupational segregation of establishments, as captured by a Herfindahl-Hirschman Index (HHI) of concentration. This effect is driven by both changes within existing establishments and changes in establishment composition through entries and exits in the cities connected to the internet. ${ }^{3}$

Interestingly, outsourcing does not only affect low-skill occupations such as cleaners or drivers, but also some high-skill occupations. As an illustrative example, we show that following BI expansion, both IT specialists and cleaners are increasingly concen-

\footnotetext{
${ }^{2}$ An additional impact of BI would include a shift in the output elasticity of high skill occupations relative to low skilled occupations resulting in increasing wage returns for high skill workers. In this paper, we show that BI is indeed a skill biased technology, but we do not explicitly model it through an impact in the output elasticities. We refer the reader to Akerman et al. (2015) for such a model.

${ }^{3}$ This evidence is in line with the trends described by Godechot et al. (2020), who, based on administrative data in several high-income countries, document a steep increase in both earnings and occupational segregation at work, which, especially with regard to occupation, is particularly pronounced in France.
} 
trated in establishments specializing in these particular services, and thus less likely to be employed in-house by establishments active in other sectors. Finally, we provide suggestive evidence that the impact of domestic outsourcing on wages is heterogeneous across skills: high-skill workers experience wage increases after outsourcing while low-skill workers see their wages decrease, implying that outsourcing tends to widen pre-existing disparities in earnings.

The analysis in this paper contributes to several strands of literature. First, we relate to a small empirical literature exploiting BI expansion as a plausibly exogenous technological and informational shock. In France, Malgouyres et al. (2019) show that the BI expansion was associated with an increase in imports among firms treated by the policy. ${ }^{4}$ More closely related to our study, Akerman et al. (2015) evaluate the skill-bias of BI in Norway. They find that broadband availability increases both firm productivity and the skill wage premium. We contribute to this literature by documenting one of the mechanisms behind the BI skill-bias. In particular, we show that it operates through the reallocation of high and low-skill workers across firms -consistent with an increase of productivity and a reduction of outsourcing cost- and not only through a shift in the firm's production function. These reorganizations affect heterogeneous workers in a way that amplifies pre-existing wage inequalities.

Second, our paper is linked to the literature on domestic outsourcing. Weil (2014) describes how the nature of work has changed in the 21st century as a result of large companies switching to a "fissured workplace" business model. Goldschmidt and Schmieder (2017) show how Germany has experienced an explosion of domestic outsourcing of low-skill non-core activities since the early 1990 s. $^{5}$ In their paper, outsourcing results in wage reductions for outsourced jobs, mainly driven by the loss of firm-specific rents. ${ }^{6}$ Song et al. (2019) underline how the increase in sorting and the segregation of low-skill workers contributed to the surge in income inequality. Technology has also been related to outsourcing: using data on US firms, Fort (2017) shows that technology lowers the cost of coordination within a firm and leads to an increase in the fragmentation of production. Cortes and Salvatori (2019) show that

\footnotetext{
${ }^{4}$ Consistently, Akerman et al. (2018) show that BI narrows the role of distance in explaining bilateral trade in Norway. In the United Kingdom, DeStefano et al. (2018) find that a similar shock did not affect firms' productivity but only their size, which suggests that local institutions matter in explaining the effect of broadband expansion.

${ }^{5}$ They focus on four emblematic activities: cleaning, logistics, security and food services and introduce an innovative measure to capture outsourcing of such tasks.

${ }^{6}$ Drenik et al. (2020) quantify this loss and show that the share of the firm-specific wage premium that outsourced workers earn is about half of the premium that an insider earns.
} 
firms in the UK have become increasingly specialized over the past 20 years, and that this was partly driven by an increase in domestic outsourcing in high-skill non-routine cognitive tasks. Aghion et al. (2019a) characterize so-called "good jobs" that are protected from outsourcing as technology advances, even among low-educated workers. We contribute to this literature in two main aspects. First, we look explicitly at the effect of a specific technology and extend the spectrum of affected workers to high-skill occupations. ${ }^{7}$ Our estimate represents intent-to-treat as we do not track a firm-level measure of actual ICT adoption. As such, our results complement the survey evidence (Abramovsky and Griffith, 2006) which points to a positive association between direct measures of firm-level ICT-intensity and the propensity to outsource and purchase services on the market. Second, we capture margins of adjustment largely ignored by the existing literature. Although most work focuses on either individual transitions from in-house to outsourced activities (Dube and Kaplan, 2010) or on plant-level outsourcing events (Goldschmidt and Schmieder, 2017), domestic outsourcing is likely to become more prevalent through the allocation of new labor-market entrants to firms operating the business services sectors and the entry of new firms in such sectors. Our city-level approach to analyzing the local evolution of the allocation of workers and occupations across firms in reaction to a change in the set of available technologies allows us to capture such margins.

In a recent work, Bilal and Lhuillier (2021) consider the aggregate implications of domestic outsourcing in terms of wage and productivity in France. They develop a model where firms face labor market frictions when hiring workers and can instead buy the services from outsourcing firms. Their structurally estimations suggest that that the rise of outsourcing in France have positively contributed to global output and reduced the labor share. We depart from this work mostly by estimating in a reduced-form framework how the propensity to outsource respond to a change in available technology.

Our paper is also more generally connected to the literature on technology and firm

\footnotetext{
${ }^{7}$ Abramovsky et al. (2017) discuss the evolution of high skill occupations' offshoring. The literature has also identified occupations that are more likely to be domestically outsourced to the growing business service sector, which can include some high-skill occupations such as advertisers, accountants, IT specialists and legal professionals (Ono, 2003; Berlingieri, 2014; Goldschmidt and Schmieder, 2017).

${ }^{8}$ Our theoretical framework builds partly on the same intuition-namely that rent-sharing when hiring in-house workers provides an incentive to outsource-, but departs from this work by introducing an explicit distinction between core and non-core occupations depending on how substitutable outsourcing and in-house labor services are within an occupation. We further focus on the qualitative, partial equilibrium predictions of our model in order to guide the interpretation of our event-study results rather than carry out the structural estimation of a general equilibrium model.
} 
organization of labor. In France, Caliendo et al. (2015) analyze how the hierarchical structure changes as a firm grows, underlining the importance of considering layers when studying the dynamics of employment and wages. Le Moigne (2020) describes how, over the period from 1995 to 2015, French plants have become increasingly prone to removing their "middle layer", and show that these reorganizations are associated with greater productivity for firms but lower internal promotion opportunities for workers at the bottom of the job ladder. While theses papers do not formally consider new technologies, their role in skill-biased organizational change has been documented in previous papers (see e.g. Autor et al., 2003; Michaels et al., 2014) and has been found to be associated with a reduction in layers by accentuating the "flatness" of a firm (Caroli and Van Reenen, 2001; Aghion et al., 2019a). The literature on the effects of ICT usually considers separately the effect of a reduction in the cost of communication and in the cost of information on the organizational structure of a firm (see e.g. Bloom et al., 2014). For instance, Garicano and Rossi-Hansberg (2006) makes a clear distinction between the cost of communication and the cost of acquiring knowledge. In their model, a reduction in communication cost fosters a firm's reorganization, where more problems are solved at the top of the hierarchy (typically by managers) and the knowledge content of production work shrinks. Garicano (2000) and Borghans and Ter Weel (2006) describe how improved communication increases the specialization of workers within a firm. In our paper we consider the effect of the reduction in both communication and information costs brought about by BI on reorganization beyond the boundaries of the firm, through the subcontracting of non-core activities to high and low-skill service providers.

The rest of the paper is organized as follows. Section 2 presents a simple model that will guide the empirical analysis. Section 3 present the data and our empirical methodology. Section 4 presents results regarding the effect of BI on outsourcing. Finally, Section 5 looks more closely at the consequence of outsourcing on workers' wage trajectories. Section 6 concludes.

\section{A Theory of technology-led domestic outsourcing}

In this section, we propose a simple partial equilibrium model to highlight though what mechanisms could access to broadband internet lead to higher levels of domestic outsourcing. The main goal of this exercise is to show that our empirical results are rationalizable in a model with a fairly standard set of assumptions. 
A key empirical regularity which will guide the the theory is the positive relationship between a firm size (as measured by revenue) and its propensity to outsource as shown in Figure 1. Figure 1 and the corresponding Table A1 in the Appendix show the cross-sectional correlation between the outsourcing intensity of the firm and its size, measured as net revenues and value added. The intensity of outsourcing is measured as the ratio of subcontracting expenditure to in-house workers wage bill. ${ }^{9}$

Figure 1: Correlation between outsourcing intensity and firm size

(a) Outsourcing intensity and net revenues

(b) Outsourcing intensity and value added
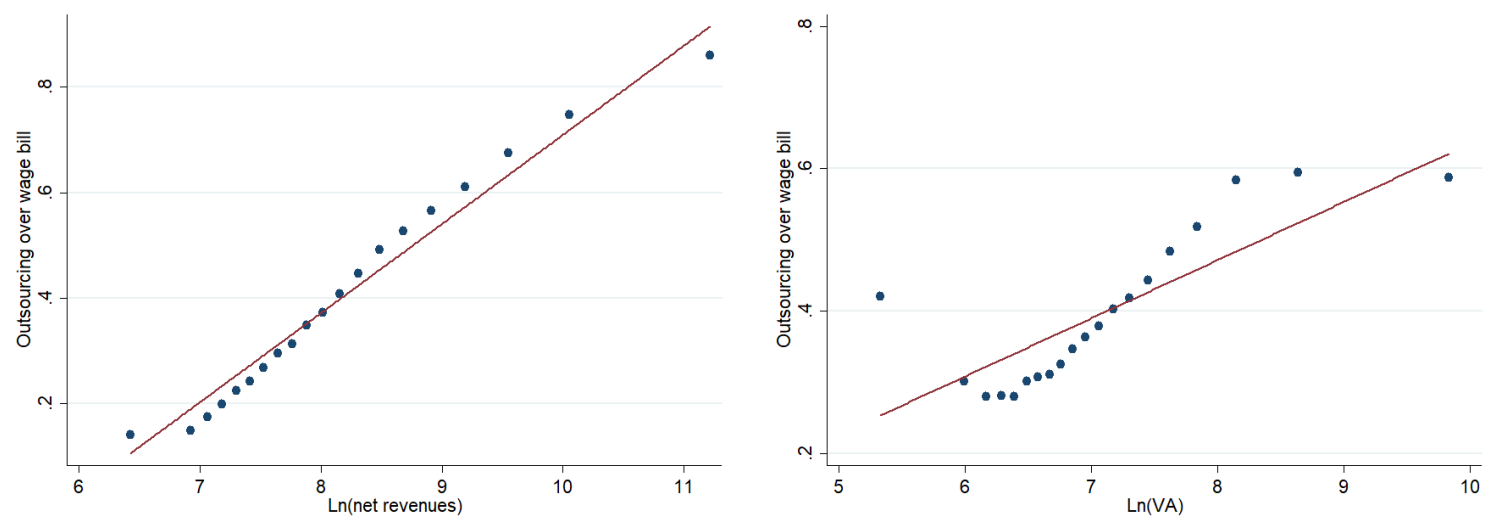

Notes: The figure presents the binned scatter plot for the correlation between firm outsourcing intensity and the $\log$ of firm revenues (panel a), a,d between firm outsourcing intensity and the log of value added (panel b).

In our model, firms choose employment across several occupations in order to maximize profit. Within each occupation, workers can be hired either in-house or through a subcontractor.

\subsection{Model setup}

Production technology: aggregation across occupations. Firms combine several occupations or tasks to produce output using a Cobb-Douglas function with constant returns to scale. We denote output of $j$ as a function of each occupation output $H_{i, j}$ as:

$$
Y_{j}=\theta_{j} \prod_{i \in \mathbf{N}} H_{i, j}^{\alpha_{i}}
$$

where $\theta$ denotes a Hicks neutral productivity shifter, $\mathbf{N}$ is the set of occupations and we have $\sum_{i} \alpha_{i}=1$, and $\alpha_{i} \in[0,1]$.

\footnotetext{
${ }^{9}$ Such correlation is also a feature of Bilal and Lhuillier (2021)'s model.
} 
Production technology: in-house and outsourced workers within occupation. Each occupation $i$ can be carried out by a mix of in-house workers which are directly employed and of outsourced workers whose labor services are hired through a third party (subcontractor). Each occupation is characterized by a specific elasticity of substitution between in-house and outsourced workers. Output by occupation $i$ depends on the number of in-house and outsourced workers denoted $n_{i}$ and $s_{i}$ respectively and writes as: ${ }^{10}$

$$
H_{i}=\left(\mu_{i}^{\frac{1}{\sigma_{i}}} n_{i}^{\frac{\sigma_{i}-1}{\sigma_{i}}}+\left(1-\mu_{i}\right)^{\frac{1}{\sigma_{i}}} s_{i}^{\frac{\sigma_{i}-1}{\sigma_{i}}}\right)^{\frac{\sigma_{i}}{\sigma_{i}-1}}
$$

where $\sigma_{i}$ is the elasticity of substitution between the services provided by in-house and outsourced workers and $\mu_{i}$ affects the relative productivity of the groups. A core occupation is defined as an occupation with a low elasticity of value for $\sigma_{i}$. It could be either a high or a low productivity occupation as measured by $\alpha_{i}$, i.e. the elasticity of overall output $Y$ to the occupational output $H_{i}$.

How does this modeling approach relates to influential theories of outsourcing? The knowledge-based view of the firm (Kogut and Zander, 1992) suggests that firms should keep in-house tasks (here occupations can be seen as bundle of tasks) that (1) are hard to codify and (2) have higher economic value to the firm. Similarly, a strand of management literature dealing with "core-competencies" recommend to focus on tasks with strategic value to the firm and outsource non-strategic routine tasks (Lepak and Snell, 1999).

The model encapsulates the key ideas from this literature through the parameter $\sigma_{i}$. The elasticity of substitution $\sigma_{i}$ will determine the extent to which firms wish to increase outsourcing as the relative cost of doing so goes down. A core occupation in that set-up is a bundle of tasks that is hard to codify and therefore has a low $\sigma_{i}$, which in turn implies that a decline in the cost of outsourcing will not provide a strong incentive to outsource this task. The economic value produced by the task is captured by its weight in the Cobb-Douglas aggregation $\left(\alpha_{i}\right)$. A core task with high economic potential is therefore an occupation with a high $\alpha_{i}$ and a low $\sigma_{i}$. On the contrary, a non-core task is characterized by a low $\alpha_{i}$ and a high $\sigma_{i}$. As we will see below, in the

\footnotetext{
${ }^{10}$ To be more consistent with the empirical analysis, we adopt an "occupation" approach. We can see each occupation as a continuum of tasks, some of which will be performed by outsourced workers and other by in-house workers. At the equilibrium, an occupation is therefore characterized by its relative level of outsourced workers, which in turns is determined by the elasticity of substitution $\sigma_{i}$.
} 
model, profit maximization implies that a decline in the relative cost of outsourcing or an increase in the optimal scale of the firm will lead to a refocusing of the firm on core tasks, whereby core occupations increase as a share of the overall wage bill.

(Labor) market structure for in-house and outsourced workers. A key difference between the hiring of in-house and outsourced workers is that each firm disposes of some wage setting power when hiring in-house workers but are price-takers with respect to the firms from which they outsource (which we call the agencies). We micro-found (occupation-specific) firm-level labor supply curves as resulting from a discrete choice modeling as in Industrial Organization and in keeping with the recent literature on monopsony (Card et al., 2018; Lamadon et al., 2019). In this setup, the labor supply curve that individual firms face (within a given occupation) is not perfectly elastic because of idiosyncratic tastes among workers for the amenities offered by the firms (for instance working conditions, commute, corporate culture). Due to asymmetric information regarding the valuation by individual workers of such amenities, firms are not able to perfectly discriminate and fully price these amenities into individual-specific wages. As we will see this assumption naturally generates the positive correlation between outsourcing intensity and size which showed in Figure 1 that is key in this model. ${ }^{11}$

This idea is summarized by equation (3) which gives the labor supply curve of a firm $j$ hiring a (in-house) worker in occupation $i$. Namely:

$$
n_{i, j}=N_{i} \frac{w_{i, j}^{1 / \rho_{i}}}{\sum_{j} w_{i, j}{ }^{1 / \rho_{i}}}=a_{i} w_{i, j}^{\frac{1}{\rho_{i}}},
$$

where $N_{i}$ is the measure of the population of workers in occupation $i$ with iid extreme value type- 1 preferences across firms with shape parameters $\rho_{i} \cdot{ }^{12}$ We consider a standard atomistic monopsonistic competition setting as firms ignore their own impact on the competition index which is captured by $a_{i}$. For simplicity, we consider in our model that all occupations $i$ have the same value of $\rho_{i}>0$ and $a_{i}$ which we denote as $\rho$ and $a$.

\footnotetext{
${ }^{11}$ We assume the market for outsourcing services is competitive and that consequently there is not rentsharing between employers and their outsourced workers. This does not preclude the possibility that outsourced workers benefits from rent-sharing with respect to their direct employer (the agencies) due to frictions on the labor market.

${ }^{12}$ This labor supply function arises from worker $k$ in occupation $i$ having utility: $u_{i, j, k}=w_{i, j}+e_{i, j, k}$ where $e_{i, j, k}$ follows an extreme-value type I distribution with scale parameters $\rho_{i}$.
} 
Profit maximization. We consider a set-up with monopolistic competition and CES demand. Each firm $j$ faces the demand function $Y^{D}=p^{-\varepsilon} I$ which yields the following revenue function:

$$
R(Y)=Y p=Y^{\frac{\varepsilon-1}{\varepsilon}} I^{\frac{1}{\varepsilon}}
$$

The cost associated with hiring a vector of workers $\left\{n_{i, j}, s_{i, j}\right\}_{i \in \mathbf{N}}$ writes as :

$$
C\left(\left\{n_{i}, s_{i}\right\}_{i \in \mathbf{N}}\right)=\sum_{i \in \mathbf{N}} n_{i, j} w_{i}\left(n_{i, j}\right)+\sum_{i \in \mathbf{N}} s_{i, j} \cdot \gamma_{i, j} r_{i}
$$

where $w_{i}\left(n_{i, j}\right)$ is the inverse labor supply function faced by firm $j$ when hiring in occupation $i$. The variable $r_{i}$ is the market price for outsourcing services in occupation $i$ and $\gamma_{i, j}$ is the firm-specific cost shifter of outsourcing.

$$
\max _{\left\{n_{i, j}, s_{i, j}\right\}_{i \in \mathbf{N}}} \pi_{i, j}=Y\left(\left\{n_{i, j}, s_{i, j}\right\}_{i \in \mathbf{N}}\right)^{\frac{\varepsilon-1}{\varepsilon}} I^{\frac{1}{\varepsilon}}-\left(\sum_{i \in \mathbf{N}} n_{i, j} w_{i}\left(n_{i, j}\right)+\sum_{i \in \mathbf{N}} s_{i, j} \cdot \gamma_{i, j} r_{i}\right)
$$

It is fairly straightforward to show that the problem defined in Equation (6) admits a unique positive solution $\left\{n_{i, j}^{*}, s_{i, j}^{*}\right\}_{i \in \mathbf{N}}{ }^{13}$

Unlike what would occur under competitive labor market, occupation-firm specific optimal wage $w_{i, j}^{*}$ depend on the level of labor demand $n_{i, j}^{*}$. This dependence precludes any closed form solution for $n_{i, j}^{*}$ but under some conditions on $\rho$ allows us to derive our main predictions.

\subsection{Outsourcing motives in our model}

At this point it is worth recalling what the literature has presented as the most important rationales for outsourcing and assess the extent to which they are captured by our model. ${ }^{14}$

Abraham and Taylor (1996) consider three main sets of considerations underpinning a firm's decision to outsource some tasks to subcontractors : (i) the wage and benefit savings it could realize, (ii) the availability of specialized skills possessed by the outside contractor (iii) the volatility of its output demand. Our model emphasize the

\footnotetext{
${ }^{13}$ The problem with fixed wages $w_{i, j}$ is entirely standard and $\pi_{i, j}$ is strictly concave in $\left\{n_{i, j}, s_{i, j}\right\}$ so that any first order condition correspond to a global maximum. Allowing $w_{i, j}$ to increase with respect to $n_{i, j}$ make the profit function more concave and does not alter the uniqueness and existence of the solution.

${ }^{14}$ Our review is primarily based on Abraham and Taylor (1996) and Appelbaum et al. (2015).
} 
first motive. As in Card et al. (2018); Lamadon et al. (2019); Kline et al. (2019); Aghion et al. (2018), the labor market power enjoyed by employers lead to some rent-sharing with in-house workers despite the absence of explicit bargaining. This rent-sharing creates an incentive to outsource some occupations to outside contractors as the market price for these services is independent of the firm's rents. This incentive becomes naturally more intense as firms become more productive or enjoy larger rents. The second motive is also incorporated in our setting, although somewhat less directly. The ability of outside contractor to provide cheaper services on a quality adjusted basis (i.e. low $\gamma_{i} r_{i}$ ) might derive from their access to more specialized skills. ${ }^{15}$ Finally, the third rationale is intrinsically dynamic and is not explicitly modeled.

\subsection{Broadband internet expansion in our model}

By its nature, BI can impact the organization of a firm through different channels:

i In line with the literature (Akerman et al., 2015) and our own findings, a first effect of $\mathrm{BI}$ is to increase firm-level productivity, i.e. $\theta$ in our model.

ii To the extent that broadband lowers inter-organization frictions, another potential effect would be to lower the relative cost of outsourced versus in-house labor, i.e. a decline in the term $\gamma_{i, j}$ 's (see Abramovsky and Griffith, 2006; Abramovsky et al., 2017).

iii A third effect, again in line with most of the literature, would be to potentially generate some degree of skill-bias technical change (Akerman et al., 2015), which we model as a shift to the output elasticity $\alpha_{i}$ of high skill versus low-skill occupations.

iv A final potential channel through which broadband would affect firm organization would be a particularly strong productivity-impact of the IT outsourcing sector.

That is we consider as plausible due to increase in the demand for IT services among producers and enhanced efficiency of IT subcontractors, the revenue

\footnotetext{
${ }^{15}$ As subcontractors become more competitive, firms will primarily choose to outsource non-core activities (high $\sigma_{i}$ ) while in core activities (low $\sigma_{i}$ ) employment in-house and outsourced will tend to grow hand-in-hand. In that sense, our model is inline with management theories recommending firms focus resources and talent on their core competencies and outsource whatever outside contractors are able to do better.
} 
marginal productivity of the IT subconstractors has gone up in the aftermath of broadband expansion.

\subsection{Predictions from the model}

Without lost of generality, we consider that:

$$
1 \leq \sigma_{1}<\sigma_{2}<\ldots<\sigma_{N}
$$

The first order conditions with respect to $s_{i}$ and $n_{i}$ for all occupations $i \in \mathbf{N}$ leads to the following relationship:

$$
s_{i, j}=\lambda_{i, j} n_{i, j}^{\rho \sigma_{i}+1}, \text { where } \lambda_{i, j}=\frac{1-\mu_{i}}{\mu_{i}}\left[\frac{\rho+1}{a_{i}^{\rho} r_{i} \gamma_{i, j}}\right]^{\sigma_{i}} \text {. }
$$

Because of this relationship, a firm can only increase its size by increasing its number of in-house workers as well as its outsourcing expenditures. $\lambda_{i, j}$ is a coefficient that measure the relative cost of these two types of labor and the level of complementarity. We assume that the parameters are distributed such that:

$$
\lambda_{1, j}<\lambda_{2, j}<\ldots<\lambda_{N, j}
$$

In the baseline version of the model, we keep the setup as simple as possible and assume that there are only two types of occupations 1 and 2 . Occupation 1 is the "core" occupation which is associated with a value of $\sigma_{1}=1$ and a value $\alpha_{1}>1 / 2$. By contrast, occupation 2 is the "non-core" occupation where in-house workers are more easily substituable by outsourcing workers $\left(\sigma_{2}>1\right)$. We primarily present results pertaining to increase in productivity. In the Appendix E, we show how the results are impacted if we allow for more than two types of occupations and we discuss the case of a decline in the cost of outsourcing. We also present a numerical resolution of the model.

Proposition 1. A positive increase in $\theta$ raises the cost share of outsourcing for each occupation i for which $\sigma_{i}>1$

Proof. See Appendix E.1

The intuition for this result comes from the fact that firms respond to a positive productivity shock by increasing their workforce. As long as the elasticity of substitution 
between the two types of workers is larger than 1, then the firm will adjust both its number of in-house and outsourced workers. Yet, because $\rho>0$, as the firm grows, it is more and more costly to hire in-house workers and the ratio $\eta_{c}$ of the labor cost coming from outsourcing over the total labor force increases.

Proposition 2. Following an increase in $\theta$, the increase in the cost share of outsourcing is larger for the non core occupations

\section{Proof. See Appendix E.2}

This Proposition shows that all occupations will not be affected equally by the BI shock. The high $\sigma_{i}$ (non-core) occupations will become more and more composed of outsourced workers. While we cannot directly identify these occupations, in the empirical part of the paper we show that workers are more likely to move to a service firms specialized in tasks that are typically considered as non-core (cleaning services, driving, security...) following the BI shock.

Proposition 3. Following an increase in $\theta$, the concentration of in-house workers increases within firms.

\section{Proof. See Appendix E.3}

Proposition 3 is easy to look at in the data as we directly observe in-house occupation composition (while we do not have direct measure of outsourcing expenditures by occupation). This result predicts that when a firm is connected to BI, its HHI of concentration should increase.

In this baseline version of the model, there are only two types of occupation. We did this to keep the model as simple as possible while keeping the core economic intuition. In Appendix E.7, we provide a numerical illustration of the comparative statics of the model. We solve the profit maximization problem of the firm for a specific case (with 4 occupations) and show how optimal choices varies as productivity increases and the cost of outsourcing decrease. Results from this simple exercise show that outsourcing intensity increases with size (as measured by sales) and that a positive productivity shock or a decline in outsourcing cost is associated with rising HHI. In Appendix E.5, we show how to extend the model to include more than two type of occupations. 


\subsection{Link to empirical analysis}

Our theoretical framework implicitly adopts a model of the core-competency of the firm, where cost-minimizing firm will concentrate on in-house occupations which are the hardest to outsource. Monopsony power on the in-house labor market implies some degree of rent-sharing with in-house workers which provides an incentive for firms to outsource that increase with the level of productivity. A motivating consideration for this set of assumptions is that it predicts a positive correlation between scale and outsourcing intensity ${ }^{16}$ which turns out to be a a salient feature of the data (Figure 1).

In that setting, a technological shock, such as broadband expansion, which decreases the cost of outsourcing directly or boost firms' productivity will lead to more outsourcing. Under a broad set of conditions, it will also leads firms to become more occupationally segregated meaning that their labor cost will be concentrated on a small set of occupations (which we capture with an HHI). We will take most of these predictions to the data.

Before we move on to the empirical sections of the paper, let us briefly discuss the case of high-skill outsourcing. In this version of the model, we have assumed that there is a negative correlation between the $\sigma_{i}$ and $\alpha_{i}$, i.e. that non-core occupations are low skilled and conversely. However, the proofs presented in the Appendix show that most of the results hold if some non-core occupations have high $\alpha_{i}$ (typically IT workers). We further present numerical results assuming a null correlation between alpha and sigma and obtain (for a particular value of the parameters) predictions similar to those presented here. ${ }^{17}$

\section{Data and Empirical Strategy}

\subsection{Data}

Administrative data on labor market outcomes. Our data comes from two main administrative sources. The first is the matched employer-employee dataset covering all workers based in France since 1994 (Déclaration annuelle des données sociales or

\footnotetext{
${ }^{16}$ See Appendix E.6 for a formal proof.

${ }^{17}$ However, if most high-skill occupations are considered non-core, the revenue share would increase with $\sigma_{i}$ which results in an opposite effect for the concentration index. We do not view this case as relevant however.
} 
DADS). This dataset constitutes the primary source used to compute payroll tax data, and gives detailed individual information including salary, hours worked, occupation, age, gender and the identifier of the employing firm and establishment. It is not possible to follow workers over time, except for a random sample of 1 out of every 24 workers, which we refer to as the DADS panel. We clean these data and restrict our sample to the French private sector. Appendix B provides details on how we depart from the raw dataset. One information set that is usually missing from such administrative data is individual education levels. Hence, we cannot control for skill level or ability based on this information. We therefore rely on occupation codes to classify workers into skill groups.

The second main source is the administrative financial records made available by the French Ministry of Finance (FIchier Complet Unifie de Suse or FICUS), which report performance indicators for each private sector firm and which are available over the same period of time. In particular, we extract information relative to each business' value added to compute a measure of labor productivity. ${ }^{18}$ Contrary to the DADS, FICUS does not provide information at the establishment level but only at the firm level. ${ }^{19}$

We put forward several measures that serve as a proxy for outsourcing. The most direct one is firm-level outsourcing expenditure scaled by the wage bill, which closely matches the outcome of the theoretical model. Secondly, to have a broader sense of how BI affects segregation of occupations across establishments, we construct a measure of establishment occupational concentration based on an HHI computed using shares in total wage bill. ${ }^{20}$ The theory predicts that the HHI should increase as a result of the BI shock. ${ }^{21}$ Finally, we define typical outsourcing sectors and outsourceable

\footnotetext{
${ }^{18}$ One information that is missing from FICUS is outsourcing expenditures, which are mixed with a broader category of spending. In order to recover a measure of outsourcing expenditure at the firm level, we take advantage of an alternative administrative dataset at the firm level which is curated by the Bank of France and called Fichier inter-Bancaire des Entreprises or FiBEn). The raw files used to build FiBEn and FICUS are the same, but the coverage is slightly different as FiBEn excludes firms that did not reach 700,000 euros in yearly turnover.

${ }^{19}$ We thus base our analysis of the effect of BI on productivity and outsourcing expenditure on singleestablishment firms, for which we can define a unique location that will serve to define the timing of arrival of Broadband Internet.

${ }^{20}$ The concentration of occupations within each establishment $i$ is computed with the following formula: $H H I_{i}=\sum_{o=1}^{18} \psi_{o i}^{2}$, where $o$ indexes each of the 18 occupational categories that compose the French private sector at the 2 digit (also known as the PCS classification), and $\psi_{o i}$ is the share of the wage bill of the establishment attributed to workers employed in a given occupation. At the city level $c$, we compute the average establishment concentration as following: $H H I_{c}=\sum_{i=1}^{N} \omega_{i c} H H I_{i c}$, where $\omega_{i c}$ is the share of employment in the city accounted for by each establishment $i$.

${ }^{21}$ See Proposition 3. In addition, we show numerical results based on a special case of the model in
} 
occupations as follows, consistent with Goldschmidt and Schmieder (2017):

- Outsourceable occupations. Non-core occupations likely to be outsourced, offshored or subcontracted, e.g. cleaners and IT specialists. The full list of occupations is given in Appendix B.

- Outsourcing sectors. Administrative and business support service sectors. Highskill outsourcing sectors: IT, accounting and consulting sectors. Low-skill outsourcing sectors: cleaning, security, food and driving services. The full list of sectors is given in Appendix B.

At the city level, we construct a measure of expansion of outsourcing sectors by looking at the share of employment accounted for by two emblematic examples: IT services and cleaning services. We further test whether their corresponding outsourceable occupations (IT specialists and cleaners) are increasingly concentrated within their respective outsourcing sector. At the individual level, we test whether workers are increasingly likely to change establishment once the city is connected to BI, and we measure whether this effect is stronger for mobility towards outsourcing sectors, both in low-skill services and in high-skill services.

Data on broadband expansion. Our main source of variation in available technology derives from the expansion of broadband internet in France. The underlying data, described in detail in Malgouyres et al. (2019), document the date when each local exchange unit was upgraded in mainland France. ${ }^{22}$ We additionally obtained data from the regulatory agency (ARCEP) on the geographical coverage of each local exchange unit. Each city in France is partitioned into census blocks, and the data document the area of each census block (IRIS) covered by a given local exchange unit. Combining both datasets, we construct a continuous measure of broadband access for city $i$ at year $t$. This measure, which we denote $\widetilde{Z}_{i t}$, is a time-weighted percentage of area covered in city $i$. It is formally defined as:

$$
\widetilde{Z}_{i t}=\sum_{b \in i} D_{b, t} \frac{\mathcal{A}_{b, t}}{\sum_{b^{\prime} \in i} \mathcal{A}_{b^{\prime}, t}},
$$

\footnotetext{
Online Appendix Section E.7, see in particular Figure E3 and associated comments.

${ }^{22}$ Throughout the paper, broadband or ADSL refers to first generation ADSL that is associated with speed of $512 \mathrm{kbit} / \mathrm{s}$. The historical operator was compelled by law to make this data available to other operators as well as websites allowing consumers to gauge the quality of their line. The data was collected through one such website by Malgouyres et al. (2019) and validated manually.
} 
where $b \in i$ denotes the census tracks included in city $i, D_{b, t}$ share of the days of year $t$ with access in $b$ since January 1st of year $t$ normalized by the number of days in year $t$. Finally, $\mathcal{A}_{b, t}$ denotes the area covered by census track $b$.

The variable $\widetilde{Z}_{i t}$ is continuous with support between 0 and 1 , reflecting both the area and time dimensions of local broadband availability. ${ }^{23}$ We refer to $\widetilde{Z}_{i t}$ as the degree of connection of a city.

In our study of the dynamics of labor market following BI expansion, it will sometimes be useful to consider a discrete analog of Z̃. We follow Malgouyres et al. (2019) and define the year of treatment as $t_{i 0}=\operatorname{argmax}_{t} \Delta \widetilde{Z}_{i t}$ and discretized treatment status as $Z_{i t}=\mathbb{1}\left\{t \geq t_{i 0}\right\}$. We denote $C_{i, t}$ the corresponding discrete (binary) variable. The discretization results in little loss of information, given the underlying distribution of the continuous variable, and allows us to implement a transparent before/after comparison through the estimation of event studies. We refer to the year that corresponds to the largest change in the share of the municipality connected to ADSL as the "year of connection". ${ }^{24}$ The latter ranges from 1999 for a handful of experimental cities to 2007 for the most remote areas.

Table 1 reports the summary statistics for the main outcomes of interest depending of the year of connection. Panel A describes the city-level data while panel B describes the establishment level data. Firms and cities connected to the internet during the first three years of ADSL expansion are larger, have a slightly higher share of highskill workers and spend more in outsourcing relative to their wage bill. All the other measures of outsourcing are also larger in earlier cohorts, except for the occupational concentration, which is slightly lower in large cities.

\subsection{The diffusion of Broadband Internet in France}

As evidenced by Malgouyres et al. (2019), the deployment of broadband internet technology beyond France's largest cities began very slowly at the dawn of the 2000's and

${ }^{23} \widetilde{Z}_{i t}$ will be equal to one if all of its areas have had access for the entire year. It will be equal to $1 / 2$ if the entire city has had access to broadband over half the year $t$. In practice however, it is very strongly concentrated on 0 and 1, with very few intermediate observations, see Figure A1 in Appendix A.

${ }^{24}$ Even if it does not mean that no one had access to the ADSL before this year in the municipality. We however choose municipality as the smallest relevant geographical unit as most administrative sources do not provide information for smaller aggregate. Mainland France has up to 36,000 municipalities but most of them are very small and rural (the median population in 2010 is 427). Municipalities are grouped into counties ("département"), there are on average 381 municipalities per county. 
Table 1: Summary Statistics

\begin{tabular}{lcccc}
\hline & & \multicolumn{3}{c}{ By cohort of ADSL arrival } \\
\cline { 3 - 5 } & All sample & $99-01$ & $02-04$ & $05-07$ \\
& $\mathrm{mn} /(\mathrm{sd})$ & $\mathrm{mn} /(\mathrm{sd})$ & $\mathrm{mn} /(\mathrm{sd})$ & $\mathrm{mn} /(\mathrm{sd})$ \\
\cline { 2 - 5 } & & & & \\
Panel A: City level & & & & \\
Share of high skill workers & & & & \\
& 0,07 & 0,09 & 0,06 & 0,05 \\
Occupational concentration (HHI) & $(0,07)$ & $(0,08)$ & $(0,06)$ & $(0,06)$ \\
& 0,37 & 0,36 & 0,37 & 0,39 \\
Value added over wage bill (2010 euros) & $(0,14)$ & $(0,11)$ & $(0,14)$ & $(0,17)$ \\
& 2,01 & 2,01 & 2,00 & 2,03 \\
Outsourcing exp. over wage bill (2010 euros) & $(1,99)$ & $(1,05)$ & $(1,58)$ & $(3,07)$ \\
& 0,30 & 0,35 & 0,28 & 0,28 \\
Share of empl. in IT services & $(0,62)$ & $(0,56)$ & $(0,66)$ & $(0,64)$ \\
& 0,005 & 0,011 & 0,002 & 0,002 \\
Share of IT specialists in IT services & $(0,04)$ & $(0,05)$ & $(0,04)$ & $(0,04)$ \\
& 0,10 & 0,15 & 0,04 & 0,04 \\
Share of empl. in cleaning services & $(0,26)$ & $(0,30)$ & $(0,18)$ & $(0,17)$ \\
& 0,011 & 0,019 & 0,009 & 0,008 \\
Share of cleaners in cleaning services & $(0,08)$ & $(0,08)$ & $(0,08)$ & $(0,07)$ \\
& 0,18 & 0,29 & 0,06 & 0,09 \\
Average establishment size & $(0,36)$ & $(0,42)$ & $(0,24)$ & $(0,28)$ \\
& 35,1 & 40,5 & 34,8 & 30,0 \\
N. of establishments & $(51,5)$ & $(52,7)$ & $(55,5)$ & $(41,7)$ \\
& 12,7 & 36,3 & 4,7 & 3,2 \\
& $(52,4)$ & $(96,6)$ & $(6,5)$ & $(10,4)$ \\
\hline Observations & $116^{\prime} 648$ & $57^{\prime} 875$ & $21^{\prime} 650$ & $37^{\prime} 123$ \\
\hline
\end{tabular}

Panel B: Establishment level

\begin{tabular}{lcccc} 
Share of high skill workers & 0,12 & 0,13 & 0,07 & 0,07 \\
& $(0,17)$ & $(0,19)$ & $(0,09)$ & $(0,10)$ \\
Occupational concentration (HHI) & 0,38 & 0,37 & 0,38 & 0,38 \\
& $(0,19)$ & $(0,18)$ & $(0,19)$ & $(0,20)$ \\
Value added over wage bill (2010 euros) & 2,08 & 2,08 & 2,06 & 2,06 \\
& $(5,05)$ & $(4,91)$ & $(6,03)$ & $(1,98)$ \\
Outsourcing exp. Over wage bill (2010 euros) & 0,39 & 0,42 & 0,30 & 0,31 \\
& $(1,33)$ & $(1,44)$ & $(0,99)$ & $(0,99)$ \\
\hline Observations & $1^{\prime} 818^{\prime} 004$ & $1^{\prime} 383^{\prime} 155$ & $336^{\prime} 103$ & $98^{\prime} 746$ \\
\hline
\end{tabular}

Notes : This table presents the summary statistics of the main variables used in the regression. The first column provides the means (and standard deviation) over the whole sample, while the subsequent three columns split the sample according to the cohorts of BI arrival. Averages are computed over the full period from 1997 to 2007.

continued up to 2007. This was mostly due to legal, political and administrative reasons (see Appendix $\mathrm{C}$ for more details). Table $\mathrm{C} 1$ in Appendix shows the percentage of cities, establishment and workers that was connected each year. In 2000, only $2 \%$ of cities were connected, although this corresponds to a much larger share of workers and establishments (respectively $25 \%$ and $22 \%$ ). By $2003,80 \%$ of workers and $76 \%$ of establishments were connected. At the end of 2005, 96\% of French workers and $80 \%$ of cities were covered.

Explaining broadband expansion Our identification strategy relies on the assumption that the coverage of cities was mostly determined by city population density which is almost fixed over time and can be controlled for - and did not take into 
account underlying local trends in productivity or propensity to outsource activities. As a result, conditional on time and city fixed effects, we consider the variation in broadband access to be as good as random. In order to assess the plausibility of this assumption, we explore the extent to which broadband coverage over time can be explained by different types of lagged city-level covariates. We group those covariates into two main groups:

1. Density: population in 1999 per square $\mathrm{km}(\mathrm{log})$, interacted with a full set of year dummy variables.

2. Industry dynamics: shares of employment in 10 economic sectors at $t-1$ as well as changes in shares between $t-1$ and $t-2$.

We then estimate the following specification:

$$
\tilde{Z}_{i t}=\operatorname{dens}_{i t}^{\prime} \rho_{1}+\operatorname{indyn}_{i t}^{\prime} \rho_{2}++\mathrm{FE}_{i}+\mathrm{FE}_{r(i), t}+\varepsilon_{i t},
$$

where $\tilde{Z}_{i t}$ is the time-weighed share of city $i$ that is covered by broadband internet as described in Equation (8). As we are mostly interested in the explanatory power of these different groups of observable variables, we only report the R-square of each regression in Table 2.

Table 2: Explaining city broadband coverage: panel analysis

\begin{tabular}{lccccc}
\hline & $(1)$ & $(2)$ & $(3)$ & $(4)$ & $(5)$ \\
& Covariates & Twoway FE & $(2)+$ density & $(2)+$ indus. & (2)+ all cova. \\
\hline \hline$R^{2}$ & 0.555 & 0.786 & 0.812 & 0.787 & 0.812 \\
\hline Industry: F-stat & 50.73 & & & 2.57 & 2.18 \\
Density: F-stat & 21583.14 & & 221.55 & & 223.93 \\
\hline
\end{tabular}

Notes : This table presents the R-square of panel regressions following equation (9). Twoway FE (Column 2) refers to a twoway fixed-effect model with city fixed effect and department $\times$ year FEs. Density (Column 3) includes 1999 population density at the city level defined as total population divided by city area interacted with year indicators. Industrial structure controls (Column 4) include the lagged share and their changes of sectoral shares (nine sectors). Column (1) includes all of the controls without fixed effects. Individual coefficients can be found in the Appendix Table C2.

Our results are summarized in Table 2. We start by regressing broadband internet coverage on all three sets of observable covariates without including any time or city fixed effects. As indicated in column (1) of Table 2, we obtain an R-square of $56 \%$ indicating that these variables capture a substantial share of the variation in treatment status. Column (2) presents the R-square of a two-way fixed effect model including 
city and department $\times$ year fixed effects. This model absorbs $78.6 \%$ of the variance in treatment intensity. Column (3) presents the same model to which we add the 1999 measure of density interacted with year dummies. The fit of the model increases by 2.6 percentage points. Interestingly, the set of industry dynamic variables barely increases the fit of the model (column (4)), indicating that, conditional on city and department-year fixed effects, they are roughly unrelated to the timing of internet coverage. Column (5) shows that the F statistics associated with the null hypothesis that all the industry variables are null is small (2.18) and two orders of magnitudes smaller than that associated with population density (223). We consider the low predictive power of observable variables as supporting our identification strategy, since a large share of the variation in timing of the broadband expansion seems to be idiosyncratic in nature.

\subsection{Empirical Strategy}

Technological change embedded in the gradual diffusion of broadband internet across municipalities is expected to be skill biased, and in particular, to increase firms' labor productivity and firms' demand for high-skill workers relative to the rest of the labor force (Akerman et al., 2015). Beyond this well-established fact, we also expect this technology to modify the optimal boundaries of the firm by increasing firm reliance on outsourced labor to perform some of the internal non-core activities. As shown by our theoretical model, the productivity shock can by itself generate these shifts towards outsourced labor. If, in addition to the increase in productivity, we hypothesize that broadband internet lowers the cost of business-to-business transactions and increases the supply of services to firm, then we expect this phenomenon to be magnified further.

To identify the causal channel, we exploit the fact that the dissemination of ADSL across municipalities was staggered over a period of nearly 10 years, from 1999 to 2007. While the timing of diffusion was clearly dependent on the size and density of the city, as described in the previous subsection, after controlling for these elements we can exploit quasi-random variation in access across cities of similar densities that are located within the same department. Formally, we use the panel of cities $c$ observed for each year $t$ from 1997 to 2007 to run the following econometric model:

$$
Y_{c, t}=\sum_{\tau=-k}^{k^{\prime}} \alpha_{\tau} \mathbb{1}\left\{t=t_{c}+\tau\right\}+\gamma_{t} X_{c, t}+v_{c}+\varepsilon_{c, t}
$$


where $Y$ is the variable of interest, $t_{c}$ is the year of ADSL arrival of a city $c$ and $X$ is a vector of control variables. $X$ contains a time unvarying measure of the density of the city in 1999 interacted with year dummies and a set of department-year intercepts. Finally, we add city-level fixed effects such that the coefficients $\alpha_{\tau}$ can be interpreted as changes within a given city resulting from the arrival of the ADSL, as compared to cities within the same department and with similar densities that have yet to be connected to BI. We exclude two dummies from the regression, respectively for $\tau=$ -1 and $\tau=-6$ as suggested in Borusyak and Jaravel (2017) in this type of event study setting with year and individual fixed effects. The regression is run over the sample of cities that have more than 100 inhabitants at the beginning of the period, to avoid capturing an effect driven by small villages, and over the years 1997-2007, which include the full period of ADSL expansion.

A recent literature underlines the caveats of using two-way fixed effects models in staggered adoption contexts (Callaway and Sant'Anna, 2020; De Chaisemartin and d'Haultfoeuille, 2020; Goodman-Bacon, 2018; Borusyak and Jaravel, 2017). The main issue resides in the fact that $\alpha_{\tau}$ for the post-treatment period is partly estimated using previously treated observations as controls. This might introduce biases in the presence of dynamic or heterogeneous treatment effects across cohorts. Given that in our context there is no pure control, since all cities are treated by the end of the period, we adopt the stacked difference in difference approach employed by Vannutelli (2020), which is also similar to Cengiz et al. (2019) and Deshpande and Li (2019). ${ }^{25}$ The latter consists in constructing a rolling control group for each treated cohort. In practice, for each treated cohort between 2000 and 2006, we construct a separate sample where we define time to treatment relative to that specific cohort, and all the cohorts treated in later years serve as controls. The observations within control cohorts are only considered before their treatment. The cohort receiving BI in 2007 serves as pure control, since there is no cohort treated afterwards to create an additional sample. Finally, we append the 8 samples constructed using this method to run the following regression model:

$$
Y_{c, s, t}=\alpha_{0} \text { Treat }_{c, s}+\sum_{\tau=-k}^{k^{\prime}} \alpha_{\tau} D^{\tau} \times \text { Treat }_{c, s}+\sum_{\tau=-k}^{k^{\prime}} \beta_{\tau} D^{\tau}+\gamma_{t} X_{c, t}+v_{c}+\pi_{s}+\varepsilon_{c, s, t}
$$

\footnotetext{
${ }^{25}$ Baker et al. (2021) show that the stacked difference in differences method gives similar results to the method proposed by Callaway and Sant'Anna (2020).
} 
Where Treat $_{c, s}$ takes the value of 1 if city $c$ is treated in sample $s$. This parameter is identified despite the city fixed effects $v_{c}$ because the same city appears in multiple samples with both treated and control status. $D^{\tau}$ are dummies for time relative to treatment (equal to $\mathbb{1}\left\{t=t_{c}+\tau\right\}$ of equation 10) and the $\alpha_{\tau}$ identify the pre- and post-treatment dynamic effects. We also add fixed effects for each one of the samples stacked $\left(\pi_{s}\right)$. Standard errors are clustered at the department level, which also account for the error correlation generated by the repeated appearance of the same cities across different samples. This constitutes our preferred strategy that we apply throughout the paper, but in Appendix A we also report results obtained from the standard twoway fixed effects model presented in equation (10) for comparison.

\section{Empirical Evidence on BI and Outsourcing}

In our theoretical model BI acts as a GPT. Once connected, firms become more productive and this raises their incentives to outsource the occupations with the smaller degree of complementarity in production. In Appendix D we present evidence that confirms the GPT nature of BI and show in particular that BI is a skilled-biased technology. We use our empirical strategy described in the previous section to show that cities and firms that are connected become more productive, as measured by their value added scaled by their wage bill, and increase their share of high-skill workers (see Figure D1 and Table D1). We then go further to show that high-skill workers experience an increase in their wage once their firm receives access to $\mathrm{BI}$, even conditional on a rich set of fixed-effects (commuting zone $\times$ year and individual). In particular, results in Table D2 show that, consistent with Akerman et al. (2015), that wage dynamics are positively impacted by broadband expansion $(+3 \%$ in the baseline specification) but that this average effect conceals a strong degree of heterogeneity between low skill $(+1 \%)$ and high-skill workers $(+5.2 \%)$. In this section, we go beyond the predictions of the skilled-biased technological change literature and provide direct causal evidence that the arrival of $\mathrm{BI}$ is associated with an increased reliance to outsourced labor, which in turn increases the level of segregation of workers with different occupations across firms. The theory of skill-biased technological change states that technology substitutes some workers while it increases the demand for high-skill workers, but it does not speak directly about workers' reshuffling across firms. 


\subsection{At the city and establishment level}

We start by looking at the causal effect of BI on outsourcing expenditure and occupational segregation across firms. The first measures the value of outsourcing expenditure scaled by the wage bill of the firm. ${ }^{26}$ The second captures the HHI for the concentration of employment across occupations within each establishment, computed using the occupational share of wage bill. At the city level, we compute the weighted average among the firms established in the municipality.

Figure A2 in Appendix A summarizes the evolution of these two outcomes over the period. The expenditure in outsourcing grew very steeply over the end of the 1990s, going from 0.36 in 1997 to 0.42 in 2000 (a growth of 17\%), and then stabilized at this high plateau. The occupation concentration in establishments increased steadily from 0.34 in 1997 to 0.39 in 2007 (a growth of 15\%). To test whether these trends are (partly) linked to the diffusion of BI, we run the empirical specification reported in equation (11) on these outcomes. Figure 2 presents the event study graphs at the city level and at the establishment level. Municipalities belonging to different cohorts of broadband expansion followed very similar trends before the arrival of the internet, but started spending more on outsourcing and became increasingly sorted after connection. This indicates that, after the arrival of BI, establishments within the city specialize by employing fewer types of occupations in-house, while buying more and more of these services from other firms, and consequently that workers become increasingly segregated into firms that primarily hire their type. The establishment level results follow similar patterns but are smaller in magnitude, which suggests that some of the effect operates through composition: newly created firms spend more in outsourcing and are more specialized in terms of occupational composition relative to disappearing firms.

Table A2 in Appendix A quantifies the effect at the city and establishment level by presenting the dynamic post-BI coefficients. Five years after the arrival of the ADSL in the city, we observe an average increase in outsourcing expenditure over wage bill of about 0.035 , which corresponds to a growth of $12 \%$ with respect to the baseline levels. Occupational concentration increases by about 0.008 (3.2\% growth relative to baseline). The effects at the establishment level are smaller and less precise on outsourcing expenditure: the latter increases by 0,018 euros $(+5 \%)$ but is marginally not

\footnotetext{
${ }^{26}$ Since the information on expenditure cannot be broken down between establishments part of the same firm, and we need to assign a single location to each entity, we restrict this sample to monoestablishment businesses.
} 
Figure 2: Outsourcing intensity and concentration of occupations within establishments

(a) Outsourcing expenditure in city

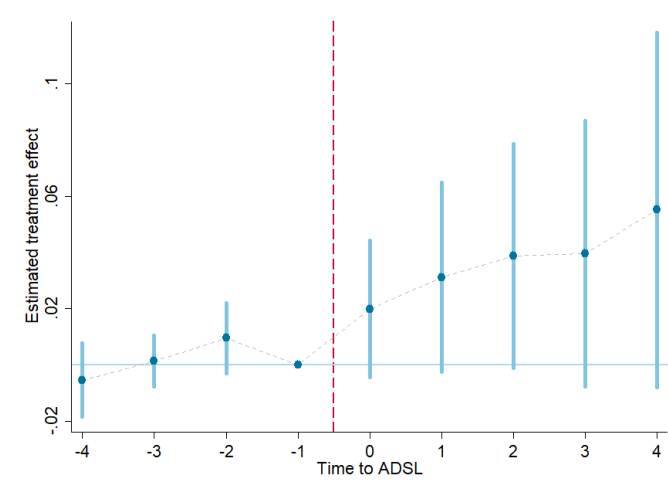

(c) Occup. concentration in city

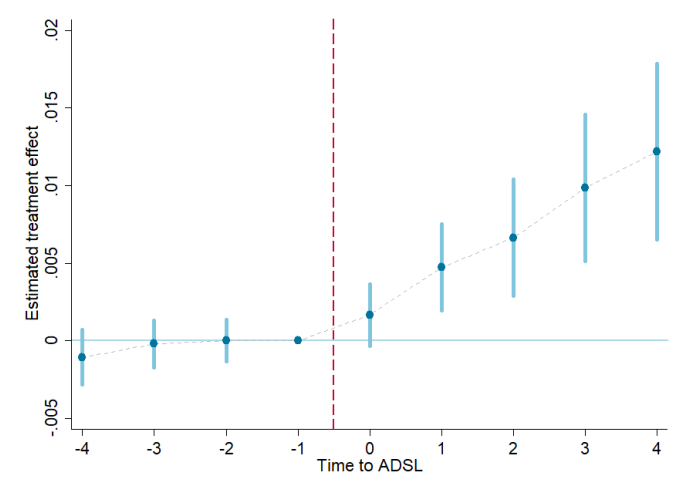

(b) Outsourcing expenditure in estab.

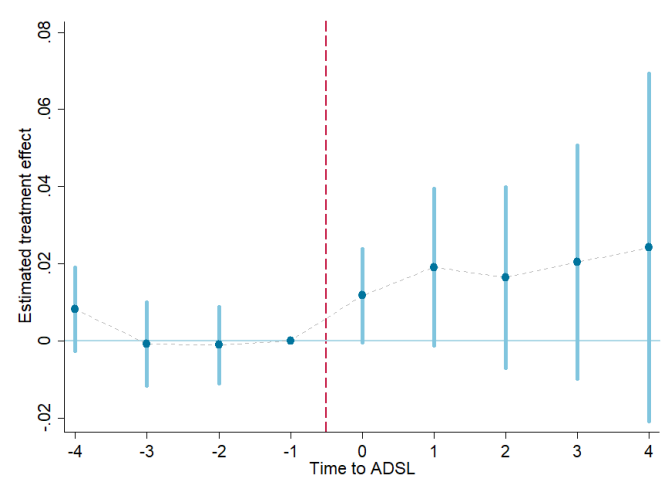

(d) Occup. concentration in estab.

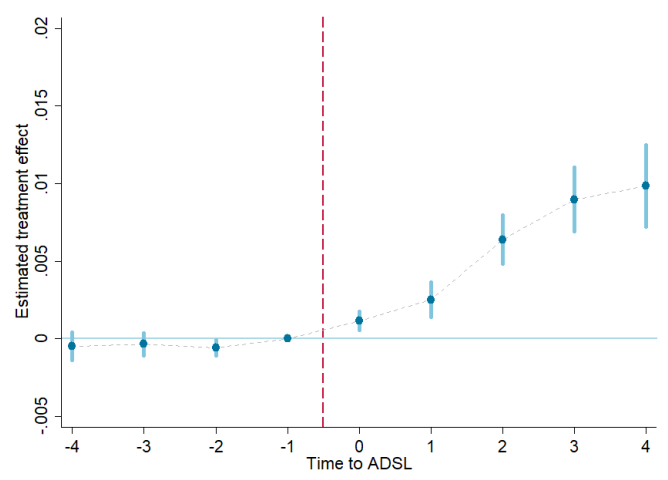

Notes: This Figure shows regression coefficients and the $95 \%$ confidence intervals from a stacked event study design. The citylevel specification follows equation 11, while the establishment-level specification follows the same logic but replaces city fixed effects with firm fixed effects.

significant, and occupation concentration increases by $0.006(+1.7 \%)$. This is line with the message that some of the effect occurs through changes in characteristics of newly created firms. Table A3 shows that these results are qualitatively similar if we control for trends explained by pre-ADSL productivity differences between cities, which suggest that differences in timing of ADSL diffusion across cities of similar density within the same department are not correlated with pre-existing differences in city-level productivity growth. Table A4 shows that results obtained from a standard dynamic two-way foxed effects model as reported in equation 10, and Table A9 reports the coefficients obtained from static regressions where the treatment status is interacted with the post-ADSL period. The magnitude is slightly smaller than the average of the dynamic coefficients but remains in line with the main results.

Further, we focus on one illustrative category of outsourceable low-skill labor - clean- 
ers - and one illustrative outsourceable high-skill occupation - IT specialists. ${ }^{27}$ We consider two main measures of outsourcing at the city level, which are computed separately for the high- and low-skill segments: (i) the share of total employment in the city concentrated within outsourcing sectors; and (ii) the share of outsourceable workers in the city that are employed in outsourcing sectors. ${ }^{28}$ While the first is a measure of supply of IT and cleaning services that might react even in the absence of an increase in outsourcing, the second captures the change in the concentration of outsourceable workers within their respective services regardless of total volume change. All measures are computed on a full-time equivalent basis.

Figure A3 in Appendix A describes the evolution of these outcomes over time. Employment in IT services almost doubled over the years of BI diffusion, going from $1.8 \%$ of the labor force in 1997 to $3.3 \%$ in 2007 . The share of employment in cleaning services increased by a lesser extent, going from $1.9 \%$ in 1997 to $2.4 \%$ in 2007 . Beyond the overall growth of these two emblematic outsourcing sectors, we also observe a shift of outsourceable occupations towards these sectors and away from the rest of the economy. The share of IT specialists employed by the IT service sector went from $47 \%$ in 1997 to $60 \%$ in 2007 . The share of cleaners employed in the cleaning service sector went from $70 \%$ in 1997 to $90 \%$ in 2007, with most of the growth taking place at the beginning of the period. These changes are substantial. In what follows we test whether they have been, at least in part, facilitated by the diffusion of the ADSL technology over the French territory.

Figure 3 reports the event study graphs of the two main outcomes, and show them separately for high- and low-skill outsourcing. Table A6 in Appendix A shows the corresponding regression coefficients, Table A7 present their robustness to the inclusion of city level productivity growth interacted with year dummies, Table A8 present the robustness to running a standard dynamic model, and Table A9 reports the coefficients obtained from static regressions. We see that the share of employment in IT services increases slightly after the arrival of ADSL, while the share of IT specialists employed in IT services grows substantially immediately after the city is connected.

\footnotetext{
${ }^{27}$ We decide to focus on cleaners and IT specialists because these occupations are well-identified into one single four-digit category in the French occupational nomenclature, and their corresponding service sectors - IT services and cleaning services, are also well identified in the classification of activities. Table A5 in Appendix describes the characteristics of firms in the IT services and cleaning services relative to the broader service sector. They are on average younger and are composed of less establishments per firms (are more likely to be mono-establishment firms).

${ }^{28}$ Outsourcing sectors refer to the IT and cleaning services respectively, while the outsourceable occupations are IT specialists and cleaners. See Appendix B for a formal definition.
} 
Figure 3: Effect of ADSL on high- and low-skill outsourcing

(a) Share of employment in IT services

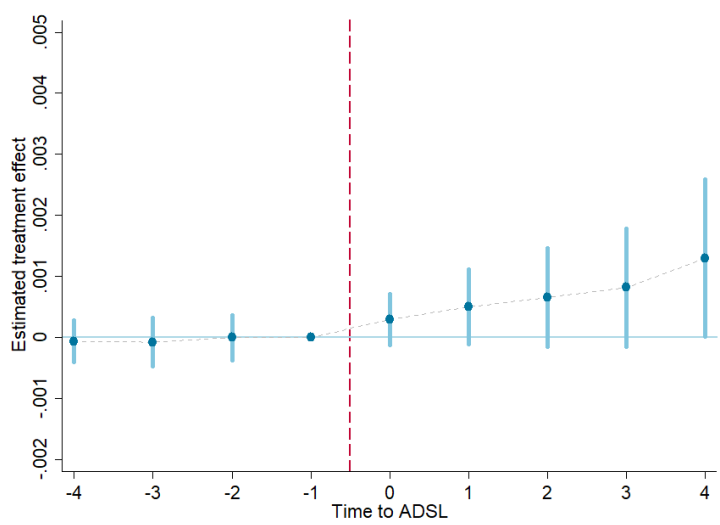

(c) Share of IT specialists in IT services

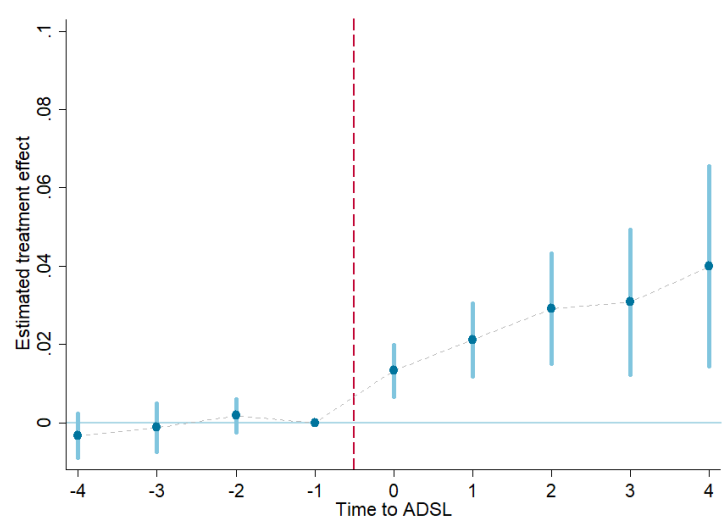

(b) Share of employment in cleaning services

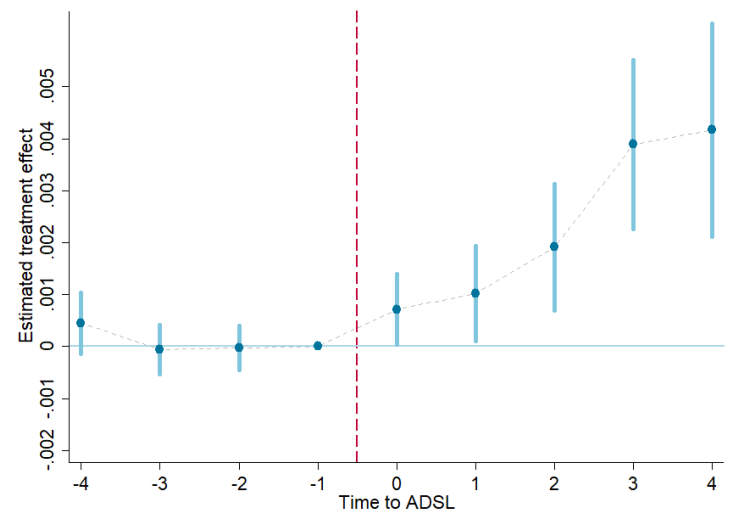

(d) Share of Cleaners in cleaning services

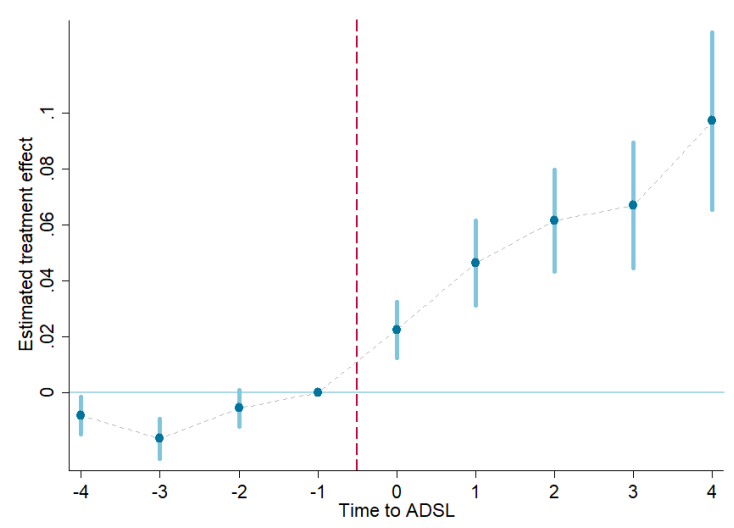

Notes: This Figure shows regression coefficients and $95 \%$ confidence intervals from a stack event study where the dependent variables are the share of workers employed in IT services (cleaning services) in a city at $t$ (Figures 3(a) and $3(\mathrm{~b})$ ) and the share of IT specialists (cleaners) working in IT services (cleaning services) in a city at $t$ (Figures $3(\mathrm{c})$ and $3(\mathrm{~d})$ ). The regression follows equation 11.

We can thus imagine that IT specialists are mostly outsourced towards establishments that were already present in the French territory, at least at the beginning of ADSL roll-out. In the low-skill segment, we observe a very striking increase in the share of employment concentrated within cleaning services after the arrival of ADSL, and the same is true for the share of cleaners that are employed directly by firms in this specialized sector.

While the magnitude of the coefficients might appear small, the effect is actually far from trivial when compared to baseline (pre-treatment) values. The average share of city employment accounted for by IT services was about $0.6 \%$ at the beginning of the period, such that the average impact of ADSL in the five years after its arrival amounts to growth of $12 \%$. Cleaning services accounted for about $1.3 \%$ of total city employment in 1997, and the BI connection led to growth of $18 \%$. When it comes to 
the concentration of IT specialists within their service sector, the baseline value is $10 \%$, and the effect of ADSL amounts to 2.7 additional percentage points (growth of 27\%). The share of cleaners within cleaning services was $12 \%$ in 1997 . This grew on average by 6.5 additional percentage points with the arrival of BI (growth of 54\%). Given these magnitudes, we can infer that the arrival of the internet generated a structural change in the way these services are used by their business customers. This is an indication that BI catalyzed growth in domestic outsourcing, and this for non-core activities situated both at the low- and high-skill ends of the spectrum.

To have a more concrete sense of the magnitude of these results, we can wonder how outsourcing would have evolved in the absence of broadband internet. Since the main driver of increased outsourcing in our model is a productivity shock, we can imagine that other forces beyond BI, such as the diffusion of robots and computers for instance, are also behind the increased popularity of this practice. To answer this question we construct a counterfactual for the evolution of outsourcing expenditure and occupation concentration, which estimates how these two outcomes would have evolved in the absence of BI. We follow the procedure adopted in Malgouyres et al. (2019) and compute the counterfactual as the actual outcome minus the predicted dynamic effects predicted by our semi-dynamic specification reported in Table A2. More specifically, we compute an average effect of broadband internet expansion for each year as:

$$
\overline{a_{t}}=\sum_{t_{0}=1999}^{2007} w_{t_{0}, t^{\prime}}^{y} \hat{\alpha}_{t-t_{0}}
$$

where $w_{t_{0}, t^{\prime}}^{y}$ represents the outcome $y$ measured in $t^{\prime}$ for firms located in cities where BI became available at $t_{0}$, weighted by the employment share of these cities in the entire national economy. We postulate that the observed outcome $y$ - in our case outsourcing expenditure and occupational concentration -, is given by a baseline level $y_{t}(0)$ that would have occurred in the absence of broadband diffusion multiplied by the predicted effect of BI: $y_{t}=\exp \left(\bar{a}_{t}\right) y_{t}(0)$. We obtain the counterfactual series by inverting this relationship: $y_{t}(0)=\left(-\bar{a}_{t}\right) y_{t}$. Results are reported in Figure 4 . Outsourcing expenditure over wage bill would have been 0.05 euros lower in 2007 in the the absence of $\mathrm{BI}(-12 \%)$, and the occupational concentration would have been lower by $0.013(-3.4 \%)$. 
Figure 4: Counterfactual aggregate trends

(a) Outsourcing expenditure

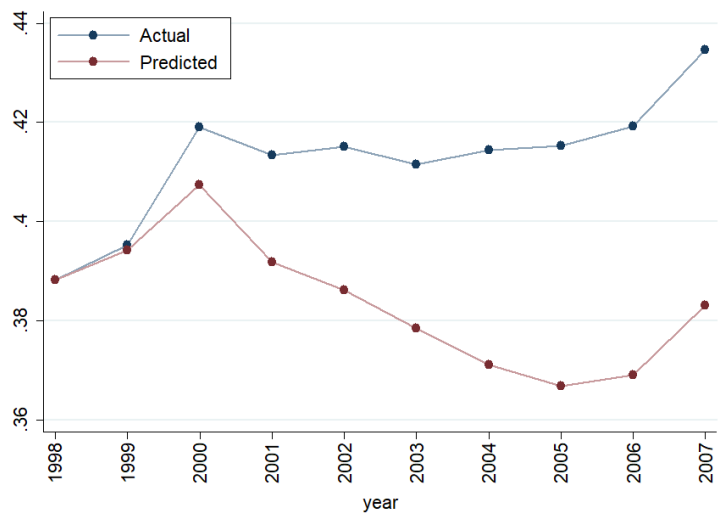

(b) Occupation concentration

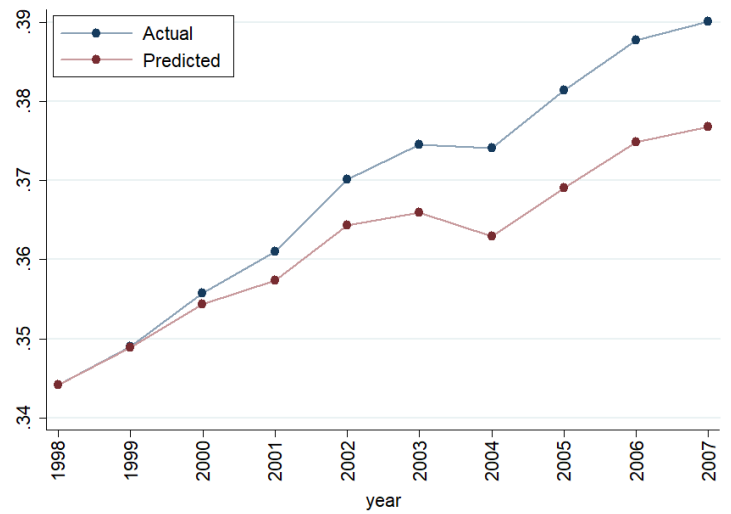

Notes: The actual outcomes are the weighted averages of the outcomes observed in our sample aggregated at the economy level. The predicted outcomes are obtained by subtracting the predicted effect of broadband internet to the actual outcomes. The latter is computed using a weighted average of the estimated $\alpha_{\tau}$, for $\tau>0$ where the weights correspond to the share in national employment of each cohort of firms (i.e. all firms for which broadband expansion occurs the same year) measured the year of broadband expansion. The weights are normalized so that they sum to one.

\subsection{At the individual level}

In this section, we leverage our panel data to follow the workers over time and study their mobility decisions. More precisely, we look at the effect of BI expansion on the probability that workers switch jobs. We consider different types of mobility: within/between the same city or labor market area (Zone d'Emploi) and/or from an establishment outside the outsourcing sector to an establishment in the outsourcing sector.

We therefore estimate the following linear probability model:

$$
\operatorname{Move}_{i, t}=\beta \tilde{Z}_{c(i), t}+X \gamma+\psi_{k, t}+\zeta_{s(i)}+\varepsilon_{i, t}
$$

where $M o v e_{i, t}$ is a binary variable equal to 1 if the worker $i$ has moved on year $t$ and 0 otherwise. ${ }^{29} \quad \tilde{Z}$ has been defined above and measures the exposition to BI. $X$ is a vector of standard time-varying individual characteristics usually included in wage regressions: age, age squared, an indicator of whether the job is part-time (as opposed to full-time). Finally, $\psi_{k, t}$ and $\zeta_{s(i)}$ are a set of labor market area $k$ times year $t$ fixed effects and sector $s(i)$ fixed effects. $\varepsilon$ is an idiosyncratic error that we assume

\footnotetext{
${ }^{29}$ Specifically, we set this dependent variable to 1 in year $t$ if a worker is not in the same establishment in year $t+2$ when compared to year $t$. This is because workers sometimes disappear from the sample the year immediately following a mobility.
} 
can be correlated within labor market areas but not across. $\beta$ captures the effect of being connected to $\mathrm{BI}$ on the probability of moving, controlling for observable and time-varying unobservable worker characteristics.

Table 3: EFFEct of ADSL on wORKERs' MOBILITY

\begin{tabular}{|c|c|c|c|c|c|c|}
\hline \multirow[b]{3}{*}{ Mobility } & \multicolumn{3}{|c|}{ High-skill workers } & \multicolumn{3}{|c|}{ Low-skill workers } \\
\hline & (1) & $(2)$ & (3) & (4) & (5) & (6) \\
\hline & Any move & To outsourcing & Other & Any move & To outsourcing & Other \\
\hline Any & $\begin{array}{c}0.063^{* * *} \\
(0.020)\end{array}$ & $\begin{array}{l}0.177^{* *} \\
(0.081)\end{array}$ & $\begin{array}{c}0.066^{* * *} \\
(0.022)\end{array}$ & $\begin{array}{c}0.070^{* * *} \\
(0.012)\end{array}$ & $\begin{array}{c}0.086^{*} \\
(0.046)\end{array}$ & $\begin{array}{c}0.064^{* * *} \\
(0.013)\end{array}$ \\
\hline Same city & $\begin{array}{l}-0.013 \\
(0.097)\end{array}$ & $\begin{array}{c}-0.189 \\
(0.138)\end{array}$ & $\begin{array}{l}-0.004 \\
(0.100)\end{array}$ & $\begin{array}{c}0.257^{* * *} \\
(0.040)\end{array}$ & $\begin{array}{c}0.367^{* * *} \\
(0.115)\end{array}$ & $\begin{array}{c}0.262^{* * *} \\
(0.043)\end{array}$ \\
\hline Same LMA & $\begin{array}{c}-0.004 \\
(0.038)\end{array}$ & $\begin{array}{c}0.062 \\
(0.084)\end{array}$ & $\begin{array}{c}0.020 \\
(0.033)\end{array}$ & $\begin{array}{c}0.129^{* * *} \\
(0.017)\end{array}$ & $\begin{array}{l}0.164^{* *} \\
(0.066)\end{array}$ & $\begin{array}{c}0.130^{* * *} \\
(0.017)\end{array}$ \\
\hline Different city & $\begin{array}{l}0.102^{* *} \\
(0.048)\end{array}$ & $\begin{array}{c}0.314^{* * *} \\
(0.097)\end{array}$ & $\begin{array}{c}0.096 \\
(0.067)\end{array}$ & $\begin{array}{l}-0.021 \\
(0.018)\end{array}$ & $\begin{array}{c}0.033 \\
(0.046)\end{array}$ & $\begin{array}{l}-0.015 \\
(0.019)\end{array}$ \\
\hline Different LMA & $\begin{array}{c}0.174^{* * *} \\
(0.054)\end{array}$ & $\begin{array}{l}0.328^{* *} \\
(0.130)\end{array}$ & $\begin{array}{l}0.132^{* *} \\
(0.053)\end{array}$ & $\begin{array}{l}-0.040^{*} \\
(0.022)\end{array}$ & $\begin{array}{c}-0.003 \\
(0.058)\end{array}$ & $\begin{array}{l}-0.036 \\
(0.024)\end{array}$ \\
\hline 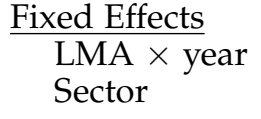 & $\begin{array}{l}\checkmark \\
\checkmark\end{array}$ & $\begin{array}{l}\checkmark \\
\checkmark\end{array}$ & $\begin{array}{l}\checkmark \\
\checkmark\end{array}$ & $\begin{array}{l}\checkmark \\
\checkmark\end{array}$ & $\begin{array}{l}\checkmark \\
\checkmark\end{array}$ & $\begin{array}{l}\checkmark \\
\checkmark\end{array}$ \\
\hline Obs. & $1,054,063$ & $1,054,063$ & $1,054,063$ & $5,143,010$ & $5,143,010$ & $5,143,010$ \\
\hline
\end{tabular}

Table 3 presents our results. We report coefficient $\beta$ from equation (12) for different types of mobility. Columns (1) to (3) refer only to high-skill workers. In column (1), the dependent variable is equal to 1 in the case of a mobility, regardless of the sector of the destination firm. Column (2) is conditional on moving to a firm in any of the highskill outsourcing sector (IT, accounting etc.) and column (3) is conditional on moving to a firm outside these outsourcing sectors. Columns (4) to (6) do the same but for low-skill workers, and for the corresponding outsourcing sectors (cleaning, driving, security etc.). Each line then considers different types of mobility: within a city, within a labor market area (Zone d'emploi), between cities and between labor market areas. We have standardized the dependent variable by its sample mean for each regression. Hence the coefficient should be interpreted as a deviation in percentage point from the average probability of moving.

These results show that being connected to BI is associated with a greater propensity to move, both for high and low-skill workers with a larger relative effect for mobility to an outsourcing sector. Yet, the patterns of mobility are different across skill groups. Low-skill workers tend to move locally while high-skilled workers are more mobile 
and can move across different labor market areas.

\section{Effect of outsourcing on wages}

Our findings suggest that BI was a significant shock to the labor market and impacted workers' wages. Importantly for this section, BI expansion also increased mobility of workers across establishments, with a particularly strong effect for some occupations on mobility towards firms in outsourcing sectors. To the extent that this shock can be considered exogenous, it allows us to consider individual outsourcing events, defined as follows:

- Individual outsourcing event. The mobility of one worker from a firm outside the outsourcing sector to a firm belonging to the outsourcing sector.

This definition allows us to capture many outsourcing events, for high and low-skill workers, respectively. We thus look in greater detail at the dynamics in wage and working conditions of workers around these events.

Table A10 in Appendix A describes the average wage and employment of outsourceable occupations across sectors, aiming at comparing their working conditions in the outsourcing sectors with the ones elsewhere. IT specialists earn a gross hourly wage of about $26 €$ in their outsourcing service, which is slightly higher than the one they gain in other services and in manufacturing ( $24 €$ and $25 €$ respectively). Cleaners, on the other hand, earn less when they are employed in cleaning services $(9.8 €)$ than when they are employed in other services or manufacturing (10.6€ and $11.7 €$ respectively). These characteristics are consistent with the idea that high-skill outsourcing may be voluntary, while low-skill outsourcing is not. Establishments in IT services employed on average 109 IT specialists before the arrival of BI, and grow substantially afterwards, reaching 133 workers in full-time equivalent. The number of IT specialists employed by other services and manufacturing is much smaller and relatively stable after BI arrival (3 and 12 respectively). A similar picture arises for low-skill outsourcing. The number of cleaners employed in the average cleaning service establishment goes from 91 before BI arrival to 171 afterwards, while it remains close to 1 in establishments in other services and manufacturing.

To test the direct effect of outsourcing on individual wages, we leverage our individual panel data and follow outsourced workers before and after an individual outsourcing event. We restrict our analysis to the subset of workers that experience only one 
outsourcing event over the period of observation, which allows us to define our event study. We then look at the evolution of their hourly wage by estimating the following dynamic model:

$$
\log \left(w_{i t}^{o w}\right)=\sum_{\tau=-v}^{v^{\prime}} \alpha_{\tau} \mathbb{1}\left\{t=t_{i}+\tau\right\}+X \gamma+\psi_{k, t}+v_{i}+\zeta_{s(i)}+\varepsilon_{i, t}
$$

where $w_{i t}^{o w}$ represents the hourly wage of workers that are being outsourced by their firms, and $t_{i}$ is the year of the event. $X$ is a vector of time-varying individual characteristics: age, age squared and an indicator of whether the job is part-time and $\psi_{k, t}, v_{i}$, $\zeta_{s(i)}$ are a set of labor market area $k$ times year $t$ fixed effects, individual fixed effects and sector $s(i)$ fixed effects. $\varepsilon$ is an idiosyncratic error that we assume can be correlated within labor market areas but not across. We estimate this regression separately for low-skill workers and high-skill workers, with a respective sample of 16,271 and 8,530 different workers.

Figures 5(a) and 5(b) show that the hourly wage of outsourced low-skill workers sharply decreases after the outsourcing event. This finding is in line with results evidenced by Goldschmidt and Schmieder (2017), which explain this phenomenon by the fact that firms in the outsourcing sectors benefit from lower rents, on average, than another 25 companies. This translates into lower wage premia for their employees. ${ }^{30}$ We find an average effect that ranges from $-4 \%$, immediately after the outsourcing event, to $-2 \%$ five years later, gradually converging towards the pre-treatment level. By contrast, outsourced high-skill workers enjoy a small but significant gain in hourly wage in the long run after the outsourcing transition ( $+1 \%$ five years after the event), a pattern that is consistent with broadband stimulating demand for IT services and thus resulting in an increase in IT workers' outside options and voluntary job-to-job transitions. These particular high-skill occupations indeed continue to be in high demand and can easily be contracted, especially as communication technologies improve. By regrouping these occupations, specialized firms can serve different clients and generate more profit first by maximizing the utilization rate of their inputs (mainly labor) and second by reducing fixed costs. This mechanism is similar in certain respects to some low-skill outsourcing, but in the case of IT specialists or accountants, the outsourced workers have greater bargaining power and can capture part of the rent by

\footnotetext{
${ }^{30}$ The shaded area corresponds to the year of the move, when the outsourced worker quit its previous employer to join an outsourcing firm. This transition period is known to create reporting errors of the number of hours worked and the wage in the data, resulting in an outlier estimate for the dummy +1 . In consequence, we focus on the coefficient from +2 to +5 in our analysis.
} 
Figure 5: Wage of outsourced workers before and after the outsourcing event

(a) Low-skill workers \& LS outsourcing

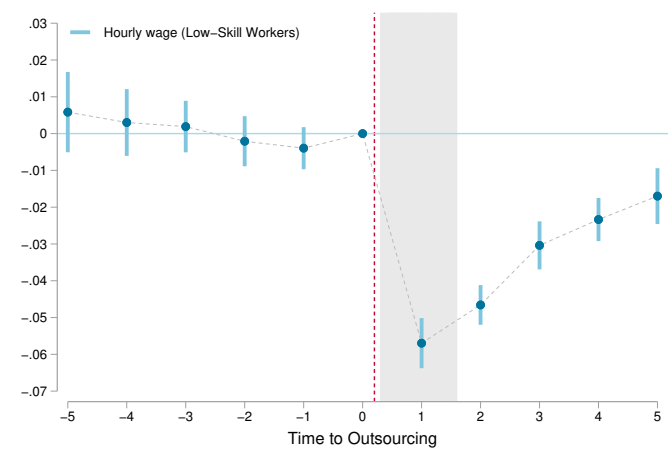

(c) Low-skill workers \& LS outsourcing

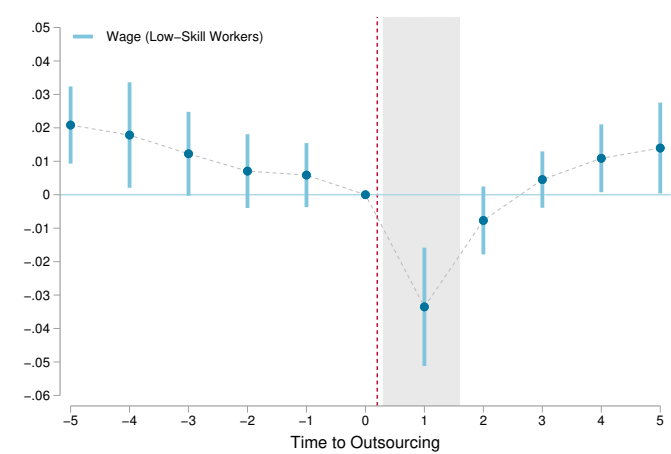

(b) High-skill workers \& HS outsourcing

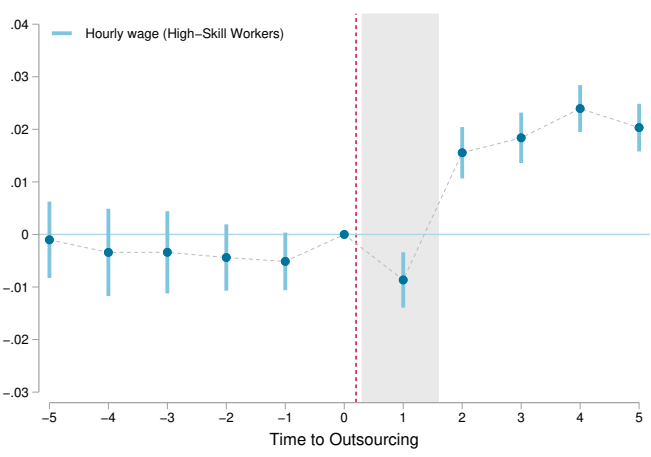

(d) High-skill workers \& HS outsourcing

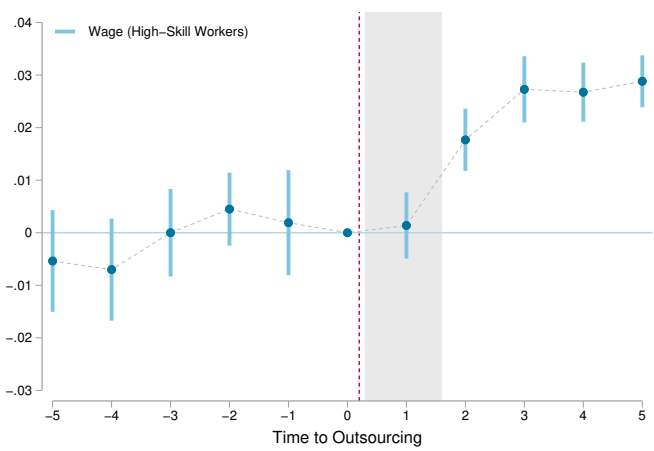

Notes: This Figure shows regression coefficients and confidence intervals at \pm 2 standard errors from a dynamics event study where the dependent variables are the log hourly wage (top panels) and the log of wage (bottom panels) of workers being outsourced from the establishment at time $t$, and the regressors are dummies for the number of years before/after the establishment experiences an outsourcing event as well as control variables: age, age squared, short-time dummy and a set of year times labor market area and individual fixed effects. Shaded area denotes the year of the mobility which is associated with noisy measures of work duration. Left-hand side panels restrict to low skill outsourcing (16,271 workers) and right-hand side to high skill outsourcing (8,530 workers). Standard errors are computed using an heteroskedastic robust variance covariance estimators allowing for autocorrelation at the labor market area level.

commanding a higher wage. Overall, these results emphasize a heterogeneous impact of outsourcing on workers' wages. While low-skill workers suffer from a significant wage loss, high-skill workers seem to benefit from outsourcing, as they are able to capture part of the increased profit made by firms as a result of this cost reduction.

In Figures 5(c) and 5(d), we reproduce the same exercise but using only the log of wage (as opposed to hourly wage). The negative wage outcome for low skilled workers seems to vanish which could suggest that most of the effect found in Figure 5(a) comes from an increase in the number of hours which is not compensated by higher wages. 


\section{Conclusion}

The diffusion of the internet has fostered many changes in the way firms operate, some of which differ from those observed in the previous waves of technological change. In particular, this technology has enabled better long-distance communication and information sharing, and is thus likely to have affected firms' optimal boundaries. In this paper we examine the role that broadband internet played in incentivizing firms to outsource some activities, both in the high and low-skill segment, and we describe its consequences on the affected workers. We leverage the staggered roll-out of broadband connection across the French territory to adopt an event study design. The latter compares similarly dense municipalities within a given department, which gain access to BI at different times. Our results show that the internet is not only skill biased, but also increases the degree of occupational concentration within establishments by pushing firms to outsource activities with lower degrees of complementarity in production. This phenomenon touches both low-skill occupations such as cleaning, and high-skill occupations such as IT. Finally, we provide suggestive evidence that high-skill workers experience wage gains through outsourcing, while low-skill workers experience wage losses. These findings confirm that the impact of internet technology is not homogeneous across the skill distribution, and reveal that domestic outsourcing is an additional mechanism through which this effect plays out. More broadly, it appears that these forces contribute to increasing the segregation of workers in the labor market of advanced countries, which might have detrimental effects on the level of trust and cohesion in our societies. 


\section{Appendix}

\section{Outline}

- Appendix A presents additional empirical results

- Appendix B presents the data in more details

- Appendix C presents the roll-out of broadband internet in France

- Appendix D presents evidence that broadband internet is skill-biased

- Appendix E presents the proofs and extension of the theoretical model 


\section{A Additional Results}

\section{A.1 Tables}

Table A1: Correlation between outsourcing intensity and firm size

\begin{tabular}{|c|c|c|c|c|c|c|c|c|c|c|}
\hline & (1) & (2) & (3) & (4) & (5) & (6) & (7) & (8) & (9) & (10) \\
\hline & \multicolumn{4}{|c|}{ Outsourcing / wage bill } & \multicolumn{2}{|c|}{ Outsourcing } & \multicolumn{4}{|c|}{ Outsourcing / (wage bill + outsourcing) } \\
\hline & OLS & OLS & OLS & OLS & OLS & OLS & OLS & OLS & OLS & OLS \\
\hline $\ln$ (net revenues) & $\begin{array}{c}0.173^{* * *} \\
(0.00461)\end{array}$ & $\begin{array}{c}0.206^{* * *} \\
(0.00474)\end{array}$ & & & & & & & & \\
\hline $\ln$ (Value added) & & & $\begin{array}{l}0.0809^{* * *} \\
(0.00367)\end{array}$ & $\begin{array}{l}0.0472^{* * *} \\
(0.00377)\end{array}$ & & & & & & \\
\hline Value added & & & & & $\begin{array}{c}0.138^{* * *} \\
(0.00189)\end{array}$ & $\begin{array}{c}0.134^{* * *} \\
(0.00187)\end{array}$ & & & & \\
\hline Value added / wage bill & & & & & & & $\begin{array}{c}0.0199^{* * *} \\
(0.000720)\end{array}$ & $\begin{array}{c}0.0264^{* * *} \\
(0.000678)\end{array}$ & & \\
\hline Value added / (wage bill & + outsourci & ing) & & & & & & & $\begin{array}{l}-0.144^{* * *} \\
(0.00103)\end{array}$ & $\begin{array}{c}-0.130^{* * *} \\
(0.000929)\end{array}$ \\
\hline Observations & $1,040,578$ & $1,040,578$ & $1,030,298$ & $1,030,298$ & $1,072,414$ & $1,072,414$ & $1,042,898$ & $1,042,898$ & $1,043,250$ & $1,043,250$ \\
\hline R-squared & 0.017 & 0.080 & 0.003 & 0.062 & 0.214 & 0.261 & 0.007 & 0.157 & 0.257 & 0.333 \\
\hline Year FE & $\checkmark$ & $\checkmark$ & $\checkmark$ & $\checkmark$ & $\checkmark$ & $\checkmark$ & $\checkmark$ & $\checkmark$ & $\checkmark$ & $\checkmark$ \\
\hline Sector FE & & $\checkmark$ & & $\checkmark$ & & $\checkmark$ & & $\checkmark$ & & $\checkmark$ \\
\hline
\end{tabular}


Table A2: Effect of ADSL on outsourcing expenditure and occup. sorting

\begin{tabular}{|c|c|c|c|c|}
\hline & \multirow{2}{*}{\multicolumn{2}{|c|}{$\begin{array}{c}(1) \\
\text { Outsourcing / wage bill }\end{array}$}} & \multirow{2}{*}{\multicolumn{2}{|c|}{$\begin{array}{l}(3) \quad(4) \\
\text { Occup. concentration } \\
\text { (wage bill HHI) }\end{array}$}} \\
\hline & & & & \\
\hline & City level & Estab. Level & City level & Estab. Level \\
\hline $\mathrm{T}=0$ & $\begin{array}{c}0.0183 \\
(0.0118)\end{array}$ & $\begin{array}{c}0.0111^{*} \\
(0.00590)\end{array}$ & $\begin{array}{l}0.00218^{* *} \\
(0.00107)\end{array}$ & $\begin{array}{l}0.00147^{* * *} \\
(0.000352)\end{array}$ \\
\hline $\mathrm{T}=+1$ & $\begin{array}{l}0.0293^{*} \\
(0.0166)\end{array}$ & $\begin{array}{l}0.0185^{*} \\
(0.0102)\end{array}$ & $\begin{array}{l}0.00535^{* * *} \\
(0.00145)\end{array}$ & $\begin{array}{l}0.00284^{* * *} \\
(0.000640)\end{array}$ \\
\hline $\mathrm{T}=+2$ & $\begin{array}{c}0.0370^{*} \\
(0.0198)\end{array}$ & $\begin{array}{c}0.0159 \\
(0.0120)\end{array}$ & $\begin{array}{c}0.00756^{* * *} \\
(0.00198)\end{array}$ & $\begin{array}{l}0.00669^{* * *} \\
(0.000865)\end{array}$ \\
\hline $\mathrm{T}=+3$ & $\begin{array}{c}0.0379 \\
(0.0236)\end{array}$ & $\begin{array}{c}0.0199 \\
(0.0153)\end{array}$ & $\begin{array}{l}0.0113^{* * *} \\
(0.00247)\end{array}$ & $\begin{array}{c}0.00927^{* * *} \\
(0.00111)\end{array}$ \\
\hline $\mathrm{T}=+4$ & $\begin{array}{l}0.0535^{*} \\
(0.0316)\end{array}$ & $\begin{array}{c}0.0238 \\
(0.0230)\end{array}$ & $\begin{array}{l}0.0138^{* * *} \\
(0.00299)\end{array}$ & $\begin{array}{l}0.0101^{* * *} \\
(0.00139)\end{array}$ \\
\hline Average effect & $\begin{array}{l}0.0352^{*} \\
(0.0203)\end{array}$ & $\begin{array}{c}0.0179 \\
(0.0124)\end{array}$ & $\begin{array}{l}0.00804^{* * *} \\
(0.00184)\end{array}$ & $\begin{array}{l}0.00608^{* * *} \\
(0.000795)\end{array}$ \\
\hline Observations & 300,050 & $1,519,949$ & 549,321 & $3,632,561$ \\
\hline R-squared & 0.529 & 0.731 & 0.776 & 0.852 \\
\hline
\end{tabular}

Notes: Columns (1) and (3) run the regression at the city level, following equation 11, where the dependent variables are the weighted average of the firm outcomes at the city level, and controls are the population density in 1999 interacted with year dummies, department $x$ year fixed effects, city fixed effects and sample fixed effects. Standard errors are clustered at the department level. Columns (2) to (4) run the same specification on the outcome computed at the establishment level, replacing city fixed effects by establishment fixed effects. 
Table A3: Effect of ADSL on outsourcing expenditure and occup. sorting controlling for for pre-BI productivity growth

\begin{tabular}{|c|c|c|c|c|}
\hline & \multirow{2}{*}{\multicolumn{2}{|c|}{$\begin{array}{c}(1) \\
\text { Outsourcing / wage bill }\end{array}$}} & \multirow{2}{*}{\multicolumn{2}{|c|}{$\begin{array}{l}(3) \\
\text { Occup. concentration } \\
\text { (wage bill HHI) }\end{array}$}} \\
\hline & & & & \\
\hline & City level & Estab. Level & City level & Estab. Level \\
\hline $\mathrm{T}=0$ & $\begin{array}{c}0.0183 \\
(0.0118)\end{array}$ & $\begin{array}{c}0.0111^{*} \\
(0.00590)\end{array}$ & $\begin{array}{c}0.00273^{* * *} \\
(0.00102)\end{array}$ & $\begin{array}{l}0.00147^{* * *} \\
(0.000360)\end{array}$ \\
\hline $\mathrm{T}=+1$ & $\begin{array}{c}0.0293^{*} \\
(0.0166)\end{array}$ & $\begin{array}{l}0.0185^{*} \\
(0.0102)\end{array}$ & $\begin{array}{c}0.00636^{* * *} \\
(0.00140)\end{array}$ & $\begin{array}{l}0.00242^{* * *} \\
(0.000617)\end{array}$ \\
\hline $\mathrm{T}=+2$ & $\begin{array}{l}0.0370^{*} \\
(0.0198)\end{array}$ & $\begin{array}{c}0.0159 \\
(0.0120)\end{array}$ & $\begin{array}{c}0.00889^{* * *} \\
(0.00182)\end{array}$ & $\begin{array}{l}0.00605^{* * *} \\
(0.000842)\end{array}$ \\
\hline $\mathrm{T}=+3$ & $\begin{array}{c}0.0379 \\
(0.0236)\end{array}$ & $\begin{array}{c}0.0199 \\
(0.0153)\end{array}$ & $\begin{array}{l}0.0120^{* * *} \\
(0.00224)\end{array}$ & $\begin{array}{l}0.00853^{* * *} \\
(0.00110)\end{array}$ \\
\hline $\mathrm{T}=+4$ & $\begin{array}{c}0.0535^{*} \\
(0.0316)\end{array}$ & $\begin{array}{c}0.0238 \\
(0.0230)\end{array}$ & $\begin{array}{l}0.0141^{* * *} \\
(0.00269)\end{array}$ & $\begin{array}{c}0.00922^{* * *} \\
(0.00136)\end{array}$ \\
\hline Average effect & $\begin{array}{c}0.0352^{* * *} \\
(0.0203)\end{array}$ & $\begin{array}{c}0.0178 \\
(0.0124)\end{array}$ & $\begin{array}{l}0.00882^{* * *} \\
(0.00171)\end{array}$ & $\begin{array}{l}0.00554^{* * *} \\
(0.000775)\end{array}$ \\
\hline Observations & 300,050 & $1,519,949$ & 409,041 & $3,447,350$ \\
\hline R-squared & 0.529 & 0.731 & 0.767 & 0.851 \\
\hline
\end{tabular}

Notes: Columns (1) and (3) run the regression at the city level, following equation 11, where the dependent variables are the weighted average of the firm outcomes at the city level, and controls are the population density in 1999 interacted with year dummies, the productivity growth at the city level pre-BI (1996-1998) interacted with year dummies, department $x$ year fixed effects, city fixed effects and sample fixed effects. Standard errors are clustered at the department level. Columns (2) to (4) run the same specification on the outcome computed at the establishment level, replacing city fixed effects by establishment fixed effects. 
Table A4: Effect of ADSL on outsourcing expenditure and occup. sorting using the standard dynamic model

\begin{tabular}{|c|c|c|c|c|}
\hline & \multirow{2}{*}{\multicolumn{2}{|c|}{$\begin{array}{c}(1) \\
\text { Outsourcing / wage bill }\end{array}$}} & \multirow{2}{*}{\multicolumn{2}{|c|}{$\begin{array}{l}(3) \\
\text { Occup. concentration } \\
\text { (wage bill HHI) }\end{array}$}} \\
\hline & & & & \\
\hline & City level & Estab. Level & City level & Estab. Level \\
\hline $\mathrm{T}=0$ & $\begin{array}{c}0.00840 \\
(0.00595)\end{array}$ & $\begin{array}{c}0.00734 \\
(0.00504)\end{array}$ & $\begin{array}{l}0.00241^{* *} \\
(0.00101)\end{array}$ & $\begin{array}{l}0.00145^{* * *} \\
(0.000367)\end{array}$ \\
\hline $\mathrm{T}=+1$ & $\begin{array}{c}0.0110 \\
(0.00959)\end{array}$ & $\begin{array}{c}0.0108 \\
(0.00775)\end{array}$ & $\begin{array}{c}0.00534^{* * *} \\
(0.00132)\end{array}$ & $\begin{array}{l}0.00260^{* * *} \\
(0.000635)\end{array}$ \\
\hline $\mathrm{T}=+2$ & $\begin{array}{c}0.0180 \\
(0.0131)\end{array}$ & $\begin{array}{c}0.00960 \\
(0.00915)\end{array}$ & $\begin{array}{c}0.00792^{* * *} \\
(0.00189)\end{array}$ & $\begin{array}{l}0.00616^{* * *} \\
(0.000785)\end{array}$ \\
\hline $\mathrm{T}=+3$ & $\begin{array}{c}0.0144 \\
(0.0168)\end{array}$ & $\begin{array}{c}0.0110 \\
(0.0112)\end{array}$ & $\begin{array}{l}0.0119^{* * *} \\
(0.00238)\end{array}$ & $\begin{array}{l}0.00906^{* * *} \\
(0.000993)\end{array}$ \\
\hline $\mathrm{T}=+4$ & $\begin{array}{c}0.0266 \\
(0.0196)\end{array}$ & $\begin{array}{c}0.0126 \\
(0.0144)\end{array}$ & $\begin{array}{l}0.0146^{* * *} \\
(0.00283)\end{array}$ & $\begin{array}{l}0.0107^{* * *} \\
(0.00132)\end{array}$ \\
\hline $\mathrm{T}=+5$ & $\begin{array}{c}0.0195 \\
(0.0225)\end{array}$ & $\begin{array}{l}0.00959 \\
(0.0168)\end{array}$ & $\begin{array}{l}0.0185^{* * *} \\
(0.00329)\end{array}$ & $\begin{array}{l}0.0135^{* * *} \\
(0.00157)\end{array}$ \\
\hline Average effect & $\begin{array}{c}0.0163 \\
(0.0140)\end{array}$ & $\begin{array}{c}0.0101 \\
(0.0101)\end{array}$ & $\begin{array}{l}0.0101^{* * *} \\
(0.00198)\end{array}$ & $\begin{array}{l}0.00724^{* * *} \\
(0.000870)\end{array}$ \\
\hline Observations & 112,134 & 796,323 & 150,602 & $1,767,499$ \\
\hline R-squared & 0.568 & 0.700 & 0.752 & 0.825 \\
\hline
\end{tabular}

Notes: Columns (1) and (3) run the regression at the city level, following a standard dynamic event study design as reported in equation 10, where the dependent variables are the weighted average of the firm outcomes at the city level, and controls are the population density in 1999 interacted with year dummies, the productivity growth at the city level pre-BI (1996-1998) interacted with year dummies, department $x$ year fixed effects, city fixed effects and sample fixed effects. Standard errors are clustered at the department level. Columns (2) to (4) run the same specification on the outcome computed at the establishment level, replacing city fixed effects by establishment fixed effects. 
Table A5: Characteristics of outsourcing sectors

\begin{tabular}{lcccc}
\hline & IT services & $\begin{array}{c}\text { Cleaning } \\
\text { services }\end{array}$ & $\begin{array}{c}\text { other services } \\
\text { to firm }\end{array}$ & other services \\
\hline & mean/(sd) & mean/(sd) & mean/(sd) & mean/(sd) \\
\hline Average age of firm & 11,92 & 15,43 & 16,08 & 18,48 \\
Share of new firms & $(10,95)$ & $(13,91)$ & $(14,20)$ & $(14,69)$ \\
& 0,06 & 0,05 & 0,05 & 0,04 \\
Average N. estab. per firm & $(0,23)$ & $(0,22)$ & $(0,22)$ & $(0,19)$ \\
& 3,20 & 9,02 & 21,05 & 24,74 \\
Average estab. size & $(6,74)$ & $(22,37)$ & $(79,27)$ & $(105,37)$ \\
& 50,26 & 53,02 & 43,88 & 34,40 \\
& $(113,05)$ & $(97,10)$ & $(139,92)$ & $(119,79)$ \\
\hline \hline N. obs & 51633 & 38997 & 261657 & 1205134 \\
\hline Notes: Description of characteristics of outsourcing sectors relative to other services to firm and to other services in general.
\end{tabular}

Notes: Description of characteristics of outsourcing sectors relative to other services to firm and to other services in general.

Table A6: Effect of ADSL on high and low-skill outsourcing

\begin{tabular}{|c|c|c|c|c|}
\hline & (1) & $(2)$ & (3) & $(4)$ \\
\hline & \multicolumn{2}{|c|}{ IT outsourcing } & \multicolumn{2}{|c|}{ Cleaning outsourcing } \\
\hline & $\begin{array}{l}\text { Sh. of empl. in } \\
\text { IT services }\end{array}$ & $\begin{array}{c}\text { Sh. IT } \\
\text { specialists in IT } \\
\text { services }\end{array}$ & $\begin{array}{l}\text { Sh. of empl. in } \\
\text { cleaning } \\
\text { services }\end{array}$ & $\begin{array}{l}\text { Sh. cleaners in } \\
\text { cleaning } \\
\text { services }\end{array}$ \\
\hline $\mathrm{T}=0$ & $\begin{array}{c}0.000320 \\
(0.000246)\end{array}$ & $\begin{array}{l}0.0136^{* * *} \\
(0.00391)\end{array}$ & $\begin{array}{l}0.000658^{*} \\
(0.000345)\end{array}$ & $\begin{array}{l}0.0289 * * * \\
(0.00581)\end{array}$ \\
\hline $\mathrm{T}=+1$ & $\begin{array}{c}0.000525 \\
(0.000341)\end{array}$ & $\begin{array}{l}0.0214^{* * *} \\
(0.00524)\end{array}$ & $\begin{array}{l}0.000971^{* *} \\
(0.000462)\end{array}$ & $\begin{array}{l}0.0526^{* * *} \\
(0.00832)\end{array}$ \\
\hline $\mathrm{T}=+2$ & $\begin{array}{c}0.000681 \\
(0.000436)\end{array}$ & $\begin{array}{l}0.0293^{* * *} \\
(0.00757)\end{array}$ & $\begin{array}{l}0.00186^{* * *} \\
(0.000615)\end{array}$ & $\begin{array}{l}0.0675^{* * *} \\
(0.00986)\end{array}$ \\
\hline $\mathrm{T}=+3$ & $\begin{array}{c}0.000841 \\
(0.000513)\end{array}$ & $\begin{array}{l}0.0310^{* * *} \\
(0.00982)\end{array}$ & $\begin{array}{l}0.00383^{* * *} \\
(0.000821)\end{array}$ & $\begin{array}{c}0.0729^{* * *} \\
(0.0122)\end{array}$ \\
\hline $\mathrm{T}=+4$ & $\begin{array}{c}0.00132^{*} \\
(0.000677)\end{array}$ & $\begin{array}{c}0.0401^{* * *} \\
(0.0134)\end{array}$ & $\begin{array}{c}0.00411^{* * *} \\
(0.00103)\end{array}$ & $\begin{array}{l}0.103^{* * *} \\
(0.0169)\end{array}$ \\
\hline Average effect & $\begin{array}{l}0.000738^{*} \\
(0.000420)\end{array}$ & $\begin{array}{l}0.0271^{* * *} \\
(0.00732)\end{array}$ & $\begin{array}{l}0.00229^{* * *} \\
(0.000594)\end{array}$ & $\begin{array}{l}0.0650^{* * *} \\
(0.00981)\end{array}$ \\
\hline Observations & 549,322 & 71,050 & 549,322 & 111,664 \\
\hline R-squared & 0.830 & 0.797 & 0.861 & 0.765 \\
\hline
\end{tabular}

Notes: The regressions are run at the city level following equation 11. All columns control for the population density in 1999 interacted with year dummies, department $x$ year fixed effects, city fixed effects and sample fixed effects. Standard errors are clustered at the department level. 
Table A7: Effect of ADSL on high and low-skill outsourcing controlling for pre-BI productivity growth

\begin{tabular}{|c|c|c|c|c|}
\hline & (1) & (2) & (3) & (4) \\
\hline & \multicolumn{2}{|c|}{ IT outsourcing } & \multicolumn{2}{|c|}{ Cleaning outsourcing } \\
\hline & $\begin{array}{l}\text { Sh. of empl. in } \\
\text { IT services }\end{array}$ & $\begin{array}{c}\text { Sh. IT } \\
\text { specialists in IT } \\
\text { services }\end{array}$ & $\begin{array}{l}\text { Sh. of empl. in } \\
\text { cleaning } \\
\text { services }\end{array}$ & $\begin{array}{l}\text { Sh. cleaners in } \\
\text { cleaning } \\
\text { services }\end{array}$ \\
\hline \multirow[t]{2}{*}{$\mathrm{T}=0$} & $0.000448^{*}$ & $0.0139^{* * *}$ & 0.000531 & $0.0279^{* * *}$ \\
\hline & $(0.000264)$ & $(0.00403)$ & $(0.000367)$ & $(0.00588)$ \\
\hline \multirow[t]{2}{*}{$\mathrm{T}=+1$} & $0.000717^{* *}$ & $0.0219 * * *$ & $0.000982^{* *}$ & $0.0510^{* * *}$ \\
\hline & $(0.000330)$ & $(0.00546)$ & (0.000477) & $(0.00868)$ \\
\hline \multirow{2}{*}{$\mathrm{T}=+2$} & $0.00108^{* *}$ & $0.0301^{* * *}$ & $0.00185^{* * *}$ & $0.0650^{* * *}$ \\
\hline & $(0.000443)$ & $(0.00788)$ & $(0.000590)$ & $(0.0102)$ \\
\hline \multirow[t]{2}{*}{$\mathrm{T}=+3$} & $0.00130^{* *}$ & $0.0319^{* * *}$ & $0.00383^{* * *}$ & $0.0691^{* * *}$ \\
\hline & $(0.000533)$ & $(0.0102)$ & $(0.000760)$ & $(0.0127)$ \\
\hline \multirow[t]{2}{*}{$\mathrm{T}=+4$} & $0.00181^{* * *}$ & $0.0402^{* * *}$ & $0.00442^{* * *}$ & $0.0986^{* * *}$ \\
\hline & $(0.000680)$ & $(0.0139)$ & $(0.000969)$ & $(0.0175)$ \\
\hline \multirow[t]{2}{*}{ Average effect } & $0.00107^{* *}$ & $0.0276^{* * *}$ & $0.00232^{* * *}$ & $0.0623^{* * *}$ \\
\hline & $(0.000427)$ & $(0.00762)$ & $(0.000574)$ & $(0.0102)$ \\
\hline Observations & 409,042 & 66,566 & 409,042 & 102,899 \\
\hline R-squared & 0.765 & 0.791 & 0.809 & 0.754 \\
\hline
\end{tabular}

Notes: The regressions are run at the city level following equation 11. All columns control for the population density in 1999 interacted with year dummies, the productivity growth at the city level pre-BI (1996-1998) interacted with year dummies, department x year fixed effects, city fixed effects and sample fixed effects. 
Table A8: Effect of ADSL on high and low-skill outsourcing using a standard dynamic model

\begin{tabular}{|c|c|c|c|c|}
\hline & (1) & $(2)$ & (3) & $(4)$ \\
\hline & \multicolumn{2}{|c|}{ IT outsourcing } & \multicolumn{2}{|c|}{ Cleaning outsourcing } \\
\hline & $\begin{array}{l}\text { Sh. of empl. in } \\
\text { IT services }\end{array}$ & $\begin{array}{c}\text { Sh. IT } \\
\text { specialists in IT } \\
\text { services }\end{array}$ & $\begin{array}{l}\text { Sh. of empl. in } \\
\text { cleaning } \\
\text { services }\end{array}$ & $\begin{array}{l}\text { Sh. cleaners in } \\
\text { cleaning } \\
\text { services }\end{array}$ \\
\hline \multirow[t]{2}{*}{$\mathrm{T}=0$} & 0.000235 & $0.0112^{* * *}$ & 0.000499 & $0.0363^{* * *}$ \\
\hline & $(0.000210)$ & $(0.00379)$ & $(0.000345)$ & $(0.00552)$ \\
\hline \multirow[t]{2}{*}{$\mathrm{T}=+1$} & 0.000487 & $0.0183^{* * *}$ & $0.000861^{* *}$ & $0.0637^{* * *}$ \\
\hline & $(0.000306)$ & $(0.00518)$ & (0.000395) & $(0.00782)$ \\
\hline \multirow{2}{*}{$\mathrm{T}=+2$} & $0.000672^{*}$ & $0.0252^{* * *}$ & $0.00173^{* * *}$ & $0.0857^{* * *}$ \\
\hline & $(0.000399)$ & $(0.00694)$ & $(0.000501)$ & (0.00909) \\
\hline \multirow[t]{2}{*}{$\mathrm{T}=+3$} & 0.000804 & $0.0276^{* * *}$ & $0.00358^{* * *}$ & $0.0999 * * *$ \\
\hline & $(0.000492)$ & $(0.00884)$ & $(0.000689)$ & $(0.0109)$ \\
\hline \multirow[t]{2}{*}{$\mathrm{T}=+4$} & $0.00123^{*}$ & $0.0384^{* * *}$ & $0.00390^{* * *}$ & $0.143^{* * *}$ \\
\hline & $(0.000632)$ & $(0.0113)$ & $(0.000833)$ & $(0.0147)$ \\
\hline \multirow[t]{2}{*}{$\mathrm{T}=+5$} & $0.00179^{* *}$ & $0.0621^{* * *}$ & $0.00581^{* * *}$ & $0.192^{* * *}$ \\
\hline & $(0.000770)$ & $(0.0135)$ & $(0.00119)$ & $(0.0185)$ \\
\hline \multirow[t]{2}{*}{ Average effect } & $0.000871^{* *}$ & $0.0305^{* * *}$ & $0.00273^{* * *}$ & $0.104^{* * *}$ \\
\hline & $(0.000442)$ & $(0.00756)$ & $(0.000586)$ & $(0.0103)$ \\
\hline Observations & 150,603 & 27,548 & 150,603 & 37,010 \\
\hline R-squared & 0.820 & 0.758 & 0.829 & 0.749 \\
\hline
\end{tabular}

Notes: The regressions are run at the city level using a standard dynamic event study design as reported in equation 10. All columns control for the population density in 1999 interacted with year dummies, the productivity growth at the city level pre-BI (1996-1998) interacted with year dummies, department $x$ year fixed effects, city fixed effects and sample fixed effects.

Table A9: Effect of ADSL on outsourcing outcomes - static regressions

\begin{tabular}{|c|c|c|c|c|c|c|}
\hline & $\begin{array}{l}\text { Outsourcing / } \\
\text { wage bill }\end{array}$ & $\begin{array}{c}\text { Occup. } \\
\text { concentration } \\
\text { (wage bill } \\
\text { HHI) }\end{array}$ & $\begin{array}{l}\text { Sh. of empl. in } \\
\text { IT services }\end{array}$ & $\begin{array}{l}\text { Sh. IT specialists } \\
\text { in IT services }\end{array}$ & $\begin{array}{l}\text { Sh. of empl. in } \\
\text { cleaning services }\end{array}$ & $\begin{array}{l}\text { Sh. cleaners in } \\
\text { cleaning services }\end{array}$ \\
\hline \multicolumn{7}{|c|}{ Panel $A$ : city level regressions } \\
\hline Post ADSL * treated & $\begin{array}{l}0.0274^{*} \\
(0.0159)\end{array}$ & $\begin{array}{l}0.00473^{* * *} \\
(0.00133)\end{array}$ & $\begin{array}{c}0.000480 \\
(0.000312)\end{array}$ & $\begin{array}{l}0.0193^{* * *} \\
(0.00474)\end{array}$ & $\begin{array}{l}0.00120^{* * *} \\
(0.000416)\end{array}$ & $\begin{array}{l}0.0447^{* * * *} \\
(0.00699)\end{array}$ \\
\hline $\begin{array}{l}\text { Observations } \\
\text { R-squared }\end{array}$ & $\begin{array}{c}300,050 \\
0.529\end{array}$ & $\begin{array}{c}549,321 \\
0.776\end{array}$ & $\begin{array}{c}549,322 \\
0.830\end{array}$ & $\begin{array}{c}71,050 \\
0.797\end{array}$ & $\begin{array}{c}549,322 \\
0.861\end{array}$ & $\begin{array}{c}111,664 \\
0.765\end{array}$ \\
\hline \multicolumn{7}{|c|}{ Panel B : establishment level regressions } \\
\hline Post ADSL * treated & $\begin{array}{c}0.0149 * \\
(0.00847)\end{array}$ & $\begin{array}{l}0.00345^{* * *} \\
(0.000511)\end{array}$ & - & - & - & $\begin{array}{l}- \\
-\end{array}$ \\
\hline $\begin{array}{l}\text { Observations } \\
\text { R-squared }\end{array}$ & $\begin{array}{c}1,519,949 \\
0.731\end{array}$ & $\begin{array}{c}3,632,561 \\
0.852\end{array}$ & & & & \\
\hline
\end{tabular}


Table A10: Average wage and employment in outsourceable occupations across sectors

\begin{tabular}{|c|c|c|c|c|}
\hline & & $\begin{array}{c}\text { outsourcing } \\
\text { services }\end{array}$ & other services & manufacturing \\
\hline & & mean/(sd) & mean/(sd) & mean/(sd) \\
\hline \multirow[t]{5}{*}{ Gross hourly wage IT specialists (€2010) } & Overall & $\begin{array}{l}26.0 \\
(9.4)\end{array}$ & $\begin{array}{c}23.7 \\
(11.3)\end{array}$ & $\begin{array}{l}25.2 \\
(9.9)\end{array}$ \\
\hline & pre-BI & 24.7 & 21.0 & 23.7 \\
\hline & & $(8.1)$ & $(10.7)$ & $(8.1)$ \\
\hline & post-BI & 26.4 & 25.1 & 26.4 \\
\hline & & $(9.7)$ & $(11.3)$ & $(11.1)$ \\
\hline \multirow[t]{6}{*}{ N. of IT specialists per establishment (FTE) } & Overall & 127.9 & 3.0 & 12.1 \\
\hline & & $(334.6)$ & $(28.8)$ & $(66.6)$ \\
\hline & pre-BI & 108.7 & 2.3 & 11.3 \\
\hline & & $(233.4)$ & $(19.8)$ & $(59.0)$ \\
\hline & post-BI & 132.9 & 3.4 & 12.7 \\
\hline & & (356.3) & $(32.2)$ & $(71.4)$ \\
\hline \multirow[t]{6}{*}{ Gross hourly wage cleaners (€2010) } & Overall & 9.8 & 10.6 & 11.7 \\
\hline & & $(1.7)$ & $(3.6)$ & $(3.8)$ \\
\hline & pre-BI & 9.1 & 9.8 & 11.3 \\
\hline & & $(2.3)$ & $(2.7)$ & $(3.7)$ \\
\hline & post-BI & 9.9 & 11.3 & 12.3 \\
\hline & & $(1.5)$ & $(4.1)$ & $(3.9)$ \\
\hline \multirow[t]{6}{*}{ N. of cleaners per establishment (FTE) } & Overall & 150.2 & 0.6 & 1.9 \\
\hline & & $(309.7)$ & $(14.2)$ & $(16.7)$ \\
\hline & pre-BI & 91.2 & 0.7 & 2.9 \\
\hline & & $(209.6)$ & $(5.5)$ & $(21.1)$ \\
\hline & post-BI & 171.5 & 0.6 & 1.2 \\
\hline & & $(336.0)$ & $(16.8)$ & $(12.7)$ \\
\hline
\end{tabular}

Notes: Summary statistics comparing wages and employment of outsourceable workers (IT specialists and cleaners) across different sectors.

Table A11: Distribution of firms who encounter outsourcing events

\begin{tabular}{|c|c|c|c|c|c|c|c|c|c|c|}
\hline & \multicolumn{2}{|c|}{ Total } & \multicolumn{2}{|c|}{ Outsourcing only HS } & \multicolumn{2}{|c|}{ Outsourcing only LS } & \multicolumn{2}{|c|}{ Outsourcing both } & \multicolumn{2}{|c|}{ Outsourcing neither } \\
\hline & Number & Share & Number & Share & Number & Share & Number & Share & Number & Share \\
\hline N. estab. with both HS and LS workers & 132612 & $100 \%$ & 6750 & $5 \%$ & 16794 & $13 \%$ & 1304 & $1 \%$ & 107764 & $81 \%$ \\
\hline N. estab. with only HS workers & 59130 & $100 \%$ & 4405 & $7 \%$ & - & - & - & - & 54725 & $93 \%$ \\
\hline N. estab. with only LS workers & 152412 & $100 \%$ & - & - & 13108 & $9 \%$ & - & - & 139304 & $91 \%$ \\
\hline N. estab. with neither type & 151978 & $100 \%$ & - & - & - & - & - & - & - & - \\
\hline
\end{tabular}


Table A12: Effect of outsourcing on sending establishments

\begin{tabular}{|c|c|c|c|c|c|c|}
\hline & \multicolumn{3}{|c|}{ High-skill outsourcing event } & \multicolumn{3}{|c|}{ Low-skill outsourcing event } \\
\hline & $\begin{array}{l}\text { Log wages } \\
\text { incumbent HS } \\
\text { workers }\end{array}$ & $\begin{array}{l}\text { Occup. concentration } \\
\text { (empl. HHI) }\end{array}$ & $\begin{array}{c}\text { Occup. } \\
\text { Concentration } \\
\text { (wage bill HHI) }\end{array}$ & $\begin{array}{l}\text { Log wages } \\
\text { incumbent LS } \\
\text { workers }\end{array}$ & $\begin{array}{c}\text { Occup. } \\
\text { concentration (empl. } \\
\text { HHI) }\end{array}$ & $\begin{array}{c}\text { Occup. } \\
\text { concentration } \\
\text { (wage bill HHI) }\end{array}$ \\
\hline $\mathrm{T}=0$ & $\begin{array}{l}0.148^{* * *} \\
(0.0110)\end{array}$ & $\begin{array}{c}0.00662^{* * *} \\
(0.00137)\end{array}$ & $\begin{array}{c}0.00695^{* * *} \\
(0.00149)\end{array}$ & $\begin{array}{c}0.114^{* * *} \\
(0.00532)\end{array}$ & $\begin{array}{c}0.00201^{* *} \\
(0.000880)\end{array}$ & $\begin{array}{c}0.00195^{* *} \\
(0.000868)\end{array}$ \\
\hline $\mathrm{T}=+1$ & $\begin{array}{l}0.186^{* * *} \\
(0.0136)\end{array}$ & $\begin{array}{c}0.00938^{* * *} \\
(0.00172)\end{array}$ & $\begin{array}{c}0.00831^{* * *} \\
(0.00184)\end{array}$ & $\begin{array}{c}0.164^{* * *} \\
(0.00631)\end{array}$ & $\begin{array}{l}0.00203^{*} \\
(0.00111)\end{array}$ & $\begin{array}{l}0.00179^{*} \\
(0.00106)\end{array}$ \\
\hline $\mathrm{T}=+2$ & $\begin{array}{l}0.204^{* * *} \\
(0.0177)\end{array}$ & $\begin{array}{l}0.0134^{* * *} \\
(0.00230)\end{array}$ & $\begin{array}{l}0.0114^{* * *} \\
(0.00236)\end{array}$ & $\begin{array}{c}0.218^{* * *} \\
(0.00784)\end{array}$ & $\begin{array}{l}0.00282^{* *} \\
(0.00138)\end{array}$ & $\begin{array}{l}0.00305^{* *} \\
(0.00133)\end{array}$ \\
\hline $\mathrm{T}=+3$ & $\begin{array}{l}0.204^{* * * *} \\
(0.0208)\end{array}$ & $\begin{array}{l}0.0182^{* * *} \\
(0.00292)\end{array}$ & $\begin{array}{l}0.0180^{* * *} \\
(0.00294)\end{array}$ & $\begin{array}{c}0.249^{* * *} \\
(0.00907)\end{array}$ & $\begin{array}{l}0.00381^{* *} \\
(0.00167)\end{array}$ & $\begin{array}{l}0.00367^{* *} \\
(0.00160)\end{array}$ \\
\hline $\mathrm{T}=+4$ & $\begin{array}{l}0.248^{* * * *} \\
(0.0283)\end{array}$ & $\begin{array}{l}0.0182^{* * *} \\
(0.00401)\end{array}$ & $\begin{array}{l}0.0174^{* * *} \\
(0.00409)\end{array}$ & $\begin{array}{l}0.297^{* * *} \\
(0.0111)\end{array}$ & $\begin{array}{c}0.00641^{* * * *} \\
(0.00202)\end{array}$ & $\begin{array}{c}0.00590^{* * * *} \\
(0.00193)\end{array}$ \\
\hline $\mathrm{T}=+5$ & $\begin{array}{l}0.274^{* * * *} \\
(0.0384)\end{array}$ & $\begin{array}{l}0.0191^{* * *} \\
(0.00559)\end{array}$ & $\begin{array}{l}0.0211^{* * *} \\
(0.00569)\end{array}$ & $\begin{array}{l}0.338^{* * *} \\
(0.0153)\end{array}$ & $\begin{array}{c}0,00401 \\
(0.00265)\end{array}$ & $\begin{array}{l}0.00582^{* *} \\
(0.00255)\end{array}$ \\
\hline Average effect & $\begin{array}{l}0.211^{* * *} \\
(0.0160)\end{array}$ & $\begin{array}{l}0.0142^{* * * *} \\
(0.00224)\end{array}$ & $\begin{array}{l}0.0138^{* * *} \\
(0.00229)\end{array}$ & $\begin{array}{c}0.230^{* * *} \\
(0.00693)\end{array}$ & $\begin{array}{c}0.00352^{* * *} \\
(0.00123)\end{array}$ & $\begin{array}{c}0.00370^{* * *} \\
(0.00118)\end{array}$ \\
\hline Observations & 29,143 & 32,78 & 32,780 & 86,325 & 93,432 & 93,432 \\
\hline R-squared & 0.930 & 0,911 & 0.901 & 0,932 & 0.930 & 0.920 \\
\hline
\end{tabular}




\section{A.2 Figures}

Figure A1: Distribution of $\widetilde{Z}_{i t}: 1999-2007$

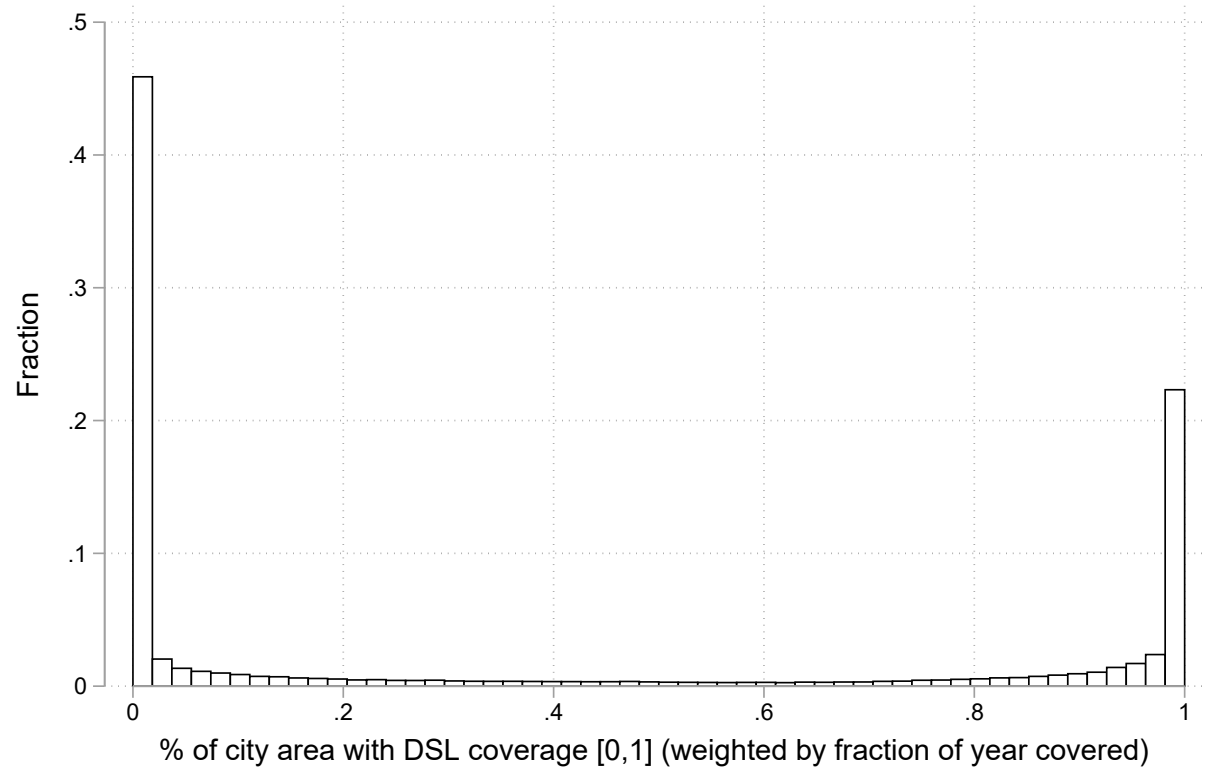

Notes: This figure plots the distribution of the continuous measure of local broadband availability (variable $\widetilde{Z}$ ) as defined in Equation (8). We see that while the measure is continuous and contained between 0 and 1 but presents point of accumulation on 0 and 1 .

Figure A2: Overall trends in outsourcing expenditure and occupation concentration

(a) Outsourcing expenditure over wage bill

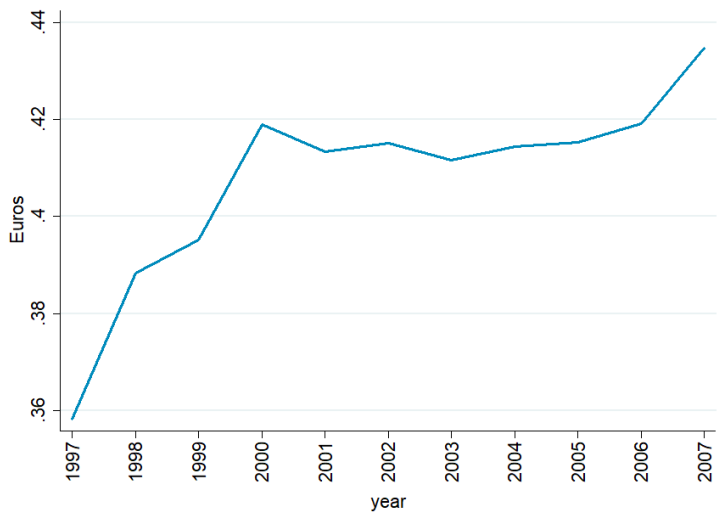

(b) Occup. concentration (HHI over wage bill)

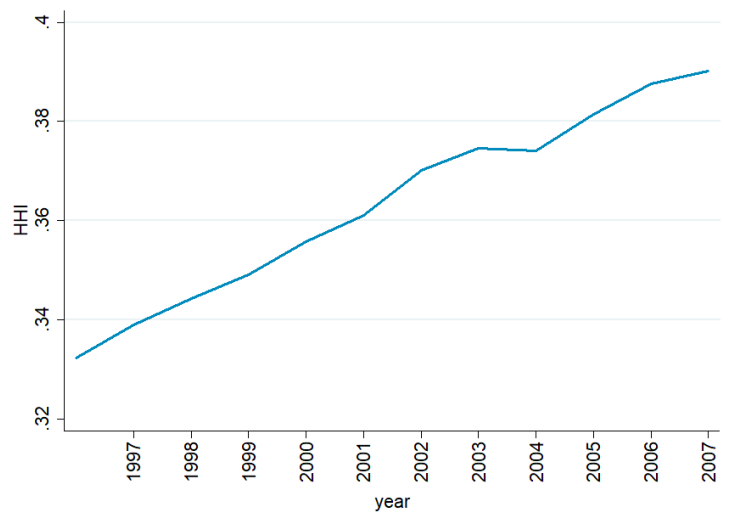

Notes: This Figure shows the evolution over time of the main outcomes of interest in the outsourcing analysis. 
Figure A3: Overall trends in high and low skill outsourcing

(a) Share of employment in IT services

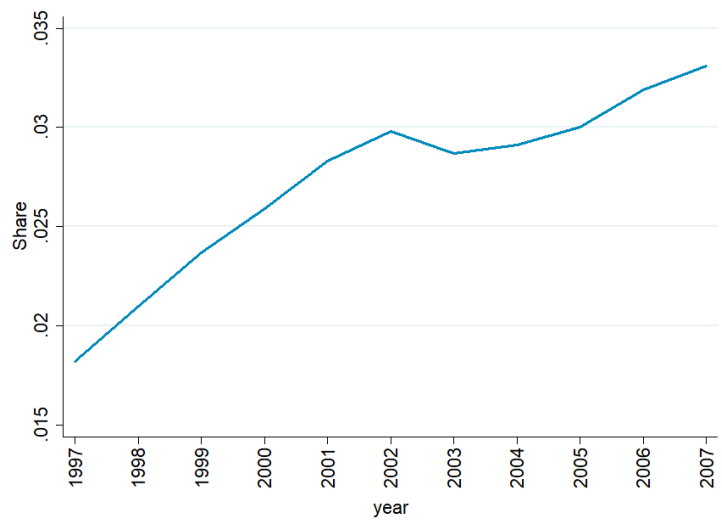

(c) Share of IT specialists in IT services

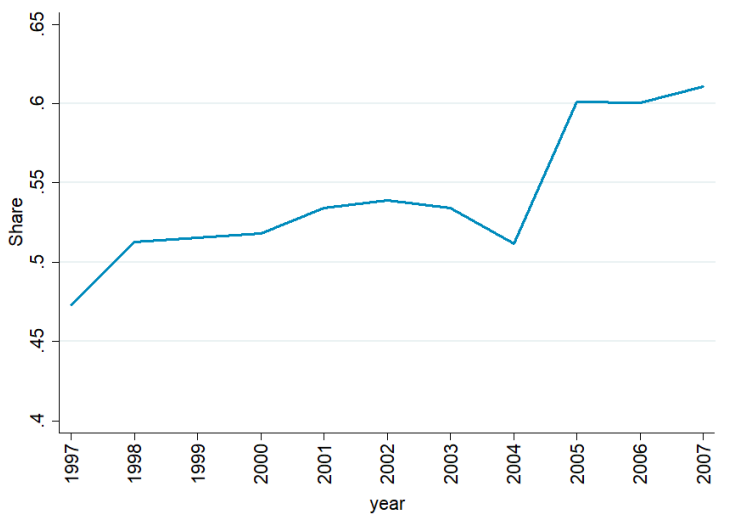

(b) Share of employment in cleaning services

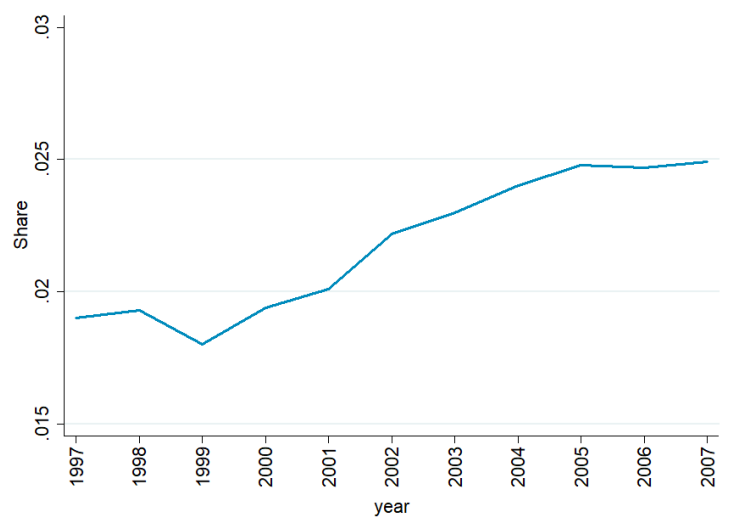

(d) Share of cleaners in cleaning services

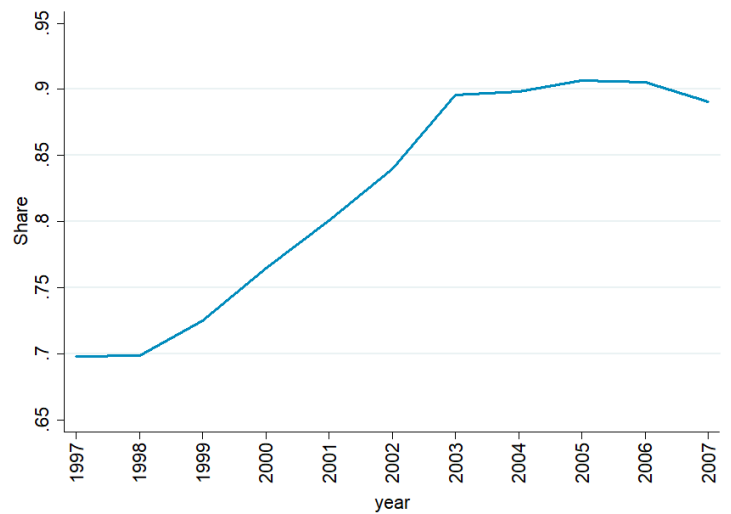

Notes: This Figure shows the evolution over time of the main outcomes of interest in the outsourcing analysis. 


\section{B Data Appendix: Administrative Employer-Employee Data}

Our main analysis relies on data from the administrative records used by the French government to compute payroll taxes. Our period of analysis spans from 1996 to 2007. The first year is chosen to include a few years prior to the beginning of broadband diffusion, which started in 1999, while the last year corresponds to the final year of broadband expansion. We chose not to include later years because of the effect of the financial crisis. These data are collected yearly by INSEE (the French statistics office) and are known as DADS ("Déclarations annuelles des données sociales"). The main dataset contains information on all existing work contracts for each establishment in each firm operating in the French territory. The latter allows us to monitor establishments and firms over time but not workers, with the exception of a one-year worker panel dimension available since 2002. This is the main source that we use for the city and firm-level analyses. For the worker-level analysis, we rely on a subsample of this data from the DADS Panel. The latter randomly selects $1 / 24$ of the labor force and follows it across its employment over the entire period. The random selection is achieved through the inclusion of all workers born in October of an even year. The raw data provided to researchers has already undergone substantial verification, and consequently only requires a minimal amount of additional cleaning. For this study, we focus on workers with some degree of attachment to the labor market ("postes non-annexes"), which are defined as contracts involving either more than 120 hours of work or more than 30 days of work, with more than 1.5 hours of work per day, or contracts that paid more than 3 times the monthly minimum wage over the year. We also exclude firms with less than 10 employees, to avoid taking family-run companies into consideration and thus focus on formal businesses. We further exclude some occupations and industries since we are interested only in the private sector. In the following bullet points we specify the excluded occupations by their PCS-2003 classification codes and the excluded industries based on the NAF rev. 1 classification. Given that both of these classifications changed in the middle of our sample (2002), we use official crosswalk tables to identify the same groups between years.

- Selection of occupations: We exclude all categories of non-employed people OA-11 (cs $2[7,9])$ and self-employed farmers (pcs = 1). We further exclude self-employed crafts workers (pcs $=20)$, liberal professions $(\mathrm{pcs}=31)$, university professors $(\mathrm{pcs}=34)$, school teachers $(\mathrm{pcs}=42)$ and the clergy $(\mathrm{pcs}=44)$. 
- Selection of industries: We exclude mining and farming ( $N A F \in[1,9])$, utilities $(N A F \in[35,39])$, the entire public sector $(N A F \in[84,88])$, and social services $(N A F \geq 90)$.

Once this cleaning is completed, we define the main categories used in the paper as follows:

- High-skill workers: We define high-skill workers as those belonging to the category including CEOs and the category including executives, managers and engineers ( $\mathrm{pcs}=2$ and $\mathrm{pcs}=3$ ).

- Low-skill workers: We define low-skill workers as those belonging to the category including industry and services blue collar manual jobs (pcs $=6$ ) and the category including administrative and sales clerks ( $\mathrm{pcs}=5$ ).

- Outsourceable high-skill workers: In the analysis capturing the effect of broadband internet diffusion on the propensity of firms to outsource non-core activities, we take IT specialists as a typical example of outsourceable high-skill jobs. The latter are identified as IT engineers (pcs $=388)$ and IT technicians (pcs = 478).

- Outsourceable low-skill workers: In the analysis capturing the effect of broadband internet diffusion on the propensity of firms to outsource non-core activities, we take cleaners as a typical example of outsourceable low-skill jobs. The latter are identified under pcs category 684.

- Outsourcing high-skill sector: In the analysis capturing the effect of broadband internet diffusion on the propensity of firms to outsource non-core activities, we take IT services as a typical example of a high-skill outsourcing industry (NAF $=72$ ). In the analysis capturing the effect of outsourcing on salaries, we broaden the scope to include the accounting and consulting sectors, which thus allows us to increase the number of outsourcing events. This involves the addition of the following categories: NAF $=74.1$ (accounting and management consulting); $\mathrm{NAF}=74.4$ (advertising); and NAF = 74.5 (HR services).

- Outsourcing low-skill sector: In the analysis capturing the effect of broadband internet diffusion on the propensity of firms to outsource non-core activities, we take cleaning services as a typical example of a low-skill outsourcing industry $(\mathrm{NAF}=74.7)$. In the analysis capturing the effect of outsourcing on salaries, 
we broaden the scope to include security, food and driving services, which thus allows us to increase the number of outsourcing events. This involves the addition of the following categories: NAF $=74.6$ (security); NAF $=55.5$ (canteens and caterers); and NAF $=60.2$ (urban and road transports). 


\section{ADSL in France}

ADSL (Asymmetric Digital Subscriber Line) is a data communication technology that enables fast data transmission over copper telephone lines: bandwidth and bit rate are said to be asymmetric, meaning that they are greater towards the customer premises (downstream) than the reverse (upstream). Eligibility for ADSL depends on the distance between the final customer and a Local Exchange (LE), since the intensity and the quality of the analogue signal decreases as it is routed over the copper lines. LEs are telephone exchanges owned by the incumbent operator France Télécom into which subscribers' telephone lines connect. Initially dedicated to the telephone network, LEs are essential for internet users who subscribe to ADSL. LEs aggregate local traffic and then direct it via the so-called backbone (i.e. higher levels of the network) towards the World Wide Web. A key feature of ADSL technology is that one can supply high-speed internet by upgrading the LE while relying on the existing (copper) local loop to connect the premises of the final customers. The upgrading involves the installation of equipment inside the LE (a DSLAM) required in order to translate the analogical signal - transmitted via ADSL on the local copper loop - to a numerical signal that can be transmitted to the higher levels of the network. The upgrading of local LEs is the key source of variation that we use in our empirical analysis.

ADSL roll-out in France As evidenced by Malgouyres et al. (2019), the deployment of broadband internet technology beyond France's largest cities was slow at the beginning of the 2000's (see Table C1). The authors show that there were multiple reasons for this staggered deployment. First, France Télécom, the monopolistic telecom supplier, was uncertain regarding the future wholesale price it was going to be able to charge, mainly due to regulatory reasons. Second, at the same time that France Télécom had to invest massively in upgrading its LEs to ADSL, it went through a debt crisis that ended with what was essentially a government bailout in 2002. Urged on by the government - which increased its stake in the firm during the 2002 bailout of the firm - in 2003 France Télécom pledged to cover $90 \%$ of the French (mainland) population by the end of 2005, i.e. all LEs with more than 1,000 lines.

Between 2004 and 2007, local governments were involved in broadband internet deployment by subsidising the expansion and favouring competition among providers. Most relevant for broadband expansion was the creation of a contract between local governments, the Plan Département Innovant, whereby France Télécom pledged to 
Table C1: Year of connection by municipality

\begin{tabular}{lcccc}
\hline Year of Connection & \multicolumn{5}{c}{ Number connected (in \% of total) } \\
& Cities & Workers & Establishments & Population \\
\cline { 2 - 5 } & & & & \\
2000 & 2.1 & 25.0 & 22.2 & 18.5 \\
2001 & 6.6 & 35.7 & 34.7 & 28.9 \\
2002 & 8.4 & 19.3 & 19.6 & 18.4 \\
2003 & 12.4 & 6.7 & 7.8 & 9.5 \\
2004 & 18.4 & 5.0 & 5.8 & 8.4 \\
2005 & 23.0 & 4.4 & 5.4 & 8.5 \\
2006 & 18.6 & 2.2 & 2.8 & 5.3 \\
2007 & 8.8 & 1.6 & 1.7 & 2.5 \\
\hline
\end{tabular}

Notes: All values are taken in 1999. The sum of percentages in a column is different from 100 because a small number of cities are not connected to the ADSL in 2007. The number of establishments and workers is based on our final sample (therefore following our cleaning and selection procedures).

equip all LEs in a département with more than 100 connections within a year. The proclaimed target of the plan was to raise coverage to $96 \%$ of the French population by the end of 2005 and activate all the remaining LEs by the end of 2006. We account for the role of local government in our empirical analysis by including départementyear fixed effects. Overall, the account of the broadband expansion in France over the period suggests that it was gradual due to uncertainty regarding the capacity of France Télécom to undergo the investment until 2002. After 2002, with strong encouragement from the government, France Télécom started covering more secondary areas with a focus on the overall number of lines per LE, with only limited attention paid to local economic potential. Although the coverage was accelerated, it remained gradual due to France Télécom's operational limits and took about two years longer than anticipated in 2003. Because our main effects of interest are identified out of the gradual diffusion of the new technology in different LEs over space and time, addressing the endogeneity of the decision to "treat" one LE before another deserves special consideration. Malgouyres et al. (2019) show that broadband expansion occurred to maximise population coverage with no special consideration for economic potential, a fact that is strongly supported by the statistical analysis of the determinants of broadband coverage that they carried out.

Use of broadband technologies by firms ADSL technology, while progressively replaced by other technologies - notably direct access to the optic fibre or FTTO (fibre to the office) -, is the main way in which firms access the internet. A 2016 survey showed that in that year 73\% of SMEs used ADSL technology (Arcep, 2016). The large take- 
Figure C1: The progressive roll-out of the DSL technology in France- $\widetilde{Z}$
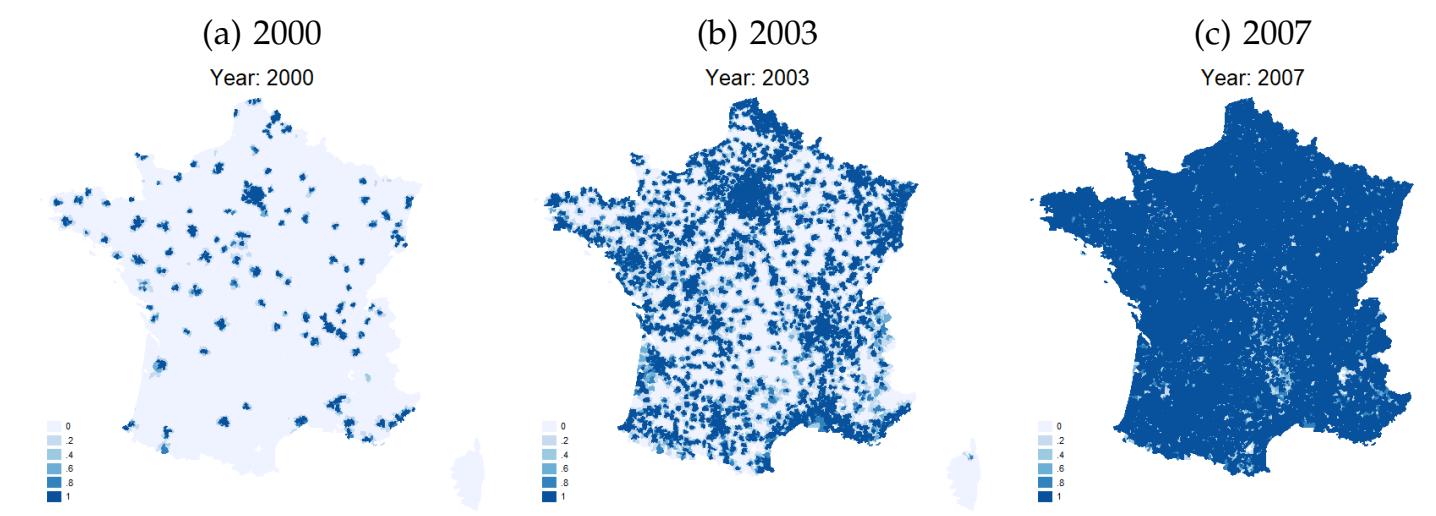

Notes: This figure presents the geographical distribution of the continuous measure of local broadband availability (variable $\widetilde{Z}$ ).

up reflects the fact that ADSL was a massive improvement in terms of speed (from 56 to $512 \mathrm{kbit} / \mathrm{s}$ for a transition from a classical to first generation ADSL connection) as well as in terms of connection cost and time. While there is no administrative data on firm-level use of broadband, based on repeated survey data, firms located in cities that received broadband internet earlier experienced higher growth in the proportion of employees that used internet on a regular basis between 1999 and 2004. This statistical association cannot be interpreted causally under the same set of assumptions as our main analysis. It is however strongly suggestive of an impact from broadband availability on broadband adoption. 
Table C2: Explaining city broadband coverage: panel analysis

\begin{tabular}{|c|c|c|c|c|c|}
\hline & $\begin{array}{c}(1) \\
\text { Covariates }\end{array}$ & $\begin{array}{c}\text { (2) } \\
\text { Twoway FE }\end{array}$ & $\begin{array}{c}\text { (3) } \\
\text { (2)+density }\end{array}$ & $\begin{array}{c}(4) \\
(2)+\text { indus. }\end{array}$ & $\begin{array}{c}(5) \\
(2)+\text { all cova. }\end{array}$ \\
\hline Lagged $\%$ primary & $\begin{array}{c}0.227^{* * *} \\
(27.65)\end{array}$ & & & $\begin{array}{c}-0.00313 \\
(-0.13)\end{array}$ & $\begin{array}{c}0.0102 \\
(0.42)\end{array}$ \\
\hline Lagged $\%$ construction & $\begin{array}{c}0.0102^{* *} \\
(2.62)\end{array}$ & & & $\begin{array}{c}0.00890 \\
(0.70)\end{array}$ & $\begin{array}{l}0.0190 \\
(1.62)\end{array}$ \\
\hline Lagged $\%$ auto & $\begin{array}{c}-0.00116 \\
(-0.11)\end{array}$ & & & $\begin{array}{c}0.00536 \\
(0.19)\end{array}$ & $\begin{array}{c}0.00357 \\
(0.13)\end{array}$ \\
\hline Lagged $\%$ retail & $\begin{array}{c}0.0197^{* * *} \\
(4.05)\end{array}$ & & & $\begin{array}{c}0.00570 \\
(0.39)\end{array}$ & $\begin{array}{c}0.00646 \\
(0.49)\end{array}$ \\
\hline Lagged \% hotel & $\begin{array}{c}-0.00608 \\
(-0.88)\end{array}$ & & & $\begin{array}{c}-0.00102 \\
(-0.05)\end{array}$ & $\begin{array}{c}-0.00270 \\
(-0.13)\end{array}$ \\
\hline Lagged $\%$ transport & $\begin{array}{c}0.00774 \\
(1.42)\end{array}$ & & & $\begin{array}{c}0.00837 \\
(0.46)\end{array}$ & $\begin{array}{l}0.0116 \\
(0.64)\end{array}$ \\
\hline Lagged \% finance & $\begin{array}{c}0.0340^{*} \\
(2.15)\end{array}$ & & & $\begin{array}{c}0.00804 \\
(0.23)\end{array}$ & $\begin{array}{c}0.0313 \\
(0.94)\end{array}$ \\
\hline Lagged \% service_pro & $\begin{array}{c}0.0935^{* * *} \\
(12.06)\end{array}$ & & & $\begin{array}{c}-0.00520 \\
(-0.34)\end{array}$ & $\begin{array}{c}-0.00349 \\
(-0.24)\end{array}$ \\
\hline Lagged \% service_pers & $\begin{array}{c}0.00258 \\
(0.58)\end{array}$ & & & $\begin{array}{c}0.0390^{*} \\
(2.61)\end{array}$ & $\begin{array}{c}0.0583^{* * *} \\
(4.01)\end{array}$ \\
\hline Lagged \% utilities & $\begin{array}{c}0.0665^{* * *} \\
(3.36)\end{array}$ & & & $\begin{array}{c}0.0201 \\
(0.34)\end{array}$ & $\begin{array}{c}0.0485 \\
(0.84)\end{array}$ \\
\hline Lagged $\Delta \%$ primary & $\begin{array}{c}-0.253^{* * *} \\
(-17.29)\end{array}$ & & & $\begin{array}{c}-0.0509^{* *} \\
(-3.10)\end{array}$ & $\begin{array}{c}-0.00248 \\
(-0.15)\end{array}$ \\
\hline Lagged $\Delta \%$ construction & $\begin{array}{c}0.00301 \\
(0.27)\end{array}$ & & & $\begin{array}{c}-0.00541 \\
(-0.58)\end{array}$ & $\begin{array}{c}-0.0115 \\
(-1.33)\end{array}$ \\
\hline Lagged $\Delta \%$ auto & $\begin{array}{c}-0.0132 \\
(-0.51)\end{array}$ & & & $\begin{array}{c}-0.0195 \\
(-0.98)\end{array}$ & $\begin{array}{c}-0.0208 \\
(-1.04)\end{array}$ \\
\hline Lagged $\Delta \%$ retail & $\begin{array}{c}0.00222 \\
(0.17)\end{array}$ & & & $\begin{array}{c}-0.000326 \\
(-0.03)\end{array}$ & $\begin{array}{c}-0.00234 \\
(-0.25)\end{array}$ \\
\hline Lagged $\Delta \%$ hotel & $\begin{array}{c}0.00606 \\
(0.34)\end{array}$ & & & $\begin{array}{c}-0.0119 \\
(-0.85)\end{array}$ & $\begin{array}{c}-0.0103 \\
(-0.75)\end{array}$ \\
\hline Lagged $\Delta \%$ transport & $\begin{array}{c}-0.0143 \\
(-0.96)\end{array}$ & & & $\begin{array}{c}-0.0134 \\
(-1.12)\end{array}$ & $\begin{array}{c}-0.0130 \\
(-1.20)\end{array}$ \\
\hline Lagged $\Delta \%$ finance & $\begin{array}{c}0.0319 \\
(1.31)\end{array}$ & & & $\begin{array}{l}0.0278 \\
(1.29)\end{array}$ & $\begin{array}{l}0.0198 \\
(0.96)\end{array}$ \\
\hline Lagged $\Delta \%$ service_pro & $\begin{array}{c}-0.0379^{*} \\
(-2.48)\end{array}$ & & & $\begin{array}{c}-0.0135 \\
(-1.01)\end{array}$ & $\begin{array}{c}-0.00496 \\
(-0.42)\end{array}$ \\
\hline Lagged $\Delta \%$ service_pers & $\begin{array}{c}0.00973 \\
(0.70)\end{array}$ & & & $\begin{array}{c}-0.0190 \\
(-1.63)\end{array}$ & $\begin{array}{c}-0.0306^{* *} \\
(-2.67)\end{array}$ \\
\hline Lagged $\Delta \%$ utilities & $\begin{array}{c}-0.0675 \\
(-1.34)\end{array}$ & & & $\begin{array}{c}0.00602 \\
(0.15)\end{array}$ & $\begin{array}{c}0.0316 \\
(0.79)\end{array}$ \\
\hline $\mathbb{1}\{$ year $=1999\} \times$ Ln Density 1990 & $\begin{array}{c}-0.0402 * * * \\
(-48.22)\end{array}$ & & & & \\
\hline $\mathbb{1}\{$ year $=2000\} \times$ Ln Density 1990 & $\begin{array}{c}-0.0257^{* * *} \\
(-30.82)\end{array}$ & & $\begin{array}{c}0.0337^{* * *} \\
(6.93)\end{array}$ & & $\begin{array}{c}0.0337^{* * *} \\
(6.92)\end{array}$ \\
\hline $\mathbb{1}\{$ year $=2001\} \times$ Ln Density 1990 & $\begin{array}{c}0.0145^{* * *} \\
(17.41)\end{array}$ & & $\begin{array}{c}0.109^{* * *} \\
(26.23)\end{array}$ & & $\begin{array}{c}0.109^{* * *} \\
(26.29)\end{array}$ \\
\hline $\mathbb{1}\{$ year $=2002\} \times$ Ln Density 1990 & $\begin{array}{c}0.0524^{* * *} \\
(62.84)\end{array}$ & & $\begin{array}{c}0.162^{* * *} \\
(34.28)\end{array}$ & & $\begin{array}{c}0.162^{* * *} \\
(34.33)\end{array}$ \\
\hline $\mathbb{1}\{$ year $=2003\} \times$ Ln Density 1990 & $\begin{array}{c}0.0881^{* * *} \\
(105.70)\end{array}$ & & $\begin{array}{c}0.170^{* * *} \\
(27.10)\end{array}$ & & $\begin{array}{c}0.170^{* * *} \\
(27.05)\end{array}$ \\
\hline $\mathbb{1}\{$ year $=2004\} \times$ Ln Density 1990 & $\begin{array}{l}0.129^{* * *} \\
(155.64)\end{array}$ & & $\begin{array}{c}0.146^{* * *} \\
(18.07)\end{array}$ & & $\begin{array}{c}0.146^{* * *} \\
(17.96)\end{array}$ \\
\hline $\mathbb{1}\{$ year $=2005\} \times$ Ln Density 1990 & $\begin{array}{l}0.170^{* * *} \\
(205.31)\end{array}$ & & $\begin{array}{l}0.0904^{* * *} \\
(12.36)\end{array}$ & & $\begin{array}{l}0.0903^{* * *} \\
(12.27)\end{array}$ \\
\hline $\mathbb{1}\{$ year $=2006\} \times$ Ln Density 1990 & $\begin{array}{l}0.196^{* * *} \\
(234.58)\end{array}$ & & $\begin{array}{l}0.0374^{* * *} \\
(8.11)\end{array}$ & & $\begin{array}{l}0.0372^{* * *} \\
(8.10)\end{array}$ \\
\hline $\mathbb{1}\{$ year $=2007\} \times$ Ln Density 1990 & $\begin{array}{l}0.206^{* * *} \\
(247.86)\end{array}$ & & $\begin{array}{c}0.0162^{* * *} \\
(5.76)\end{array}$ & & $\begin{array}{c}0.0162^{* * *} \\
(5.75)\end{array}$ \\
\hline$R^{2}$ & 0.555 & 0.786 & 0.812 & 0.787 & 0.812 \\
\hline $\begin{array}{l}\text { Industry: F-stat } \\
\text { Density: F-stat }\end{array}$ & 50.73 & & & 2.57 & $\begin{array}{c}2.18 \\
223.93\end{array}$ \\
\hline Density: F-stat & 21583.14 & & 221.55 & & 223.93 \\
\hline
\end{tabular}

Notes : This table presents the R-square of panel regressions following equation (9). Twoway FE (Column 2) refers to a twoway fixed-effect model with city fixed effect and département $\times$ year FEs. Density (Column 3) includes 1999 population density at the city level defined as total population divided by city area interacted with year indicators. Industrial structure controls (Column 4) include the lagged share and their changes of sectoral shares (nine sectors). Column (1) includes all of the controls without fixed effects. 


\section{BI Expansion and Skill-Biased Technological Change}

In this Appendix, we confirm and extend the results of Akerman et al. (2015) showing that broadband internet constitutes a skill-biased technology. In particular, we show that when a city is connected to BI (i) the labor productivity of establishments located in the city increases, (ii) the demand for high-skill workers increases, and (iii) the hourly wage and salary of high-skill workers increase.

\section{D.1 At the city and establishment level}

We start by evaluating the impact that BI and the underlying ADSL technology had on firm productivity. Given that the financial data is only available at the company level, we restrict this analysis to single-establishment firms, for which it is possible to assign financial performance to a single location. We measure labor productivity as the log of value added divided by the total wage bill. At the city level, we consider average productivity taken for the single establishments located in the municipality weighted by their size. ${ }^{31}$ Secondly - to capture skill-biased technological change - we look at the impact of BI on the share of high-skill workers in the city and establishments. ${ }^{32}$

Results obtained from both city and firm-level regressions are reported in Figure D1 and the corresponding coefficients are given in Table D1. These findings confirm what was expected: the productivity of firms increases when the city in which they are located is connected to BI. The average labor productivity of firms located in the city increases by about $2 \%$ over the first five years, and about half of this effect $(0.9 \%)$ takes place in firms already present in the area before the shock. ${ }^{33}$

Similarly, before the arrival of BI, the share of high skill workers evolved comparably across cities belonging to different cohorts of ADSL diffusion, conditional on department-specific time trends and the other controls. The parallel trends are a validation of our identification strategy. When cities get access to BI, they experience a

\footnotetext{
${ }^{31}$ See Table 1 for summary statistics for the main outcome variables in the city level and establishment level samples.

${ }^{32}$ All our measures of employment are expressed in terms of full-time equivalents. High-skill workers are defined based on their occupation, and include executive positions, managers and engineers, which correspond to the highest socio-professional category.

${ }^{33}$ The positive effect of BI on labor productivity is not purely driven by an increase in the skill intensity of the firms located in the city, but goes beyond that. First, by dividing the value added of the firm by the wage bill, instead of the firm size, we partially account for the fact that high-skill workers are paid more. Second, if we include the share of high-skill workers as an additional control in the productivity regressions, the coefficients remain widely unchanged (results available upon request).
} 
Figure D1: Firm productivity and broadband access

(a) Log VA per salary mass at city level

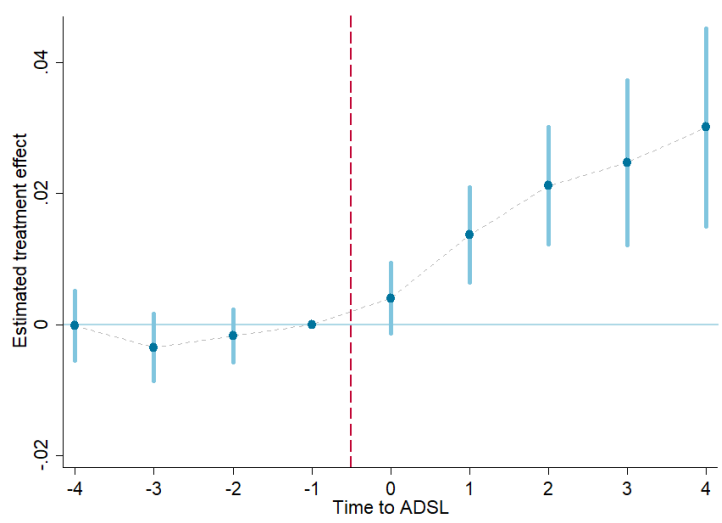

(c) Share of high-skill workers at city level

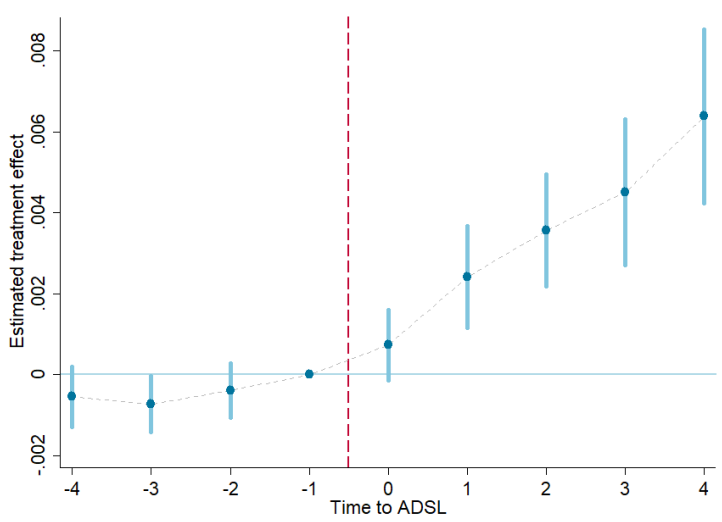

(b) Log VA per salary mass at estab. level

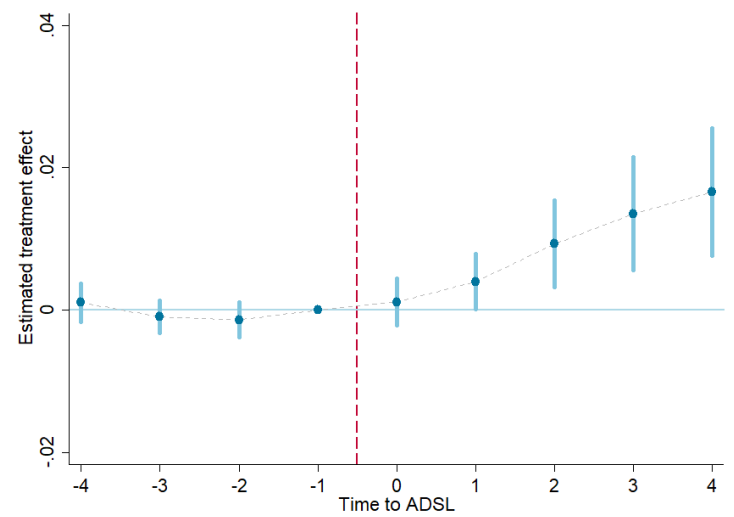

(d) Share of high-skill workers at estab. level

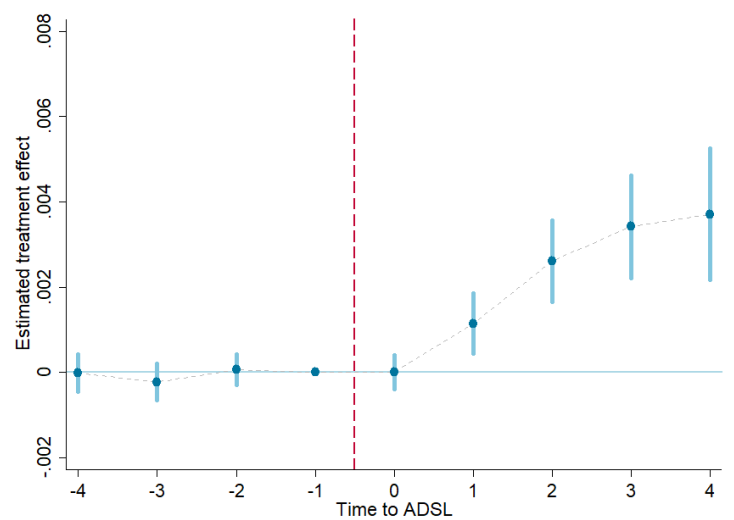

Notes: This Figure shows regression coefficients and 95\% confidence intervals from a dynamic event study where the dependent variable is the log of value added per salary mass within a city or establishment at $t$ and the regressors are dummies for the number of years before/after broadband access. The outcome at the city level captures the weighted average of establishments in the city. Only mono-establishment firms are kept in the sample since value added data is only available at the aggregated firm level. Panel (a) follow the specification reported in equation 10, while panel (b) replaces city fixed effects by establishment fixed effects.

general upskilling of their labor force relative to other municipalities. In particular, the share of full-time employment accounted for by the top socio-professional category increases, which is in line with the thesis of skill biased technological change. In terms of magnitude, the share of high-skill workers in a city increases by 0.4 percentage points following the diffusion of BI. This effect can be compared with the baseline average observed in cities at the beginning of the period, which was $6 \%$ : the share of high-skill workers thus increases by about $6.5 \%$ after the arrival of BI with respect to the baseline.

Such results could arise for two reasons: either because BI fosters the entry of new establishments with a higher average skill level than the incumbents', or because the average establishment already present in the city increases its share of high-skill workers. To capture the extent to which composition effects play a role, we compare 
our city-level results with similar event studies at the establishment level, which only keep the plants already present in the city before the arrival of ADSL in the sample. ${ }^{34}$ The effect on high skill workers within existing establishments is qualitatively similar to the one at the city level. This suggests that the increase in share of skilled workers is not (only) driven by a composition effect but is also a phenomenon taking place within existing firms. The magnitude is however smaller: BI increases the share of high skill workers within existing firms by 0.2 percentage points ( $2 \%$ growth with respect to baseline). Tables D3 and D4 show the robustness of the results to including a control for pre-BI productivity growth at the city level interacted with year dummies, and to running a standard dynamic difference-in-differences model as reported in Equation 10. Finally, Table D5 shows the static coefficients obtained from a stacked differencein-differences on the post-BI period.

\section{D.2 At the individual level}

In this subsection, we show that the evidence of increasing demand for skilled workers translates into increased wages, for our individual panel. As explained in Section 3, our data allow us to follow part of the workers over time. More precisely, we can follow every worker born in October of an even year (roughly 1/24 of the population) between 1994 and 2010. With these data, we can look at the individual wage effect of BI expansion, i.e., we can consider the change in hourly wage that follows the connection of a worker's city to ADSL. We therefore estimate the following model:

$$
\log \left(w_{i, t}\right)=\beta \tilde{Z}_{c(i), t}+X \gamma+\psi_{k, t}+v_{i}+\zeta_{s(i)}+\varepsilon_{i, t}
$$

where $w_{i, t}$ is the hourly wage of individual $i$ over year $t$ on average. $\tilde{Z}_{c(i), t}$ is the variable that captures the share of the city $c(i)$, where individual $i$ works, that is connected to BI. To some reasonable extent, $\tilde{Z}$ can be seen as a dummy variable indicating whether the city has been connected to BI prior to year $t$. $X$ is a vector of time-varying individual characteristics: age, age squared, an indicator of whether the job is part-time (as opposed to full-time) and gender. Finally, $\psi_{k, t}, v_{i}, \zeta_{s(i)}$ are a set of labor market area $k$ times year $t$ fixed effects, individual fixed effects and sector $s(i)$ fixed effects. $\varepsilon$ is an idiosyncratic error that we assume can be correlated

\footnotetext{
${ }^{34}$ The model is the same as in equation (11) but with establishment fixed effects instead of city fixed effects. These results can be interpreted as the pure within-firm effect that excludes any changes due to composition.
} 
Table D1: Effect of ADSL on productivity and demand for high-skill workers

\begin{tabular}{|c|c|c|c|c|}
\hline & \multirow{2}{*}{\multicolumn{2}{|c|}{$\begin{array}{c}(1) \\
\text { Log VA / salary mass }\end{array}$}} & \multirow{2}{*}{\multicolumn{2}{|c|}{$\begin{array}{l}(3) \\
\text { Sh. of high skill workers }\end{array}$}} \\
\hline & & & & \\
\hline & City level & Estab. Level & City level & Estab. Level \\
\hline $\mathrm{T}=0$ & $\begin{array}{c}0.00518^{*} \\
(0.00289)\end{array}$ & $\begin{array}{c}0.00159 \\
(0.00153)\end{array}$ & $\begin{array}{l}0.00103^{* *} \\
(0.000441)\end{array}$ & $\begin{array}{c}5.14 \mathrm{e}-05 \\
(0.000246)\end{array}$ \\
\hline $\mathrm{T}=+1$ & $\begin{array}{l}0.0148^{* * * *} \\
(0.00394)\end{array}$ & $\begin{array}{l}0.00447^{* * *} \\
(0.00195)\end{array}$ & $\begin{array}{l}0.00269^{* * *} \\
(0.000659)\end{array}$ & $\begin{array}{l}0.00118^{* * *} \\
(0.000389)\end{array}$ \\
\hline $\mathrm{T}=+2$ & $\begin{array}{l}0.0223^{* * *} \\
(0.00487)\end{array}$ & $\begin{array}{c}0.00978^{* * *} \\
(0.00306)\end{array}$ & $\begin{array}{l}0.00380^{* * *} \\
(0.000729)\end{array}$ & $\begin{array}{l}0.00265^{* * *} \\
(0.000512)\end{array}$ \\
\hline $\mathrm{T}=+3$ & $\begin{array}{l}0.0259^{* * *} \\
(0.00666)\end{array}$ & $\begin{array}{l}0.0140^{* * *} \\
(0.00399)\end{array}$ & $\begin{array}{l}0.00468^{* * *} \\
(0.000931)\end{array}$ & $\begin{array}{l}0.00345^{* * *} \\
(0.000646)\end{array}$ \\
\hline $\mathrm{T}=+4$ & $\begin{array}{l}0.0313^{* * *} \\
(0.00801)\end{array}$ & $\begin{array}{l}0.0171^{* * *} \\
(0.00451)\end{array}$ & $\begin{array}{l}0.00655^{* * *} \\
(0.00112)\end{array}$ & $\begin{array}{l}0.00374^{* * *} \\
(0.000816)\end{array}$ \\
\hline Average effect & $\begin{array}{l}0.0199 * * * \\
(0.00470)\end{array}$ & $\begin{array}{l}0.00939^{* * *} \\
(0.00276)\end{array}$ & $\begin{array}{l}0.00375^{* * *} \\
(0.000710)\end{array}$ & $\begin{array}{l}0.00222^{* * *} \\
(0.000486)\end{array}$ \\
\hline Observations & 506,726 & $2,609,671$ & 549,322 & $3,631,648$ \\
\hline R-squared & 0.551 & 0.697 & 0.721 & 0.899 \\
\hline
\end{tabular}

Notes: Columns (1) and (3) run the regression at the city level, following equation 11, where controls are the population density in 1999 interacted with year dummies, department $x$ year fixed effects, city fixed effects and sample fixed effects. Standard errors are clustered at the department level. Columns (2) to (4) run the same specification on the outcome computed at the establishment level, replacing city fixed effects by establishment fixed effects. Regressions on share of high-skill workers are run on the full sample of establishments, while the ones on value added over wage bill are restricted to mono-establishment firms.

within labor market areas but not across. Finally, $\beta$ captures the effect (in percentage points) of being connected to BI on wage, controlling for observable and time-varying unobservable worker characteristics.

Table D2 presents our results and Table D6 presents the summary statistics of the variables used for the regression. Column (1) includes all workers (around 11 millions) and shows that the coefficient of the dummy variable $C_{c(i), t}$ (first line, labeled "connected") is positive and significant. Its magnitude suggests that the hourly wage permanently increases by $3 \%$ on average for all workers once connected to BI. In this specification, we did not include individual fixed effects $v_{i}$ but control for initial wage to capture the level of skill of the worker. ${ }^{35}$ Including an individual fixed effect would better control for unobserved worker heterogeneity (which includes education) and

\footnotetext{
${ }^{35}$ Initial wage is defined as the logarithm of wage per hour taken in the first year in which the worker appears in the panel, this year is then removed from the regression.
} 
Table D2: EFFEct of ADSL ON INDIVIDUAL WAGE

\begin{tabular}{|c|c|c|c|c|c|c|}
\hline \multirow{2}{*}{$\begin{array}{l}\text { Sample } \\
\text { Connected }\end{array}$} & (1) & (2) & (3) & (4) & (5) & (6) \\
\hline & \multicolumn{2}{|c|}{ All workers } & \multicolumn{2}{|c|}{3 skills } & \multicolumn{2}{|c|}{2 skills } \\
\hline $\begin{array}{l}\text { Connected } \\
\qquad \begin{array}{l}\times \text { High-Skilled } \\
\times \text { Int-Skilled }\end{array}\end{array}$ & $\begin{array}{c}0.030^{* * *} \\
(0.003)\end{array}$ & $\begin{array}{c}0.006^{* * *} \\
(0.001)\end{array}$ & $\begin{array}{c}0.013^{* * *} \\
(0.004) \\
0.042^{* * *} \\
(0.013) \\
0.004 \\
(0.004)\end{array}$ & $\begin{array}{c}-0.016^{* * *} \\
(0.003) \\
0.116^{* * *} \\
(0.007) \\
0.025^{* * *} \\
(0.003)\end{array}$ & $\begin{array}{c}0.010^{*} \\
(0.005) \\
0.052^{* * *} \\
(0.015)\end{array}$ & $\begin{array}{c}-0.014^{* * *} \\
(0.003) \\
0.116^{* * *} \\
(0.009)\end{array}$ \\
\hline Age & $\begin{array}{c}0.032^{* * *} \\
(0.003)\end{array}$ & $\begin{array}{c}0.044^{* * *} \\
(0.006)\end{array}$ & $\begin{array}{c}0.026^{* * *} \\
(0.002)\end{array}$ & $\begin{array}{c}0.041^{* * *} \\
(0.005)\end{array}$ & $\begin{array}{c}0.020^{* * *} \\
(0.001)\end{array}$ & $\begin{array}{c}0.035^{* * *} \\
(0.003)\end{array}$ \\
\hline Age Sq. & $\begin{array}{c}-0.000^{* * *} \\
(0.000)\end{array}$ & $\begin{array}{c}-0.000^{* * *} \\
(0.000)\end{array}$ & $\begin{array}{c}-0.000^{* * *} \\
(0.000)\end{array}$ & $\begin{array}{c}-0.000^{* * *} \\
(0.000)\end{array}$ & $\begin{array}{c}-0.000^{* * *} \\
(0.000)\end{array}$ & $\begin{array}{c}-0.000^{* * *} \\
(0.000)\end{array}$ \\
\hline Gender & $\begin{array}{c}0.106^{* * *} \\
(0.004)\end{array}$ & & $\begin{array}{c}0.123^{* * *} \\
(0.007)\end{array}$ & & $\begin{array}{c}0.125^{* * *} \\
(0.002)\end{array}$ & \\
\hline Short Time & $\begin{array}{c}-0.043^{* * *} \\
(0.009)\end{array}$ & $\begin{array}{c}0.035^{* * *} \\
(0.001)\end{array}$ & $\begin{array}{c}-0.020^{* * *} \\
(0.004)\end{array}$ & $\begin{array}{c}0.035^{* * *} \\
(0.001)\end{array}$ & $\begin{array}{c}0.001 \\
(0.005)\end{array}$ & $\begin{array}{c}0.059 * * * \\
(0.002)\end{array}$ \\
\hline High Skill & & & $\begin{array}{c}0.649^{* * *} \\
(0.005)\end{array}$ & $\begin{array}{c}0.210^{* * *} \\
(0.005)\end{array}$ & $\begin{array}{c}0.644^{* * *} \\
(0.008)\end{array}$ & $\begin{array}{l}0.337^{* *} \\
(0.007)\end{array}$ \\
\hline Int. skill & & & $\begin{array}{c}0.168^{* * *} \\
(0.003)\end{array}$ & $\begin{array}{c}0.039^{* * *} \\
(0.002)\end{array}$ & & \\
\hline Initial wage (log) & $\begin{array}{c}0.346^{* * *} \\
(0.025)\end{array}$ & & $\begin{array}{c}0.334^{* * *} \\
(0.016)\end{array}$ & & $\begin{array}{c}0.249^{* * *} \\
(0.020)\end{array}$ & \\
\hline Fixed Effects & & & & & & \\
\hline LMA $\times$ year & $\checkmark$ & $\checkmark$ & $\checkmark$ & $\checkmark$ & $\checkmark$ & $\checkmark$ \\
\hline $\begin{array}{l}\text { Sector } \\
\text { Individual }\end{array}$ & $\checkmark$ & $\begin{array}{l}\checkmark \\
\checkmark\end{array}$ & $\checkmark$ & $\begin{array}{l}\checkmark \\
\checkmark\end{array}$ & $\checkmark$ & $\begin{array}{l}\checkmark \\
\checkmark\end{array}$ \\
\hline Obs. & $7,810,286$ & $7,808,176$ & $7,810,286$ & $7,808,176$ & $4,316,357$ & $4,256,281$ \\
\hline R Sq. & 0.46 & 0.78 & 0.62 & 0.79 & 0.70 & 0.85 \\
\hline
\end{tabular}

this is presented in column (2). Our coefficient of interest remains positive and significant but somehow lower $(0.6 \%)$. Columns (3) and (4) produce the same type of regression as Akerman et al. (2015) where we interact $C_{c(i), t}$ with a dummy variable for each skill level. In line with their results, we see that the effect of BI on wages is significantly larger for high skill-workers than for others. Columns (5) and (6) confirm these results by restricting our analysis to only low and high-skill workers (i.e. excluding intermediate skill workers from the sample).

Overall, these results confirm what we reported at the city level: BI is associated with a larger demand for high-skill workers and this translates into higher wages, even when controlling for unobserved heterogeneity and the usual controls. These results also show that the increasing demand for high-skill workers observed at the city and establishment level is not a pure composition effect as, overall, the arrival of 
BI benefits this class of workers more.

\section{D.3 Additional Tables}

Table D3: Effect of ADSL on productivity and demand for high-skill workers controlling for pre-BI productivity growth

\begin{tabular}{|c|c|c|c|c|}
\hline & \multirow{2}{*}{\multicolumn{2}{|c|}{$\begin{array}{c}(1) \\
\text { Log VA / salary mass }\end{array}$}} & \multirow{2}{*}{\multicolumn{2}{|c|}{$\begin{array}{l}\text { (3) } \\
\text { Sh. of high skill workers }\end{array}$}} \\
\hline & & & & \\
\hline & City level & Estab. Level & City level & Estab. Level \\
\hline \multirow[t]{2}{*}{$\mathrm{T}=0$} & $0.00906^{* * *}$ & $0.00246^{*}$ & $0.000719^{*}$ & $8.60 \mathrm{e}-05$ \\
\hline & $(0.00292)$ & $(0.00144)$ & $(0.000411)$ & (0.000258) \\
\hline \multirow[t]{2}{*}{$\mathrm{T}=+1$} & $0.0180^{* * *}$ & $0.00498^{* *}$ & $0.00236^{* * *}$ & $0.00123^{* * *}$ \\
\hline & (0.00438) & $(0.00201)$ & (0.000628) & (0.000414) \\
\hline \multirow[t]{2}{*}{$\mathrm{T}=+2$} & $0.0264^{* * *}$ & $0.0102^{* * *}$ & $0.00394^{* * *}$ & $0.00270^{* * *}$ \\
\hline & $(0.00523)$ & (0.00303) & (0.000776) & (0.000543) \\
\hline \multirow[t]{2}{*}{$\mathrm{T}=+3$} & $0.0262^{* * *}$ & $0.0143^{* * *}$ & $0.00459^{* * *}$ & $0.00350^{* * *}$ \\
\hline & (0.00699) & (0.00397) & $(0.000991)$ & (0.000685) \\
\hline \multirow[t]{2}{*}{$\mathrm{T}=+4$} & $0.0340^{* * *}$ & $0.0176^{* * *}$ & $0.00612^{* * *}$ & $0.00374^{* * *}$ \\
\hline & $(0.00898)$ & $(0.00451)$ & $(0.00123)$ & $(0.000863)$ \\
\hline \multirow[t]{2}{*}{ Average effect } & $0.0227^{* * *}$ & $0.00992^{* * *}$ & $0.00354^{* * *}$ & $0.00225^{* * *}$ \\
\hline & $(0.00509)$ & $(0.00272)$ & $(0.000747)$ & $(0.000515)$ \\
\hline Observations & 400,980 & $2,481,432$ & 409,042 & $3,446,526$ \\
\hline R-squared & 0.537 & 0.696 & 0.723 & 0.900 \\
\hline
\end{tabular}

Notes: Columns (1) and (3) run the regression at the city level, following equation 11, where controls are the population density in 1999 interacted with year dummies, the productivity growth at the city-level preBI (1996-1998) interacted with year dummies, department $x$ year fixed effects, city fixed effects and sample fixed effects. Standard errors are clustered at the department level. Columns (2) to (4) run the same specification on the outcome computed at the establishment level, replacing city fixed effects by establishment fixed effects. Regressions on share of high-skill workers are run on the full sample of establishments, while the ones on value added over wage bill are restricted to mono-establishment firms. 
Table D4: Effect of ADSL on productivity and demand for high-skill workers using a standard dynamic model

\begin{tabular}{|c|c|c|c|c|}
\hline & \multirow{2}{*}{\multicolumn{2}{|c|}{$\begin{array}{c}(1) \\
\text { Log VA / salary mass }\end{array}$}} & \multirow{2}{*}{\multicolumn{2}{|c|}{$\begin{array}{l}\text { (3) } \\
\text { Sh. of high skill workers }\end{array}$}} \\
\hline & & & & \\
\hline & City level & Estab. Level & City level & Estab. Level \\
\hline \multirow[t]{2}{*}{$\mathrm{T}=0$} & $0.00545^{* *}$ & $0.00331^{* *}$ & $0.00117^{* * *}$ & 0.000226 \\
\hline & $(0.00272)$ & $(0.00153)$ & $(0.000402)$ & (0.000265) \\
\hline \multirow[t]{2}{*}{$\mathrm{T}=+1$} & $0.0149^{* * *}$ & $0.00519^{* *}$ & $0.00274^{* * *}$ & $0.00128^{* * *}$ \\
\hline & $(0.00372)$ & (0.00209) & (0.000570) & (0.000447) \\
\hline \multirow[t]{2}{*}{$\mathrm{T}=+2$} & $0.0224^{* * *}$ & $0.0106^{* * *}$ & $0.00400^{* * *}$ & $0.00269^{* * *}$ \\
\hline & (0.00433) & (0.00302) & (0.000658) & (0.000611) \\
\hline \multirow[t]{2}{*}{$\mathrm{T}=+3$} & $0.0274^{* * *}$ & $0.0161^{* * *}$ & $0.00496^{* * *}$ & $0.00364^{* * *}$ \\
\hline & $(0.00580)$ & (0.00385) & (0.000864) & (0.000764) \\
\hline \multirow[t]{2}{*}{$\mathrm{T}=+4$} & $0.0350^{* * *}$ & $0.0201^{* * *}$ & $0.00706^{* * *}$ & $0.00446^{* * *}$ \\
\hline & $(0.00694)$ & $(0.00445)$ & $(0.00104)$ & (0.000950) \\
\hline \multirow[t]{2}{*}{$\mathrm{T}=+5$} & $0.0468^{* * *}$ & $0.0280^{* * *}$ & $0.00927^{* * *}$ & $0.00590^{* * *}$ \\
\hline & (0.00820) & $(0.00551)$ & $(0.00123)$ & $(0.00118)$ \\
\hline \multirow[t]{2}{*}{ Average effect } & $0.0253^{* * *}$ & $0.0139^{* * *}$ & $0.00487^{* * *}$ & $0.00303^{* * *}$ \\
\hline & $(0.00466)$ & $(0.00318)$ & $(0.000721)$ & (0.000671) \\
\hline Observations & 140,450 & $1,203,898$ & 150,603 & $1,767,096$ \\
\hline R-squared & 0.497 & 0.656 & 0.752 & 0.905 \\
\hline \multicolumn{5}{|c|}{$\begin{array}{l}\text { Notes: Columns (1) and (3) run the regression at the city level, following a standard dynamic event stud } \\
\text { design as reported in equation } 10 \text {, where controls are the population density in } 1999 \text { interacted with yea } \\
\text { dummies, department } x \text { year fixed effects, city fixed effects and sample fixed effects. Standard errors ar } \\
\text { clustered at the department level. Columns (2) to (4) run the same specification on the outcome computec } \\
\text { at the establishment level, replacing city fixed effects by establishment fixed effects. Regressions on share o } \\
\text { high-skill workers are run on the full sample of establishments, while the ones on value added over wag } \\
\text { bill are restricted to mono-establishment firms. }\end{array}$} \\
\hline
\end{tabular}


Table D5: Effect of ADSL on productivity and demand for high-skill workers - static regressions

\begin{tabular}{lll}
\hline $\begin{array}{l}\text { Log VA / } \\
\text { salary mass }\end{array}$ & Sh. of high skill \\
workers
\end{tabular}

Panel A : city level regressions

$\begin{array}{lll}\text { Post ADSL * treated } & 0.0126^{* * *} & 0.00229 * * * \\ (0.00331) & (0.000543)\end{array}$

$\begin{array}{lcc}\text { Observations } & 506,726 & 549,322 \\ \text { R-squared } & 0.551 & 0.721\end{array}$

Panel B : establishment level regressions

$\begin{array}{lcc}\text { Post ADSL * treated } & \begin{array}{c}0.00491^{* *} \\ (0.00187)\end{array} & \begin{array}{c}0.00114^{* * *} \\ (0.000337)\end{array} \\ & & \\ \text { Observations } & 2,609,671 & 3,631,648 \\ \text { R-squared } & 0.697 & 0.899\end{array}$

Notes: The regressions are run at the city and establishment level following a model similar to equation 11, but where instead of including the dynamic postADSL effects for every year, we just include a dummy for post-ADSL period interacted with the treatment indicator. All columns control for the population density in 1999 interacted with year dummies, department $x$ year fixed effects, city fixed effects and sample fixed effects.

Table D6: Variable description for Table D2

\begin{tabular}{llccc}
\hline Variable & Description & Mean & p25 & p75 \\
\hline Log of wage & log of hourly wage (dependent variable) & 2.41 & 2.10 & 2.63 \\
Age & Age of the worker & 37 & 28 & 46 \\
Age Sq. & Age $\times$ Age & 1,507 & 784 & 2,116 \\
Gender & Gender of the worker & 0.63 & 0 & 1 \\
Short Time & Dummy for declaring working part time & 0.17 & 0 & 1 \\
High Skill & Dummy for working in a high skill occu- & 0.13 & 0 & 1 \\
& pation & & & \\
Int. Skill & $\begin{array}{l}\text { Dummy for neither working in high or low } \\
\text { skill occupation }\end{array}$ & 0.45 & 0 & 1 \\
Initial Wage $(\log )$ & $\begin{array}{l}\text { Log of hourly wage taken in the first year } \\
\text { the worker appear in the data }\end{array}$ & & & \\
& & & & \\
\hline
\end{tabular}

Notes: Variable description used in the panel data wage regression and basic descriptive statistics. 


\section{E Theory Appendix}

Note: we drop the index $j$ when the context does not command it.

\section{E.1 Proof of Proposition 1}

Proof. First, the CES structure of the production function for a given occupation yields the following elasticities:

$$
\begin{aligned}
\frac{\partial H_{i}}{\partial n_{i}} & =H_{i}^{1 / \sigma_{i}} \mu_{i}^{1 / \sigma_{i}} n_{i}^{-1 / \sigma_{i}} \Longrightarrow \frac{\partial H_{i}}{\partial n_{i}} \frac{n_{i}}{H_{i}}=H_{i}^{\frac{1-\sigma_{i}}{\sigma_{i}}} \mu_{i}^{\frac{1}{\sigma_{i}} n_{i}^{\frac{\sigma_{i}-1}{\sigma_{i}}}} \\
\frac{\partial H_{i, j}}{\partial s_{i, j}} & =H_{i, j}^{1 / \sigma_{i}}\left(1-\mu_{i}\right)^{1 / \sigma_{i}} s_{i, j}^{-1 / \sigma_{i}} \Longrightarrow \frac{\partial H_{i}}{\partial s_{i}} \frac{s_{i}}{H_{i}}=H_{i}^{\frac{1-\sigma_{i}}{\sigma_{i}}}\left(1-\mu_{i}\right)^{\frac{1}{\sigma_{i}}} s_{i}^{\frac{\sigma_{i}-1}{\sigma_{t} i}}
\end{aligned}
$$

Note also that this elasticity:

$$
e_{i} \equiv \frac{\partial H_{i}}{\partial s_{i}} \frac{s_{i}}{H_{i}}=\frac{\left(1-\mu_{i}\right)^{\frac{1}{\sigma_{i}}} s_{i}{ }^{\frac{\sigma_{i}-1}{\sigma_{i}}}}{\left(1-\mu_{i}\right)^{\frac{1}{\sigma_{i}}} s_{i}{ }^{\frac{\sigma_{i}-1}{\sigma_{i}}}+\mu_{i}^{\frac{1}{\sigma_{i}}} n_{i}^{\frac{\sigma_{i}-1}{\sigma_{i}}}} \in[0,1]
$$

and $\frac{\partial H_{i}}{\partial n_{i}} \frac{n_{i}}{H_{i}}=1-e_{i}$

Second, the first-order conditions can be combined to give a relationship between $s_{i}$ and $n_{i}$ :

$$
s_{i}=\frac{1-\mu_{i}}{\mu_{i}}\left[\frac{\rho+1}{a_{i}^{\rho} r_{i} \gamma_{i}}\right]^{\sigma_{i}} n_{i}^{\rho \sigma_{i}+1}=\lambda_{i} n_{i}^{\rho \sigma_{i}+1},
$$

and the cost share of outsourced workers is thus given by:

$$
\eta_{i}^{c} \equiv \frac{\gamma_{i} r_{i} s_{i}}{\gamma_{i, j} r_{i} s_{i}+w\left(n_{i}\right) n_{i}}=1-\frac{1}{1+\gamma_{i} r_{i} a^{\rho} \lambda_{i} n_{i}^{\rho\left(\sigma_{i}-1\right)}}
$$

As long as $\sigma_{i}>1$ and $\rho>0$, we therefore have:

$$
\frac{\partial \eta_{i}^{c}}{\partial n_{i}}>0
$$

Using the relationship between $n_{i}$ and $s_{i}$ and $\log$ differentiating $H_{i}$, it is straightfor- 
ward to show that

$$
d \log \left(H_{i}\right)=d \log n_{i}\left(1+H_{i}^{1 / \sigma_{i}-1}\left(1-\mu_{i}\right)^{1 / \sigma_{i}} s_{i}^{1-1 / \sigma_{i}} \rho \sigma_{i}\right)=d \log n_{i}\left(1+e_{i} \rho \sigma_{i}\right)
$$

Next, log-differentiating $P Y$ :

$$
d \log \theta \frac{\varepsilon-1}{\varepsilon}+\left(\sum_{i^{\prime}} \alpha_{i^{\prime}} d \log \left(H_{i^{\prime}}\right)\right) \frac{\varepsilon-1}{\varepsilon}=\left(1 / \sigma_{i}+\rho\right) d \log n_{i}+d \log H_{i}
$$

which can be rewritten as:

$$
d \log \theta+\left(\sum_{i^{\prime}} \alpha_{i^{\prime}} d \log n_{i^{\prime}}\left(1+e_{i^{\prime}} \rho \sigma_{i^{\prime}}\right)\right)=\frac{\varepsilon}{\varepsilon-1}\left(1 / \sigma_{i}+\rho+1+e_{i} \rho \sigma_{i}\right) d \log n_{i}
$$

This expression is valid for all $i$ which shows that $d \log n_{i}$ are either all positive or all negative as $d \log \theta>0$. To show that they are all positive, we first multiply the above equation by $\alpha_{i}$ and then sum for all $i$ :

$$
d \log \theta=\frac{1}{\varepsilon-1}\left(\sum_{i^{\prime}} \alpha_{i^{\prime}} d \log n_{i^{\prime}}\left(1+e_{i^{\prime}} \rho \sigma_{i^{\prime}}+\varepsilon\left(1 / \sigma_{i^{\prime}}+\rho\right)\right)\right)>0 .
$$

This implies that $\frac{d \log \left(n_{i}\right)}{d \log \theta}>0$ and then $\frac{d \eta_{i}^{c}}{d \theta}>0$

\section{E.2 Proof of Proposition 2}

Proof. Starting from equation (15) and using the fact that $s_{i}=\lambda_{i} n_{i}^{\rho \sigma_{i}+1}$, we know that:

$$
\frac{1}{\left(\rho \sigma_{i}+1\right)} \frac{d \log \left(s_{i}\right)}{d \log (\theta)}\left(\frac{1}{\sigma_{i}}+1+\rho+\rho \sigma_{i} e_{i}\right),
$$

is independent of $i$. Hence, a sufficient condition to have $\frac{d \log \left(s_{1}\right)}{d \log (\theta)}<\frac{d \log \left(s_{2}\right)}{d \log (\theta)}$ is:

$$
\left(\rho \sigma_{2}+1\right)\left(\frac{1}{\sigma_{1}}+1+\rho+\rho \sigma_{1} e_{1}\right)=\left(1+\rho \sigma_{2}\right)\left(2+\rho+\rho e_{1}\right)>(\rho+1)\left(\frac{1}{\sigma_{2}}+1+\rho+\rho \sigma_{2} e_{2}\right)
$$

Because $e_{1} \in(0,1)$, then a larger sufficient condition is:

$$
\left(1+\rho \sigma_{2}\right)(2+\rho)>(1+\rho) \rho \sigma_{2}+(1+\rho)\left(1+\frac{1}{\sigma_{2}}+\rho\right)
$$

which is true as long as $\sigma_{2}>1+\rho$. 
Similarly, equation (15) can be used to show that:

$$
\frac{d \log \left(n_{i}\right)}{d \log (\theta)}\left(\frac{1}{\sigma_{i}}+1+\rho+\rho \sigma_{i} e_{i}\right)
$$

is independent of $i$. This shows that as long as:

$$
\sigma_{2} e_{2}>\frac{1+\rho}{\rho}, \text { then } \frac{d \log \left(n_{2}\right)}{d \log (\theta)}<\frac{d \log \left(n_{1}\right)}{d \log (\theta)} \text {. }
$$

This show that:

$$
\frac{d \log \left(s_{1} / n_{1}\right)}{d \log (\theta)}<\frac{d \log \left(s_{2} / n_{2}\right)}{d \log (\theta)}
$$

and thus:

$$
\frac{d \log \left(r_{1} \gamma_{1} s_{1} /\left(n_{1} w\left(n_{1}\right)\right)\right.}{d \log (\theta)}<\frac{d \log \left(r_{2} \gamma_{2} s_{2} /\left(n_{2} w\left(n_{2}\right)\right)\right.}{d \log (\theta)}
$$

Then following an increase in $\theta$, the non-core occupation will experience a relative increase in the share of its labor cost coming from outsourced workers that is larger than what the core occupation experiences. In fact, because we have assumed that $\sigma_{1}=1$, the core occupation do not experience any change in its cost share of outsourced workers which concludes the proof.

\section{E.3 Proof of Proposition 3}

Proof. The first order conditions can be combined to show that:

$$
\frac{n_{i} w_{i}}{P Y}=\alpha_{i} \frac{\varepsilon-1}{\varepsilon} \frac{1-e_{i}}{1+\rho} \text { and } \frac{r_{i} s_{i}}{P Y}=\alpha_{i} \frac{\varepsilon-1}{\varepsilon} e_{i}
$$

so that the revenue share of occupation $i$ is given by:

$$
\frac{n_{i} w_{i}+r_{i} s_{i}}{P Y}=\alpha_{i} \frac{\varepsilon-1}{\varepsilon} \frac{1+\rho e_{i}}{1+\rho} \in\left[\alpha_{i} \frac{\varepsilon-1}{\varepsilon(1+\rho)} ; \alpha_{i} \frac{\varepsilon-1}{\varepsilon}\right]
$$

This shows that as long as $\alpha_{i+1}<\frac{\alpha_{i}}{1+\rho}$, the revenue share increases as $\sigma_{i}$ decreases. Note that with two occupations 1 and 2, this is true as long as:

$$
\rho<\frac{2 \alpha_{1}-1}{1-\alpha_{1}}
$$


Because $\lambda_{1}<\lambda_{2}<\ldots<\lambda_{N}$, then: ${ }^{36}$

$$
n_{i} w_{i}+r_{i} s_{i}>n_{i+1} w_{i+1}+r_{i+1} s_{i+1} \Longrightarrow n_{i}>n_{i+1}
$$

Adding to the fact that $\frac{d \log \left(n_{1}\right)}{d \log (\theta)}>\frac{d \log \left(n_{2}\right)}{d \log (\theta)}$, this shows that the larger occupation in terms of in-house workers $\left(n_{1}>n_{2}\right)$ is also the one that will increase the most its number of in-house workers, which results in an increase in the HHI index.

\section{E.4 The case of a reduction in the cost of outsourcing}

In this extension, we consider the case of a reduction in the value of $\gamma_{i, j}$ for a firm $j$. We assume that the relative decrease is the same for all occupations, i.e. that $d \log \left(\gamma_{i, j}\right)=d \log (\gamma)$. As usual, we drop the subscript $j$ for the sake of clarity.

We show that under a large set of assumptions, firms respond to a reduction of the cost of outsourcing $\gamma$ by increasing their outsourcing intensity which results in an increasing level of concentration of occupation in the firm.

To show this, first note that as long as $\sigma_{i}>0$ :

$$
\frac{d \log \left(\eta_{i}^{c}\right)}{d \log (\gamma)}<0 \Longleftrightarrow \frac{d \log \left(n_{i}\right)}{d \log (\gamma)}<1 / \rho
$$

The combination of the two first order conditions continue to give the same relationship between $n_{i}$ and $s_{i}$, only this time:

$$
d \log \left(s_{i}\right)=-\sigma_{i} d \log (\gamma)+\left(\rho \sigma_{i}+1\right) d \log \left(n_{i}\right)
$$

Lemma 1. At least one type of occupation must have $d \log \left(s_{i}\right) / d \log (\gamma)<0$

Proof. The full differentiation of $d \log \left(H_{i}\right)$ gives:

$$
d \log \left(H_{i}\right)=e_{i} d \log \left(s_{i}\right)+\left(1-e_{i}\right) d \log \left(n_{i}\right)=d \log \left(s_{i}\right) \frac{1+\rho \sigma_{i} e_{i}}{1+\rho \sigma_{i}}+\frac{\left(1-e_{i}\right) \sigma_{i}}{1+\rho \sigma_{i}} d \log (\gamma)
$$

Hence, differentiating the first order condition with respect to $s_{i}$ and summing over

\footnotetext{
${ }^{36}$ This is because $n_{i+1} w_{i+1}+r_{i+1} s_{i+1}=a^{-\rho} n_{i+1}^{\rho+1}+\lambda_{i+1} n_{i+1}^{\rho \sigma_{i+1}+1}>a^{-\rho} n_{i+1}^{\rho+1}+\lambda_{i} n_{i+1}^{\rho \sigma_{i}+1}$
} 
all $i$ after having pre-multiplied by $\alpha_{i}$

$$
\frac{\varepsilon-1}{\varepsilon} \sum_{j \in \mathbf{N}} \alpha_{j} d \log \left(H_{j}\right)=d \log \left(H_{i}\right)+d \log (\gamma)+\frac{1}{\sigma_{i}} d \log \left(s_{i}\right),
$$

becomes:

$$
-\sum_{i \in \mathbf{N}} \alpha_{i} \frac{d \log \left(s_{i}\right)}{d \log (\gamma)}\left[\frac{1}{\varepsilon} \frac{1+\rho e_{i} \sigma_{i}}{1+\rho \sigma_{i}}+\frac{1}{\sigma_{i}}\right]=1+\frac{1}{\varepsilon} \sum_{i \in \mathbf{N}} \alpha_{i} \frac{1-e_{i}}{1+\rho \sigma_{i}} \sigma_{i}>0
$$

Which shows that at least one $\frac{d \log \left(s_{i}\right)}{d \log (\gamma)}$ must be smaller than 0 .

Coming back to the two type of occupation case where $\mathbf{N}=\{1,2\}$ and $\sigma_{1}=1$, we know that $\eta_{1}^{c}$ is constant and $\eta_{2}^{c}$ will increase following a drop in $\gamma$ if $d \log \left(n_{2}\right) / d \log (\gamma)<$ $1 / \rho$. Let's assume that this is not the case, i.e. that $d \log \left(n_{2}\right) / d \log (\gamma) \geq 1 / \rho>0$.

Then $d \log \left(s_{2}\right) / d \log (\gamma)>1 / \rho$ from equation (16). And from the previous lemma, we know that $d \log \left(s_{1}\right) / d \log (\gamma)<0$.

Using again equation (16), we also have

$$
\frac{d \log \left(n_{1}\right)}{d \log (\gamma)}<\frac{\sigma_{1}}{\rho \sigma_{1}+1} \leq \frac{1}{\rho}
$$

and finally:

$$
\frac{d \log \left(H_{1}\right)}{d \log (\gamma)}<\frac{1-e_{1}}{\rho}<\frac{1}{\rho} \text { while } \frac{d \log \left(H_{2}\right)}{d \log (\gamma)}>\frac{1}{\rho}
$$

Using the differentiated first order condition with respect to the second occupation yields:

$$
\frac{\varepsilon-1}{\varepsilon}\left(\alpha_{1} d \log \left(H_{1}\right)+\left(1-\alpha_{1}\right) d \log \left(H_{2}\right)\right)=d \log \left(H_{2}\right)+\frac{1}{\sigma_{2}} d \log \left(s_{2}\right)+d \log (\gamma)
$$

whence:

$$
\begin{aligned}
\frac{\varepsilon-1}{\varepsilon}\left(\frac{\alpha_{1}}{\rho}+\frac{\left(1-\alpha_{1}\right) d \log \left(H_{2}\right)}{d \log (\gamma)}\right) & >\frac{\varepsilon-1}{\varepsilon}\left(\alpha_{1} d \log \left(H_{1}\right)+\left(1-\alpha_{1}\right) d \log \left(H_{2}\right)\right) \\
& \geq \frac{d \log \left(H_{2}\right)}{d \log (\gamma)}+1+\frac{d \log \left(s_{2}\right)}{d \log (\gamma)} \\
\Longrightarrow\left(\frac{\varepsilon-1}{\varepsilon}\left(1-\alpha_{1}\right)-1\right) \frac{d \log \left(H_{2}\right)}{d \log (\gamma)} & >1-\frac{\varepsilon-1}{\varepsilon} \frac{\alpha_{1}}{\rho}+\frac{1}{\sigma_{2}} \frac{d \log \left(s_{2}\right)}{d \log (\gamma)}
\end{aligned}
$$


The left-hand side of this last inequality is negative and the right hand side is larger than:

$$
\frac{1}{\sigma_{2} \rho}+1-\frac{\varepsilon-1}{\varepsilon} \frac{\alpha_{1}}{\rho}
$$

which is positive as long as $\alpha_{1}$ is not too large or $\rho$ is not too small. This leads to an impossible statement and hence contradict the assumption that $d \log \left(n_{2}\right) / d \log (\gamma) \geq$ $1 / \rho$.

\section{E.5 Extension to more than 2 occupations}

The model can be extended to a fixed number of occupation $N=|\mathbf{N}|$. The proof of Proposition 1 already considers the general case. The proof from Proposition 2 can be extended in the following way.

We know that for every occupation $i$ :

$$
\frac{1}{\left(\rho \sigma_{i}+1\right)} \frac{d \log \left(s_{i}\right)}{d \log (\theta)}\left(\frac{1}{\sigma_{i}}+1+\rho+\rho \sigma_{i} e_{i}\right)
$$

is independent of $i$ which means that $\frac{d \log \left(s_{i}\right)}{d \log (\theta)}<\frac{d \log \left(s_{i+1}\right)}{d \log (\theta)}$ is true as long as:

$$
\left(\rho \sigma_{i+1}+1\right)\left(\frac{1}{\sigma_{i}}+1+\rho+\rho \sigma_{i} e_{i}\right)>\left(\rho \sigma_{i}+1\right)\left(\frac{1}{\sigma_{i+1}}+1+\rho+\rho \sigma_{i+1} e_{i+1}\right)
$$

a sufficient condition is that:

$$
\frac{1}{1+\rho \sigma_{i+1}}>1-\left(\frac{1}{\sigma_{i}}-\frac{1}{\sigma_{i+1}}\right)
$$

This is true as long as $\rho$ is sufficiently close to 0 .

Similarly:

$$
\frac{d \log \left(n_{i}\right)}{d \log (\theta)}\left(\frac{1}{\sigma_{i}}+1+\rho \sigma_{i} e_{i}\right)
$$

is independent of $i$ which means that $\frac{d \log \left(n_{i+1}\right)}{d \log (\theta)}<\frac{d \log \left(n_{i}\right)}{d \log (\theta)}$ is true as long as:

$$
\sigma_{i+1} e_{i+1}>\frac{1}{\rho \sigma_{i}}+\sigma_{i}
$$

This in particular implies that the $\sigma_{i}$ are not too close with each other, i.e. that the different occupations are characterised by very different level of substituability. In 
such a case, Proposition 3 also applies and the concentration of i-house occupation following an increase in $\theta$ becomes larger.

Note that these are sufficient conditions that can be derived without solving numerically the model for $N>2$. In Appendix E.7, we present some simulation for $N=4$ and show that the concentration of in-house workers indeed increase following a shock in $\theta$.

\section{E.6 Markups and outsourcing share}

The model gives a clear prediction on the sign of the relationship of the inverse inhouse labor share and the outsourcing intensity as well as the relationship of sales over total labor cost and outsourcing intensity. To see this formally, we start from the first order conditions which can be combined to show that:

$$
\frac{n_{i} w_{i}}{P Y}=\alpha_{i} \frac{\varepsilon-1}{\varepsilon} \frac{1-e_{i}}{1+\rho} \text { and } \frac{r_{i} s_{i}}{P Y}=\alpha_{i} \frac{\varepsilon-1}{\varepsilon} e_{i},
$$

where we recall that $e_{i}=\partial \log \left(H_{i}\right) / \partial \log \left(s_{i}\right)$. The revenue share of occupation $i$ is given by:

$$
\frac{n_{i} w_{i}+r_{i} s_{i}}{P Y}=\alpha_{i} \frac{\varepsilon-1}{\varepsilon} \frac{1+\rho e_{i}}{1+\rho}
$$

We define the markup $\mathcal{M}$ as the ratio of PY over total cost:

$$
\mathcal{M}=\frac{P Y}{\sum_{i \in \mathbf{N}} s_{i} \gamma_{i} r_{i}+w\left(n_{i}\right) n_{i}}=\frac{\varepsilon}{\varepsilon-1} \frac{1+\rho}{1+\rho \sum_{i \in \mathbf{N}} \alpha_{i} e_{i}}
$$

Let us now define $\mathcal{O}$ as the share of total labor cost coming from outsourced workers:

$$
\mathcal{O}=\frac{\sum_{i \in \mathbf{N}} s_{i} \gamma_{i} r_{i}}{\sum_{i \in \mathbf{N}} s_{i} \gamma_{i} r_{i}+w\left(n_{i}\right) n_{i}}=\frac{(1+\rho) \sum_{i \in \mathbf{N}} \alpha_{i} e_{i}}{1+\rho \sum_{i \in \mathbf{N}} \alpha_{i} e_{i}}
$$

This implies in particular that:

$$
\sum_{i \in \mathbf{N}} \alpha_{i} e_{i}=\frac{\mathcal{O}}{1+\rho-\rho \mathcal{O}}
$$

And finally:

$$
\mathcal{M}=\frac{\varepsilon(1+\rho)}{\varepsilon-1}\left(1-\frac{\rho}{1+\rho} \mathcal{O}\right)
$$


Hence the model predicts a negative relationship between the ratio of revenue over total labor cost and outsourcing intensity.

Taking back this last equation and multiplying by $1 /(1-\mathcal{O})$ yields:

$$
\frac{P Y}{\sum_{i \in \mathbf{N}} w_{i} n_{i}}=\frac{\varepsilon}{\varepsilon-1}\left[\frac{1}{1-\mathcal{O}}+\rho\right]
$$

So that the model predicts a positive relationship between the inverse in-house labor share and outsourcing intensity.

These relationships are tested empirically in Table A1.

\section{E.7 Numerical examples}

Comparative statics: increase in productivity $\theta$. We consider a specific case with a firm with 4 occupations: 2 high skill $\left(\alpha_{i}=1 / 3\right)$ and 2 low skill $\left(\alpha_{i}=1 / 6\right), 2$ core $\left(\sigma_{i}=0.50\right)$ and 2 non-core occupations $\left(\sigma_{i}=2.5\right)$. In the baseline, we consider that the two dimensions are unrelated. Here, we consider how different variable of interest evolve with respect to $\theta$. We consider support the interval $[1,2]$ as support for $\theta .{ }^{37}$

Figure E1 starts by showing the positive relationship between firm size, as measured by sales and outsourcing intensity defined here as the ratio of outsourcing expenditures to sales.

Figure E2 presents a set of results. Panel 2(a) shows how the optimal scale of production and sales evolves as productivity increase. Production $Y$ increases log-linearly with $\theta$, with an elasticity close to 1 . Sales, which are proportional to profit in this model, increases also linearly but because the elasticity of demand $\varepsilon$ is finite, the revenue / profit function is concave in productivity. Panel 2(b) displays the effect of productivity on the use of in-house and outsourced labor services. Both increase with a roughly constant elasticity (log-linear) but we see that, due to the rising cost of hiring in-house faced by monopsonic employers as they scale-up, they progressively outsource more, resulting in a shrinking in-house to outsourced labor ratio. Panel 2(c) show that this declining ratio is heterogeneous across occupations. It displays the ratio for a core and non-core occupation with the same weight in the Cobb-Douglas

\footnotetext{
${ }^{37}$ The number of occupations is set to 4 so that $\mathbf{N}=\{1,2,3,4\}$. The vector of parameters regarding occupations in production function are as followed: $\sigma=[0.5,0.5,2.5,2.5] ; ; \gamma \boldsymbol{r}=[0.25,0.25,0.25,0.25]$ $; \mu=[.75, .75, .75, .75] ; \alpha=[1 / 3,1 / 6,1 / 3,1 / 6]$. Regarding labor supply, we set: $\rho=[1,1,1,1]$, $\mathbf{a}=[1,1,1,1]$. The other parameters are: $\varepsilon=5, I=1$ and $N_{i}=1, \forall i \in \mathbf{N}$.
} 
Figure E1: Outsourcing intensity as a function of sales following an increase in productivity

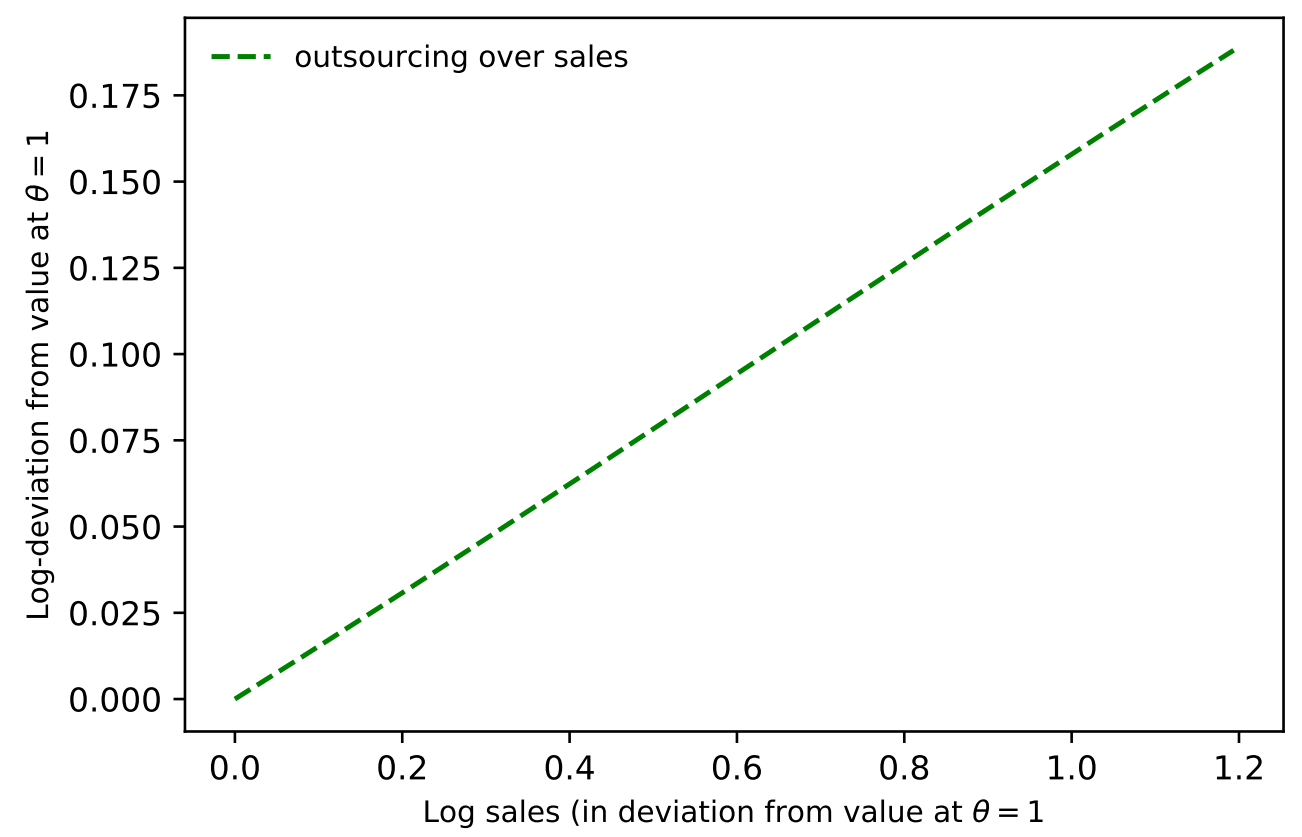

Notes: The figure provide comparative statics with respect to an increase in Hicks neutral productivity shifter $\theta$. We consider support the interval $[1,2]$ as support for $\theta$.

production function. Panel 2(d) makes the same point but focusing on the level of the cost share represented by in-house labor. We see that both shares are high for core occupation and tend to increase with size while the opposite is true of the two non-core occupations.

The figure E3 displays four other comparative statics. Panel 3(a) shows the wage in level. Unsurprisingly, high-skill occupations (1 and 3) have the highest wages. We see however that the firm size wage premium is stronger among core occupations independently of skill-level. Panel 3(b) show how log-wage deviates from the initial situation. We see that core and non-core determines almost entirely the magnitude of the elasticity of wage to size. Overall, panels 3(a) and 3(b) are consistent with the empirical existence of a size wage-premium (Oi and Idson, 1999). Moreover, it has been documented that skill-wage premium is stronger in large firms. Through the lenses of our model, this would imply that skills $\left(\alpha_{i}\right)$ tend to be higher in more core occupation (smaller $\sigma_{i} \mathrm{~s}$ ). Here, we have explicitly made the choice of decorrelating these dimensions, it is plausible however that skill and "core-ness" are positively correlated, in particular if coreness of an occupation is determined by how difficult the tasks it entails are to codify, it seems likely that such tasks might also be requiring high-skill 
Figure E2: Scale of production, employment and outsourcing as productivity goes up

(a) Scale of production

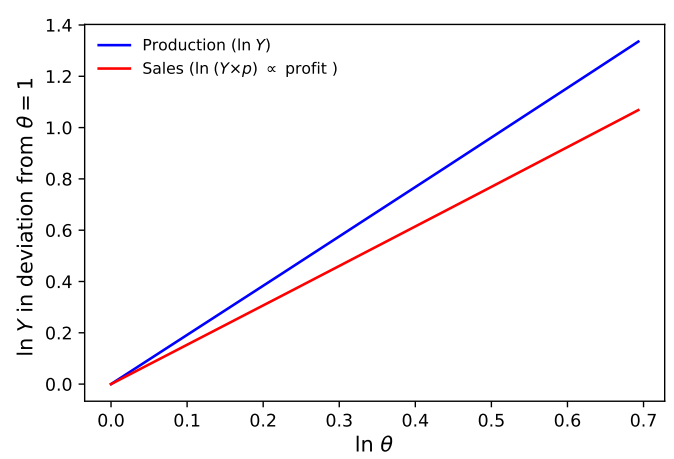

(c) In-house ratio in employment, across occupations

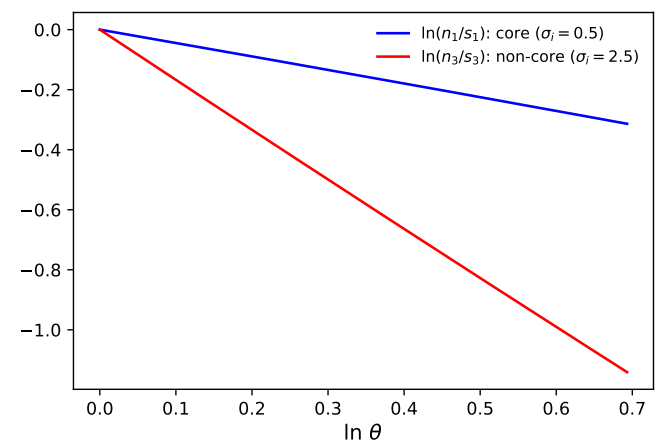

(b) Employment : in-house versus outsourced

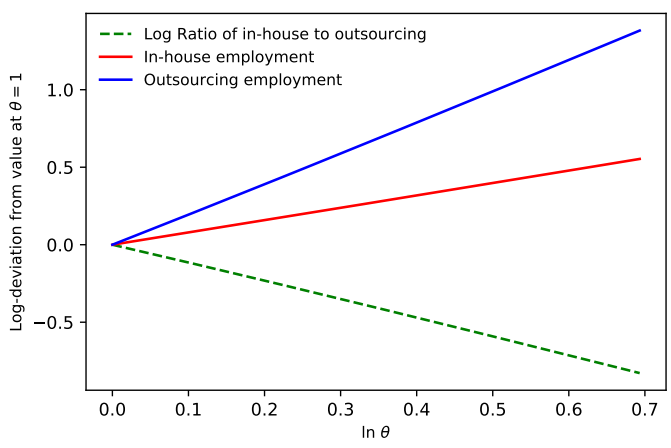

(d) In-house cost share, across occupations

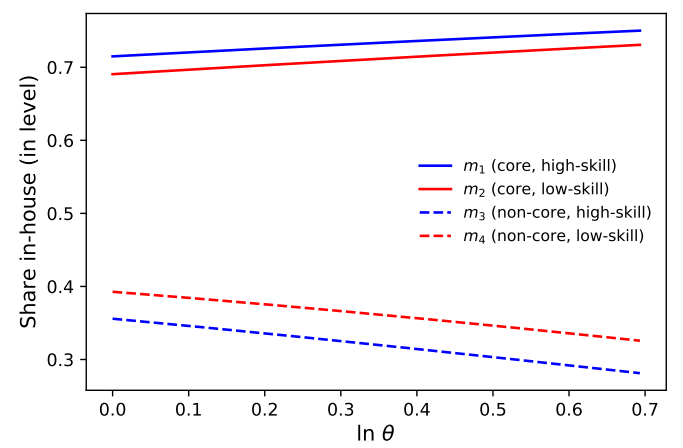

$\begin{array}{lllll}\text { Notes: } & \text { The figure provide } & \text { comparative statics with respect to an increase in Hicks neu- } \\ \text { tral productivity shifter } & \theta & \text { We consider support the interval }[1,2] \text { as support for } \theta \text {. }\end{array}$

labor and have a high economic return. Correlating these dimensions is straightforward in our model and strengthens the key results displayed below regarding the increase in the share of outsourcing and the increase in occupational specialization. Panel 3(c) compute the HHI index for in-house labor and cost at the firm level across occupations. We see that both employment and cost based HHI increases and that this increase is stronger in terms of costs. This indicates that overall, the firm is concentrating its employment in and spending on in-house labor services on a fewer core occupations. This is a prediction we will be able to test explicitly. Finally, panel 3(d) presents how spending on outsourcing over in-house labor cost (both summed across all occupations) evolves as productivity and scale go up. We do see an increase in this ratio which is somewhat less marked than the equivalent ratio in terms of employment because of the size wage premium associated (see Panel 2(b)) with in-house labor services. 
Figure E3: Wage premium, outsourcing over in-house cost and index of occupational segregation $(\mathrm{HHI})$

(a) Wage by occupation

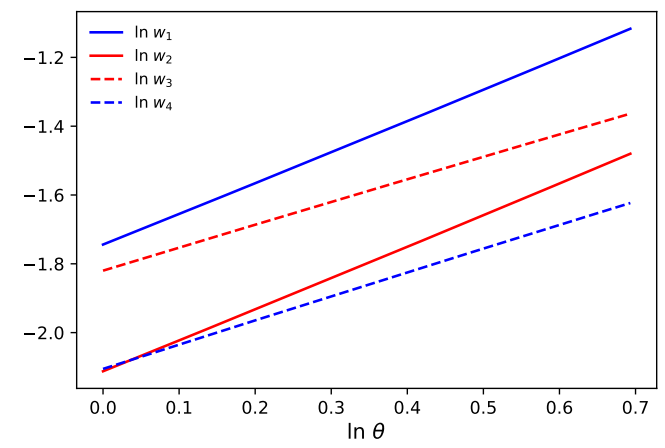

(c) $\mathrm{HHI}$ in terms of cost shares

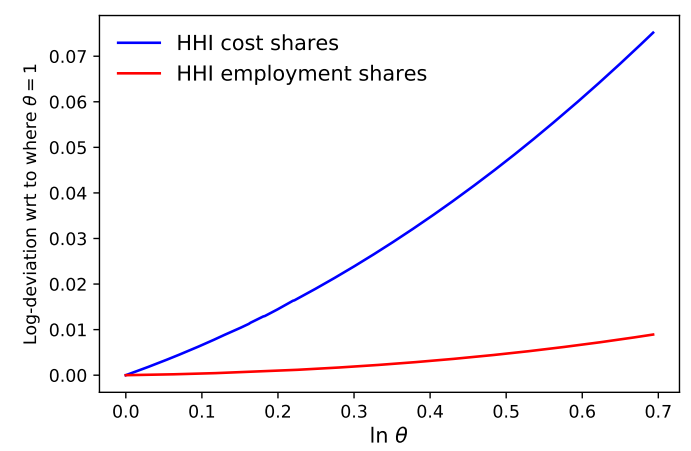

$\begin{array}{cccl}\text { Notes: The figure provide } & \text { comparative } \\ \text { tral productivity shifter } & \theta . & \text { We consider }\end{array}$ (b) - normalized with respect to $\theta=1$

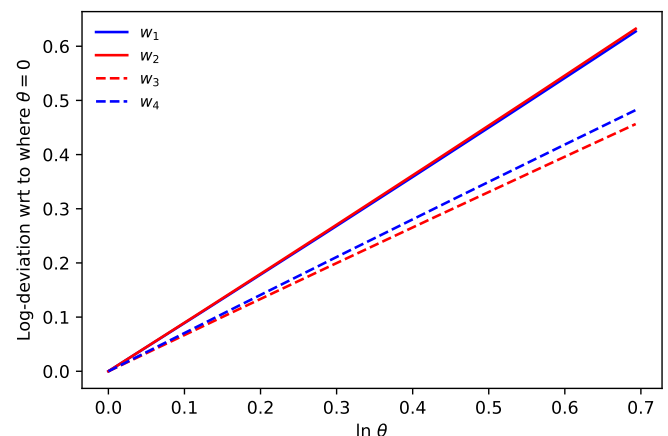

(d) Outsourcing over in house labor cost

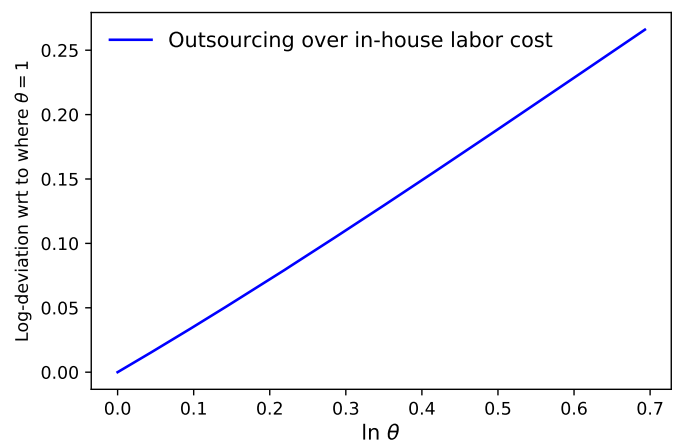

with respect to an increase in Hicks neusupport the interval $[1,2]$ as support for $\theta$.

Additional comparative statics. Figure E4 displays similar comparative statics comparing the baseline case and the case $\left(\rho_{i}=1\right)$ with no market power on the in-house labor market $\left(\rho_{i}=0\right)$. It shows see that the in-house cost share per occupation $\left(m_{i}\right)$ and the the outsourcing over in-house labor cost ratio does not change with productivity when wage are competitively set, highlighting the key role of labor market frictions in explaining our results.

As mentioned above, broadband is also likely to result in a decrease of outsourcing cost, which we capture with a decline in the term $\gamma_{i j}$. Decrease in this parameter leads to broadly similar comparative statics as the previous case as display in Figure E5. 
Figure E4: Increase in $\theta$ with $\rho_{i}=1$ (baseline) and $\rho_{i}=0$ (no market power)

(a) Scale of production

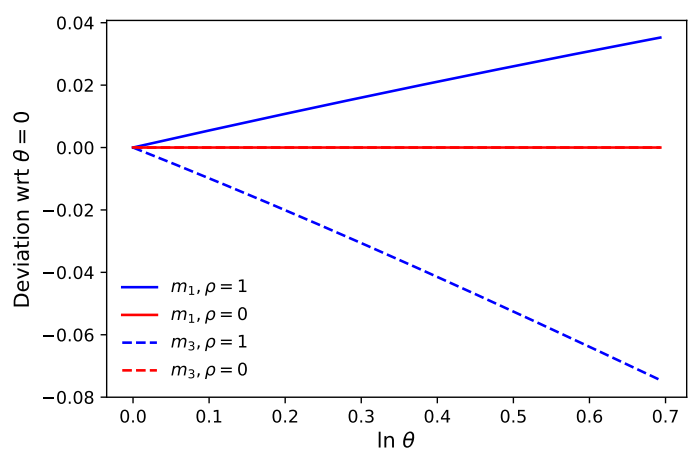

(b) Employment : in-house versus outsourced

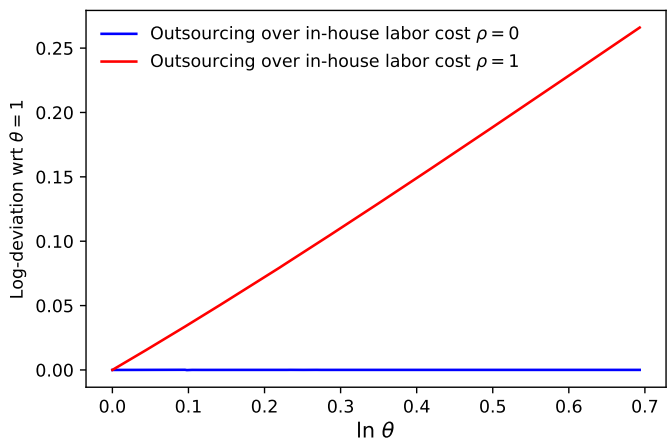

Notes: The figure provide comparative statics with respect to an increase in Hicks neutral productivity shifter $\theta$. We consider support the interval $[1,2]$ as support for $\theta$.

Figure E5: Scale of production, employment and outsourcing as cost of outsourcing goes down

(a) Scale of production

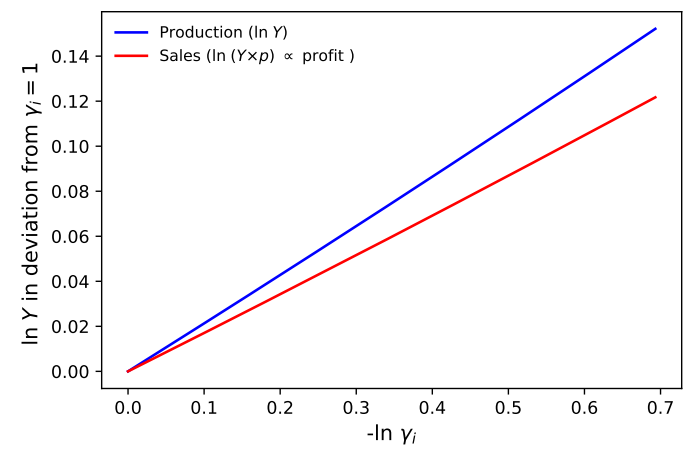

(c) In-house ratio in employment, across occupations

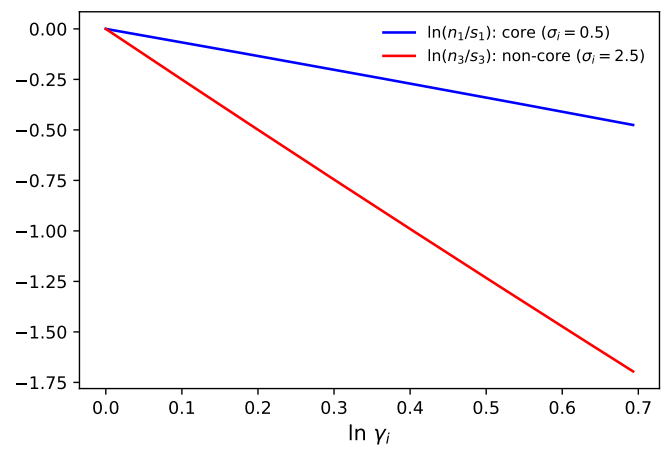

(b) Employment : in-house versus outsourced

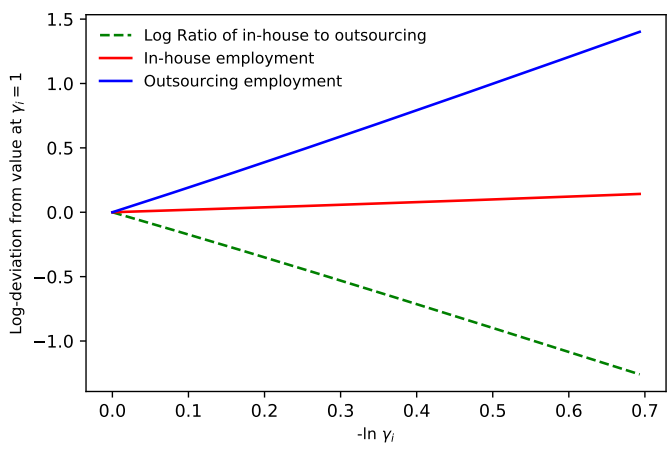

(d) In-house cost share, across occupations

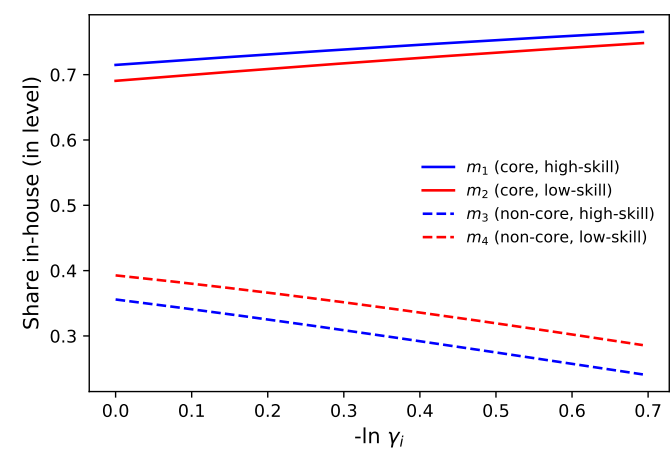

Notes: The figure provide comparative statics with respect to an decrease in shifter of out-

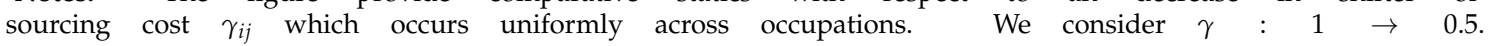




\section{References}

Abraham, Katharine G and Susan K Taylor, "Firms' use of outside contractors: Theory and evidence," Journal of Labor Economics, 1996, 14 (3), 394-424.

Abramovsky, Laura and Rachel Griffith, "Outsourcing and offshoring of business services: How important is ICT?," Journal of the European Economic Association, 2006, $4(2-3), 594-601$.

_ , _, and Helen Miller, "Domestic effects of offshoring high-skilled jobs: Complementarities in knowledge production," Review of International Economics, 2017, 25 (1), 1-20.

Aghion, Philippe, Antonin Bergeaud, Richard Blundell, and Rachel Griffith, "The Innovation Premium to Soft Skills in Low Skill Occupations," Technical Report 14102, CEPR 2019.

_, _, Timo Boppart, Peter J Klenow, and Huiyu Li, "A theory of falling growth and rising rents," Technical Report w26448, National Bureau of Economic Research 2019.

_, Ufuk Akcigit, Ari Hyytinen, and Otto Toivanen, "On the returns to invention within firms: Evidence from Finland," in "AEA Papers and Proceedings," Vol. 108 2018, pp. 208-12.

Akerman, Anders, Edwin Leuven, and Magne Mogstad, "Information Frictions, Internet and the Relationship between Distance and Trade," Memorandum, Oslo University, Department of Economics February 2018.

_ , Ingvil Gaarder, and Magne Mogstad, "The skill complementarity of broadband internet," Quarterly Journal of Economics, 2015, 130 (4), 1781-1824.

Appelbaum, Eileen, Rosemary Batt, Annette Bernhardt, and Susan Houseman, "Domestic Outsourcing in the US: A Research Agenda to Assess Trends and Effects on Job Quality," in "Prepared for The Future of Work Symposium, US Department of Labor, Washington DC" 2015.

Autor, David H., Frank Levy, and Richard J. Murnane, "The skill content of recent technological change: An empirical exploration," Quarterly Journal of Economics, 2003, 118 (4), 1279-1333. 
Baker, Andrew, David F Larcker, and Charles CY Wang, "How Much Should We Trust Staggered Difference-In-Differences Estimates?," Available at SSRN 3794018, 2021.

Berlingieri, Giuseppe, “Outsourcing and the Rise in Services," Technical Report 1199, Centre for Economic Performance 2014.

Bernhardt, Annette, Rosemary Batt, Susan N Houseman, and Eileen Appelbaum, "Domestic outsourcing in the United States: a research agenda to assess trends and effects on job quality," Technical Report 16-253, Upjohn Institute Working Paper 2016.

Bilal, Adrien and Hugo Lhuillier, "Outsourcing, Inequality and Aggregate Output," 2021. Mimeo Harvard.

Biscourp, Pierre and Francis Kramarz, "Employment, skill structure and international trade: Firm-level evidence for France," Journal of International Economics, 2007, $72(1), 22-51$.

Bloom, Nicholas, Luis Garicano, Raffaella Sadun, and John Van Reenen, "The distinct effects of information technology and communication technology on firm organization," Management Science, 2014, 60 (12), 2859-2885.

Borghans, Lex and Bas Ter Weel, "The division of labour, worker organisation, and technological change," The Economic Journal, 2006, 116 (509), F45-F72.

Borusyak, Kirill and Xavier Jaravel, "Revisiting event study designs," Available at SSRN 2826228, 2017.

Caliendo, Lorenzo, Ferdinando Monte, and Esteban Rossi-Hansberg, "The anatomy of French production hierarchies," Journal of Political Economy, 2015, 123 (4), 809-852.

Callaway, Brantly and Pedro HC Sant'Anna, "Difference-in-differences with multiple time periods," Journal of Econometrics, 2020.

Card, David, Ana Rute Cardoso, Joerg Heining, and Patrick Kline, "Firms and labor market inequality: Evidence and some theory," Journal of Labor Economics, 2018, 36 (S1), S13-S70.

Caroli, Eve and John Van Reenen, "Skill-biased organizational change? Evidence from a panel of British and French establishments," Quarterly Journal of Economics, 2001, 116 (4), 1449-1492. 
Cengiz, Doruk, Arindrajit Dube, Attila Lindner, and Ben Zipperer, "The effect of minimum wages on low-wage jobs," The Quarterly Journal of Economics, 2019, 134 (3), 1405-1454.

Chaisemartin, Clément De and Xavier d'Haultfoeuille, "Two-way fixed effects estimators with heterogeneous treatment effects," American Economic Review, 2020, 110 (9), 2964-96.

Cortes, Guido Matias and Andrea Salvatori, "Delving into the demand side: Changes in workplace specialization and job polarization," Labour economics, 2019, $57,164-176$.

Deshpande, Manasi and Yue Li, "Who is screened out? application costs and the targeting of disability programs," American Economic Journal: Economic Policy, 2019, $11(4), 213-48$.

DeStefano, Timothy, Richard Kneller, and Jonathan Timmis, "Broadband infrastructure, ICT use and firm performance: Evidence for UK firms," Journal of Economic Behavior E Organization, 2018, 155, 110-139.

Dorn, David, Johannes F Schmieder, and James R Spletzer, "Domestic Outsourcing of Labor Services in the United States: 1996-2015," 2018. Department of Labor.

Drenik, Andres, Simon Jäger, Miguel Pascuel Plotkin, and Benjamin Schoefer, "Paying outsourced labor: Direct evidence from linked temp agency-worker-client data," Technical Report 26891, National Bureau of Economic Research 2020.

Dube, Arindrajit and Ethan Kaplan, "Does outsourcing reduce wages in the lowwage service occupations? Evidence from janitors and guards," ILR Review, 2010, 63 (2), 287-306.

Fort, Teresa C, “Technology and production fragmentation: Domestic versus foreign sourcing," Review of Economic Studies, 2017, 84 (2), 650-687.

Garicano, Luis, "Hierarchies and the Organization of Knowledge in Production," Journal of Political Economy, 2000, 108 (5), 874-904.

- and Esteban Rossi-Hansberg, "Organization and inequality in a knowledge economy," Quarterly Journal of Economics, 2006, 121 (4), 1383-1435.

Godechot, Olivier, Paula Apascaritei, István Boza, Lasse Folke Henriksen, Are Skeie Hermansen, Feng Hou, Naomi Kodama, Alena Křížková, Jiwook Jung, 
Marta M Elvira et al., "The great separation: Top earner segregation at work in high-income countries," Technical Report, MaxPo Discussion Paper 2020.

Goldschmidt, Deborah and Johannes F Schmieder, "The rise of domestic outsourcing and the evolution of the German wage structure," Quarterly Journal of Economics, 2017, 132 (3), 1165-1217.

Goodman-Bacon, Andrew, "Difference-in-differences with variation in treatment timing," Technical Report, National Bureau of Economic Research 2018.

Hummels, David, Jakob R Munch, and Chong Xiang, “Offshoring and labor markets," Journal of Economic Literature, 2018, 56 (3), 981-1028.

Kline, Patrick, Neviana Petkova, Heidi Williams, and Owen Zidar, "Who profits from patents? rent-sharing at innovative firms," Quarterly Journal of Economics, 2019, 134 (3), 1343-1404.

Kogut, Bruce and Udo Zander, "Knowledge of the firm, combinative capabilities, and the replication of technology," Organization science, 1992, 3 (3), 383-397.

Lamadon, Thibaut, Magne Mogstad, and Bradley Setzler, "Imperfect competition, compensating differentials and rent sharing in the US labor market," Technical Report w25954, National Bureau of Economic Research 2019.

Le Moigne, Mathilde, "Exploring the "Fissured workplace": Internal job ladders" fragmentation and its effect on plants and workers," Technical Report, Unpublished Manuscript 2020.

Lepak, David P and Scott A Snell, “The human resource architecture: Toward a theory of human capital allocation and development," Academy of management review, 1999, 24 (1), 31-48.

Lewis, Tracy R and David EM Sappington, "Technological Change and the Boundaries of the Firm," American Economic Review, 1991, pp. 887-900.

Malgouyres, Clément, Thierry Mayer, and Clément Mazet-Sonilhac, "Technologyinduced Trade Shocks? Evidence from Broadband Expansion in France," CEPR Discussion Papers 13847, C.E.P.R. Discussion Papers 2019.

Michaels, Guy, Ashwini Natraj, and John Van Reenen, "Has ICT polarized skill demand? Evidence from eleven countries over twenty-five years," Review of Economics and Statistics, 2014, 96 (1), 60-77. 
Oi, Walter Y and Todd L Idson, "Firm size and wages," Handbook of labor economics, 1999, 3, 2165-2214.

Ono, Yukako, "Outsourcing business services and the role of central administrative offices," Journal of Urban Economics, 2003, 53 (3), 377-395.

Song, Jae, David J Price, Fatih Guvenen, Nicholas Bloom, and Till Von Wachter, “Firming up inequality," Quarterly Journal of Economics, 2019, 134 (1), 1-50.

Vannutelli, Silvia, "From Lapdogs to Watchdogs: Random Auditor Assignment and Municipal Fiscal Performance in Italy," Job Market Paper, 2020.

Weil, David, The fissured workplace, Harvard University Press, 2014. 